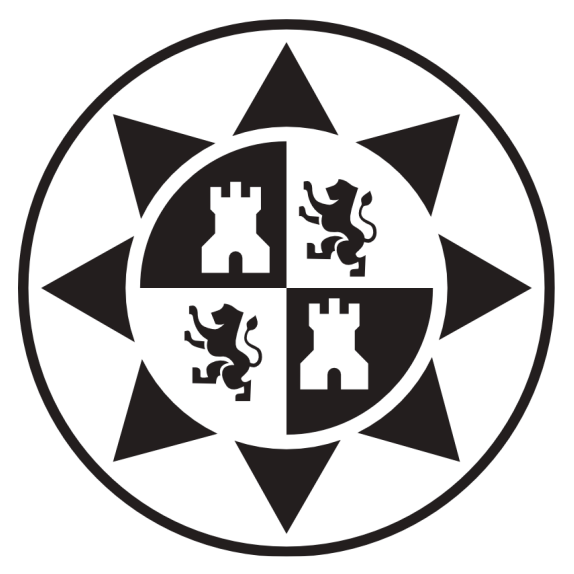

UNIVERSIDAD POLITÉCNICA DE CARTAGENA

DEPARTAMENTO DE TECNOLOGÍAS DE LA INFORMACIÓN Y LAS COMUNICACIONES

\title{
Contribución al diseño y desarrollo de herramientas docentes basadas en TIC para entornos heterogéneos
}

ANDRÉS CABRERA LOZOYA 



\section{CONFORMIDAD DE SOLICITUD DEAUTORIZACIÓN DE DEPÓSITO DE} TESIS DOCTORAL POR EL DIRECTOR Y LA CODIRECTORA DE LA TESIS

D. Fernando Cerdán Cartagena, Profesor Catedrático de Universidad y Da María Dolores Cano Baños, Profesora Titular de Universidad, ambos del Área de Ingeniería Telemática en el Departamento de Tecnologías de la Información y las Comunicaciones

\section{INFORMAN:}

Que la Tesis Doctoral titulada "Contribución al diseño y desarrollo de herramientas docentes basadas en TIC para entornos heterogéneos" ha sido realizada por D. Andrés Cabrera Lozoya, bajo nuestra dirección y supervisión, en el Departamento de Tecnologías de la Información y las Comunicaciones, dando nuestra conformidad para que sea presentada ante la Comisión de Doctorado.

La rama de conocimiento por la que esta tesis ha sido desarrollada es:

\footnotetext{
$\times$ Ciencias

$x$ Ciencias Sociales y Jurídicas

$\checkmark$ Ingeniería y Arquitectura
}

En Cartagena, a 1 de Junio de 2012

FDO: EL DIRECTOR Y LA CODIRECTORA DE LA TESIS
D. Fernando Cerdán Cartagena
Da . María Dolores Cano Baños 


\section{CONFORMIDAD DE DEPÓSITO DE TESIS DOCTORAL POR LA COMISIÓN} ACADÉMICA DEL PROGRAMA

D. Fernando Quesada Pereira, Presidente de la Comisión Académica del Programa de Doctorado en Tecnologías de la Información y las Comunicaciones,

\section{INFORMA:}

Que la Tesis Doctoral titulada “Contribución al diseño y desarrollo de herramientas docentes basadas en TIC para entornos heterogéneos" ha sido realizada por D. Andrés Cabrera Lozoya, bajo la dirección y supervisión del Catedrático D. Fernando Cerdán Cartagena y bajo la codirección de la Doctora Da . María Dolores Cano Baños, dando su conformidad a la misma la Comisión Académica, con la finalidad de que sea presentada ante la Comisión de Doctorado.

La rama de conocimiento por la que esta tesis ha sido desarrollada es:

$\times$ Ciencias

$x$ Ciencias Sociales y Jurídicas

$\checkmark$ Ingeniería y Arquitectura

En Cartagena, a 1 de Junio de 2012

FDO: EL PRESIDENTE DE LA COMISIÓN ACADÉMICA DEL PROGRAMA

D. Fernando Quesada Pereira 
"Dime y lo olvido, enséñame y lo recuerdo, involúcrame y lo aprendo"

Benjamin Franklin Político, científico e inventor estadounidense

\section{Prefacio y Agradecimientos}

A mi madre, sin duda, que tanto me ha apoyado, guiado y ayudado durante todos los días de mi vida. También a mi padre, que se ha sacrificado durante toda la suya para dar lo mejor a su familia. A ellos les debo la mayoría de mis éxitos en lo personal y lo profesional. Por último, a mi abuelo Andrés, d.e.p., que tantas ilusiones tenía depositadas en mí y en este título.

El trabajo de tesis que plasma este documento comenzó hace unos 5 años, a partir de una iniciativa conjunta de la Escuela de Telecomunicación e Industrial de la Politécnica para desarrollar un sistema que permitiera mejorar la docencia incorporando las TIC en las aulas. En aquel momento me encontraba con la carrera de Ingeniero de Telecomunicación recién acabada, y la vía de la investigación me atraía fuertemente. Además, la naturaleza del proyecto y las tecnologías que se usarían para llevarlo a cabo suponían otro fuerte incentivo para mí, dada mi afinidad por los lenguajes de programación web. Así, lo que en principio se perfilaba como una idea bastante genérica, fue evolucionando con el paso del tiempo y adaptándose a las bruscas tendencias que se iban sucediendo en materia de educación y de las tecnologías disponibles para su realización. Finalmente, el trabajo que se presenta en este documento tiene una componente eminentemente innovadora, de integración de tecnologías buscando nuevas soluciones de valor añadido para la enseñanza.

Quisiera agradecer finalmente a mi director y codirectora de tesis, Fernando Cerdán y María Dolores Cano, el apoyo que he recibido por su parte, ya que sus consejos y aportaciones han sido factores clave para que los resultados que se plasman en la tesis sean una realidad. 


\section{Resumen}

Las modalidades actuales de e-learning están basadas en la mejora del proceso de aprendizaje a través de la potenciación de ciertas habilidades en los alumnos, como en el aprendizaje colaborativo, competitivo o basado en problemas. Sin embargo, parece que aún hoy no hay ninguna fórmula de e-learning capaz de recopilar una serie de principios pedagógicos más genéricos en una única plataforma o sistema. Por ello, en este documento se presenta una plataforma basada en tecnologías web para la creación, desarrollo e implementación de ambientes educativos heterogéneos llamada CADI. Ofrece una interfaz gráfica de usuario para que los alumnos puedan interactuar con el único requisito de contar con un dispositivo genérico compatible con WiFi. Su innovador diseño permite al profesor seleccionar y combinar los recursos desarrollados para crear actividades muy variadas, mostrándose en cada caso los contenidos adaptados a cada dispositivo concreto y superándose así las fallas de estandarización existentes en la actualidad en el mundo de los dispositivos móviles. La utilidad del sistema fue evaluada a través de la realización de un proyecto piloto a un grupo de alumnos veteranos. La experiencia mostró que el uso del sistema ayudó a los estudiantes a conseguir mejores resultados académicos en su evaluación. También mostró que los alumnos no tuvieron ningún problema en interactuar con el sistema desde el principio, promoviendo en última instancia su aprendizaje activo. Este documento aborda la descripción de dicho sistema desde un punto de vista pedagógico, pero también práctico, al describir aspectos relacionados con su diseño, implementación y posterior evaluación en un escenario real de aplicación. 


\section{Abstract}

Current e-learning forms are commonly based on improving the learning process through the enhancement of certain skills in students, such as collaborative, competitive or problem-based learning. However, it seems that there is still no e-learning formula that gathers the implementation of a number of more generic educational principles in a single e-learning system or platform. Therefore, this document presents a web-based framework for the creation, development and implementation of heterogeneous learning environments called CADI. It offers a graphical user interface for students to interact with only the need for any generic WiFi compliant device. Its innovative design allows the instructor to select and combine the developed resources to create varied activities, providing content adapted to every single device, thus overcoming the current standardization issues around heterogeneous mobile devices and its capabilities. The usefulness of the system was tested by introducing a case study to a group of senior college students. The experience showed that the use of the system helped students to achieve better results in their evaluation. It also showed that the students had no problems interacting with it from the outset, promoting their active learning. This thesis deals with the characterization of the system from a pedagogical point of view, but also practical, describing aspects of their design, implementation and subsequent evaluation in a real application scenario. 



\section{Índice de contenidos}

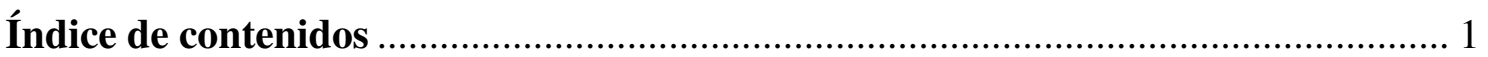

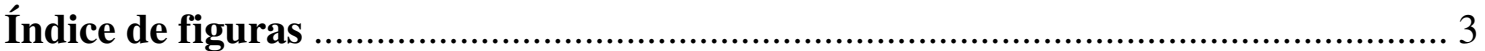

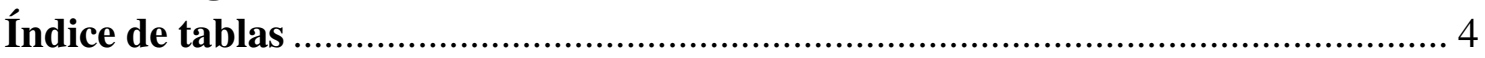

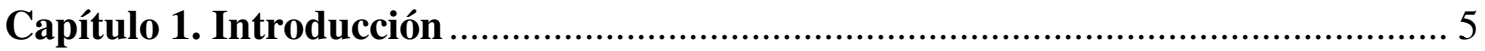

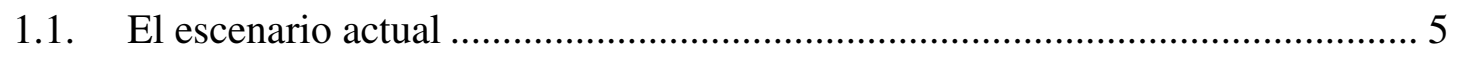

1.2. Estado del arte y motivación de la tesis …......................................................... 6

1.3. Ejemplos de plataformas virtuales de docencia ............................................. 12

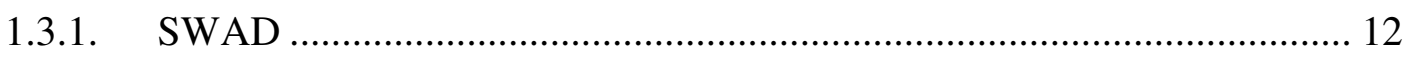

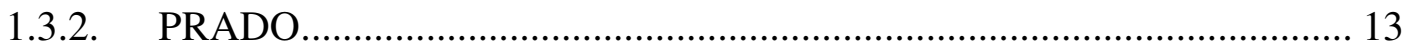

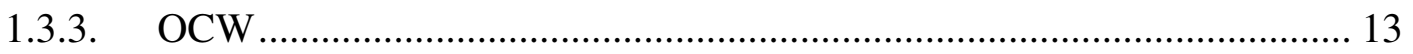

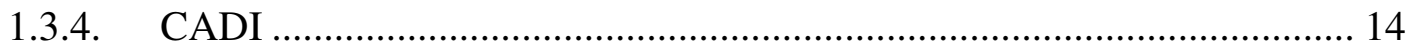

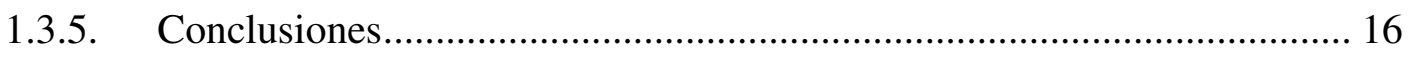

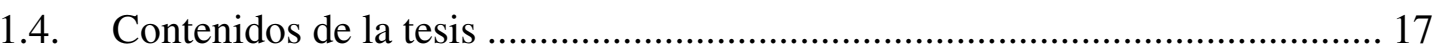

Capítulo 2. Trasfondo pedagógico de la plataforma CADI .................................. 18

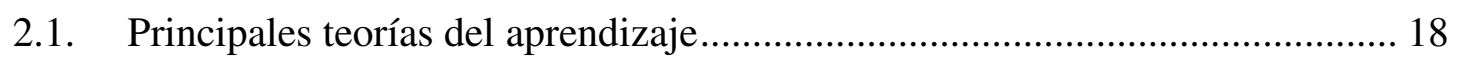

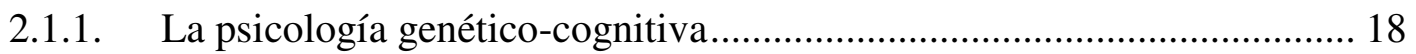

2.1.2. La psicología genético-dialéctica ..................................................... 20

2.1.3. Aprendizaje como procesamiento de la información ............................. 21

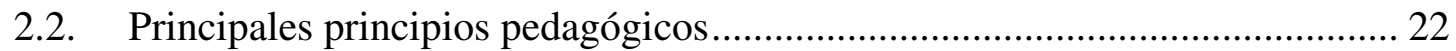

2.3. Rasgos que se han potenciado con el uso de las TIC y posibles peligros........ 24

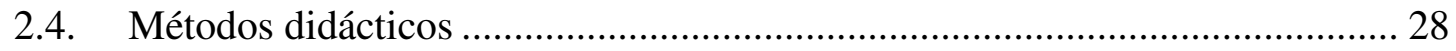

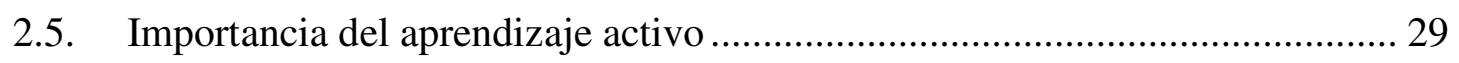

Capítulo 3. La plataforma docente interactiva CADI ........................................ 31

3.1. Principales cambios en la formación universitaria: CADI ........................... 31

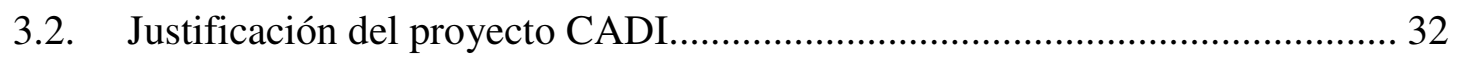

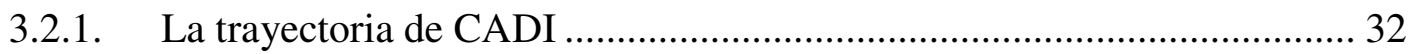

3.2.2. Potenciales beneficios de CADI ........................................................... 35

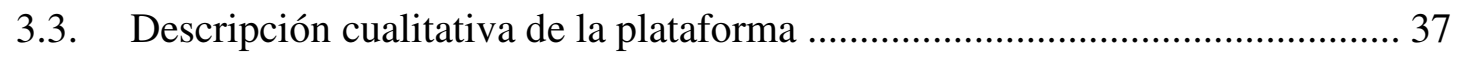

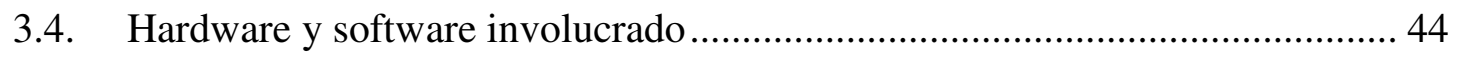

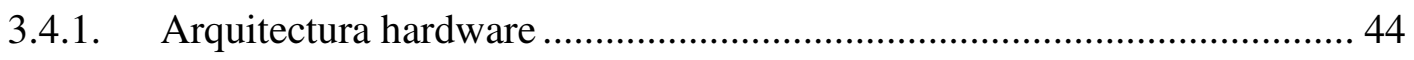

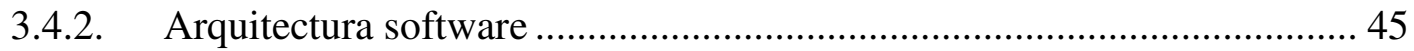

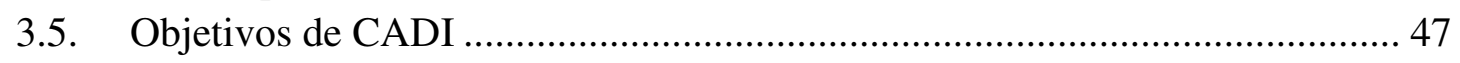

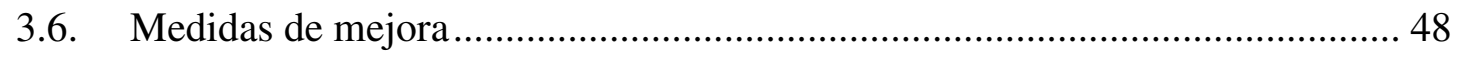

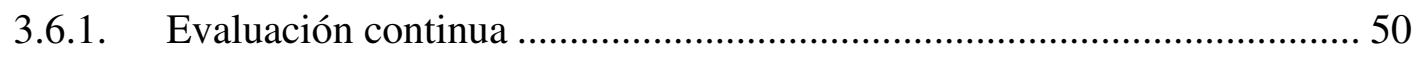




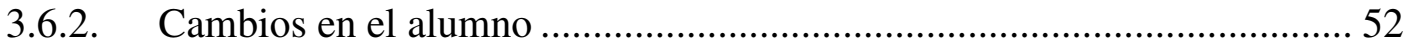

3.6.3. Cambios en el profesor ....................................................................... 54

3.7. CADI como ejemplo de pedagogía activa e interactiva.................................... 55

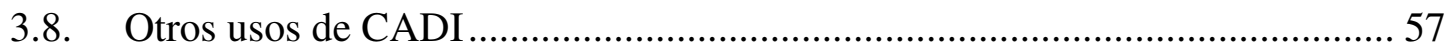

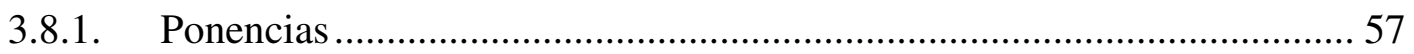

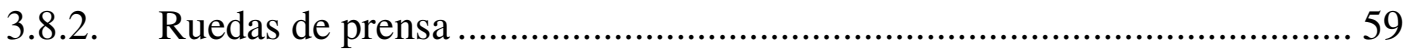

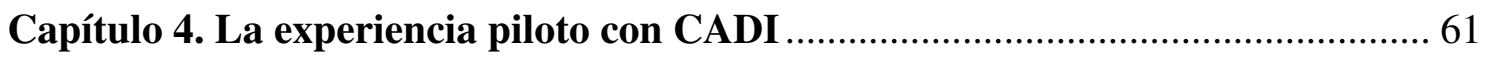

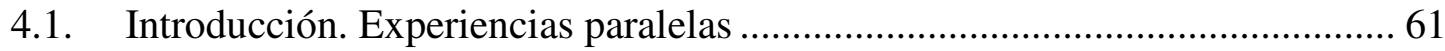

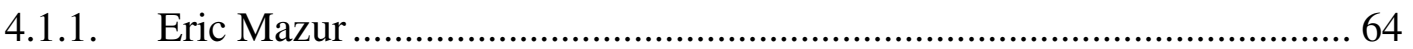

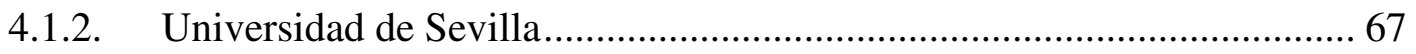

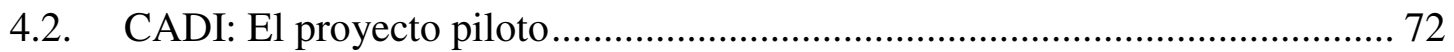

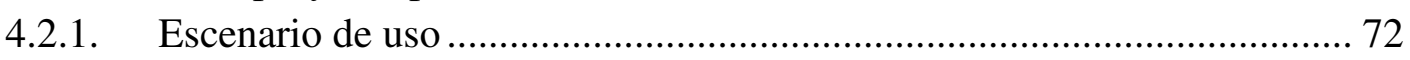

4.2.2. Metodología usada (materiales y métodos) .......................................... 75

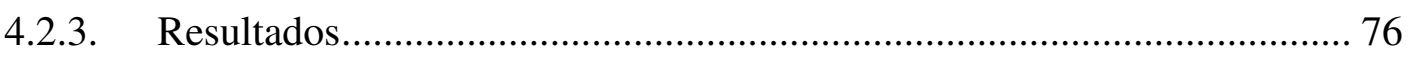

4.2.4. Perspectiva de los profesores respecto a la experiencia .......................... 84

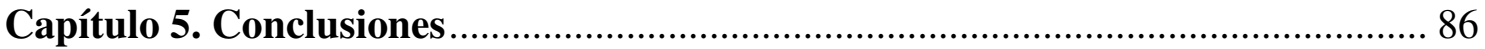

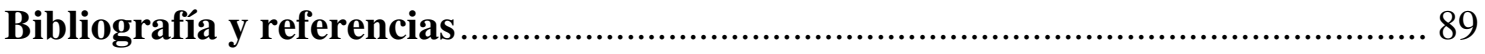

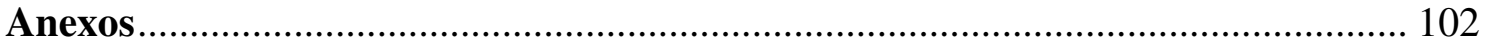

Anexo I - Encuesta final sobre la utilización del sistema CADI ................................ 103

Anexo II - Breve manual de usuario del sistema CADI .......................................... 106

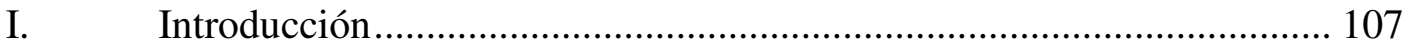

II. Acceso como alumno........................................................................ 107

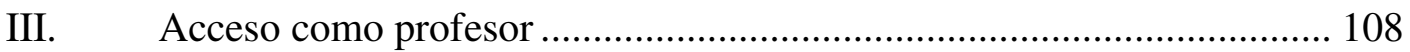




\section{Índice de figuras}

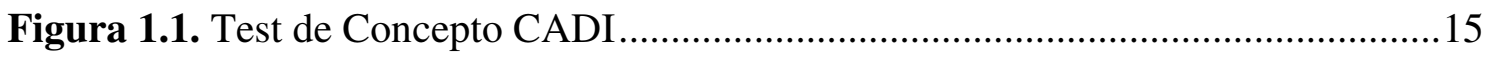

Figura 3.1. Principales diferencias entre el aprendizaje pasivo y activo.........................36

Figura 3.2. Esquema funcional de un escenario donde se está usando el sistema. ........41

Figura 3.3. Marco de funcionamiento conceptual del sistema......................................43

Figura 3.4. Esquema de la infraestructura hardware que requiere el sistema...............44

Figura 4.1. Capturas de pantalla de la interfaz gráfica de usuario (GUI)

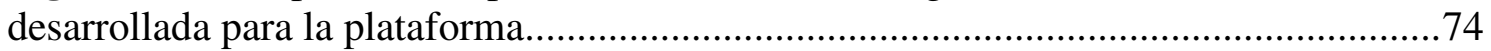

Figura 4.2. Notas medias finales e intervalos de confianza asociados ...........................78

Figura 4.3. $\mathrm{N}^{\mathrm{o}}$ de aprobados y suspensos entre los alumnos ........................................78

Figura 4.4. Puntuaciones medias e intervalos de confianza asociados a la encuesta

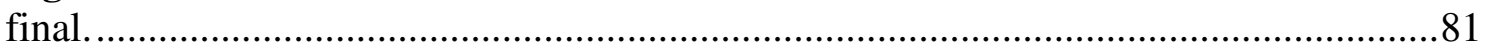

Figura 4.5. Asimetría de las respuestas de la encuesta final. ......................................... 82

Figura 4.6. Curtosis de las respuestas de la encuesta final..........................................83

Figura II.1. Interfaz principal de CADI para los clientes del sistema con los módulos de preguntas y encuestas cargados................................................................ 108

Figura II.2. Pantalla de acceso a la interfaz de administración del profesor.................109

Figura II.3. Interfaz de administración del profesor. Marco de trabajo de CADI .......110 


\section{Índice de tablas}

Tabla 2.1. Resumen de los rasgos y principios pedagógicos que han sido potenciados con la integración de las TIC en la educación.........................................26

Tabla 4.1. Experiencias con sistemas de respuesta interactiva...................................62

Tabla 4.2. Programación semanal de la asignatura......................................................... 73

Tabla 4.3. Pesos aplicados en la evaluación final de los alumnos.................................73

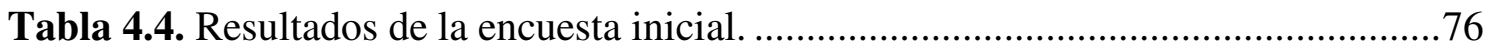

Tabla 4.5. Resultados del test ANOVA que determinan la diferencia estadística entre los cursos académicos con y sin el uso CADI .................................................... 79

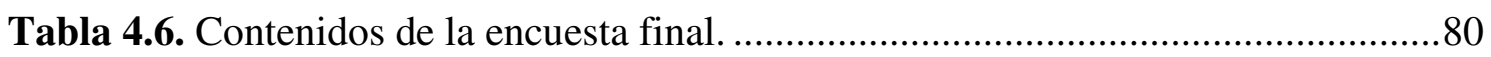

Tabla 4.7. Resultados de la encuesta del Gabinete de Calidad de la UPCT...................84 


\section{Capítulo 1. Introducción}

\subsection{El escenario actual}

Últimamente y cada vez más, con la progresiva instauración del Espacio Europeo de Educación Superior (EEES) y los créditos ECTS (European Credit Transfer System) se están investigando modalidades de aprendizaje alternativas a la siempre presente lección magistral que tienen su base en las nuevas Tecnologías de la Información y las Comunicaciones $(T I C)$.

El empleo de estas tecnologías en la enseñanza permite desarrollar de forma sencilla aspectos clave del EEES, como son la transparencia y calidad en el aprendizaje, la evaluación global del trabajo del alumno (que incluye el realizado fuera del aula) y por último y quizá más importante, la autonomía del estudiante.

Por este motivo es necesario un cambio en las actitudes tanto del estudiante como del profesor. Hoy día son innegables las posibilidades de utilización de las TIC en cualquier parcela del conocimiento. Este nuevo tipo de aprendizaje permite la interacción con el profesorado por medio de Internet y además, el alumno es el que gestiona su tiempo... por lo que nos encontramos ante un medio completamente autónomo.

El uso de plataformas virtuales es un método que está siendo ya empleado en las universidades para lograr la mejora de los procesos de enseñanza-aprendizaje. Estas herramientas suponen un medio de comunicación entre profesor / alumnos y entre los propios alumnos más allá de un espacio físico delimitado, permitiendo extender el aula y el horario lectivo del curso académico.

Las múltiples utilidades de las mismas (plataformas virtuales) son elegidas en función de las necesidades y características de las asignaturas, siendo posible a veces eliminar el uso de las tradicionales fotocopias y sirviendo de base común para compartir contenidos, apuntes, dudas, exámenes, bibliografía, glosarios, etc.

El Ministerio de Educación y Ciencia (MEC), a partir del año 2006, y a través del Consejo de Coordinación Universitaria, viene efectuando unas recomendaciones 
sobre lo que implica un nuevo estilo de trabajo, sobre todo del profesorado, haciendo hincapié en dar un mayor protagonismo al estudiante en su formación al igual que insta a fomentar el trabajo colaborativo. También apuesta por organizar la enseñanza en función de las competencias que se deban adquirir y potenciar la adquisición de herramientas de aprendizaje autónomo y permanente.

En los últimos años ha comenzado a extenderse el uso de plataformas de eLearning y bLearning (blended learning) que aglutinan los servicios software necesarios para dar soporte a una infraestructura completa de teleformación a través de Internet. Así, el profesor pasa a actuar como guía de los alumnos para facilitarles el uso de recursos y herramientas que necesiten para explorar y elaborar nuevos conocimientos y destrezas entre los que se encuentran las nuevas Tecnologías de la Información. De modo que el docente de hoy debe involucrarse en el diseño y elaboración de nuevos contenidos y su proceso de distribución, entre los que se encuentran las plataformas virtuales de docencia.

\subsection{Estado del arte y motivación de la tesis}

En los últimos años, la mayoría de intentos para introducir metodologías innovadoras de aprendizaje activo en las clases han estado basados en las Tecnologías de la Información y las Comunicaciones. Sin embargo, aunque hoy en día la tecnología está presente en casi todos los aspectos de nuestra vida, parece que en el campo de la enseñanza se está tomando su tiempo. Quizá factores económicos, socioculturales o incluso relacionados con el nivel de conocimiento tecnológico y científico de los profesores puedan explicar a priori esta situación, pero sea cual sea la razón, parece evidente que cualquiera de estos intentos de modernizar la práctica docente actual debería tenerse en cuenta de forma positiva. Precisamente es aquí donde esta tesis de innovación hace su principal aportación: el desarrollo de un sistema para mejorar la práctica docente actual. Así, este trabajo de tesis (apoyado en una beca de innovación de tres años asociada, además, a una empresa) ha tenido un enfoque eminentemente práctico y de transferencia de los resultados de la innovación a las empresas desde su concepción.

En la actualidad, una gran parte de las líneas de investigación englobadas en este campo están basadas en la rápida evolución de las tecnologías inalámbricas junto con la 
aparición de una nueva generación de dispositivos móviles y el incremento en la facilidad de conexión con cualquiera de ellos a una red inalámbrica, desde casi cualquier lugar. Por otra parte, la reciente incorporación de una serie de modernos dispositivos portables (como PDAs, smartphones u ordenadores portátiles) a los utensilios de uso cotidiano de casi todos nosotros es ya una realidad. Así, en este escenario, el uso extensivo de esos dispositivos móviles y tecnologías inalámbricas en el campo de la enseñanza representa una importante contribución al desarrollo de nuevas e innovadoras metodologías docentes.

Como ya se ha comentado, partiendo de esta idea inicial han surgido los famosos conceptos de e-learning y mobile learning que, de forma genérica, incluyen todo el trasfondo tecnológico, metodologías, aplicaciones e incluso aspectos pedagógicos de estas modernas prácticas docentes. Sobre esta base, sendos conceptos han ido evolucionando y pasando por diferentes nombres dependiendo del alcance concreto de cada aplicación, pero lo que es común a todos ellos es el afán por mejorar los métodos tradicionales de enseñanza y aprendizaje.

Los siguientes párrafos presentan algunos trabajos realizados en este campo, enumerando varias experiencias de e-learning interesantes llevadas a cabo en los últimos años. En este sentido, son clasificadas dependiendo de su alcance y principales objetivos, dando a su vez un breve resumen del estado del arte en esta área de investigación:

Hoy por hoy, el uso de sistemas de e-learning no está limitado al campo de la enseñanza en su sentido más puro: se ha extendido a muchas áreas de la ciencia (Hung, Chen \& Lee, 2009) e incluso a entornos educativos totalmente genéricos (Laine, Sedano, Vinni \& Sutinen, 2009; Shen, Callaghan \& Shen, 2008; Shen, Wang \& Shen, 2009). Como resultado, algunos autores han acuñado el término aprendizaje afectivo (Affective e-learning) para referirse a ello (Shen et al., 2008; Shen, L. et al., 2009).

Sin embargo, el concepto de e-learning y sus manifestaciones derivadas serán analizados en lo sucesivo desde un punto de vista puramente educacional. Así, el elearning (definido formalmente como el conjunto de medios y actuaciones para conseguir la integración de las TIC en el proceso de enseñanza para mejorar la calidad de la educación) representa un área de intensa investigación en el presente. Pruebas de ello son las novedosas iniciativas docentes que constantemente se están llevando a cabo por numerosos grupos de investigación. Por tanto, para resaltar la marcada naturaleza 
actual del tema, es importante darse cuenta de que todas las propuestas y artículos referenciados en esta sección han sido llevados a cabo en los últimos cinco años y son, por ello, muy representativos del estado del arte.

En los últimos años, es innegable el hecho de que están surgiendo muchas maneras diferentes de usar el e-learning para mejorar el proceso educativo: por ejemplo, a través de la creación de laboratorios virtuales interactivos (Koretsky, Amatore, Barnes \& Kimura, 2008), la implementación de sistemas de voto y respuesta electrónica en clase (King \& Robinson, 2009), o el uso de herramientas de e-learning para fomentar la competitividad (Kao, Lin \& Sun, 2008; Regueras, Verdu, Munoz, Perez, de Castro \& Verdu, 2009), entre otras muchas. En cada caso, las experiencias se centran en la potenciación o adquisición de habilidades muy específicas en los alumnos dependiendo, como es lógico, del alcance de cada actividad. En este sentido, la búsqueda de una metodología y secuenciación de actividades óptimas según los recursos disponibles o los entornos donde se lleven a cabo ha sido objeto de numerosos estudios teóricos (Castro-Schez, del Castillo, Hortolano \& Rodriguez, 2009; Hoic-Bozic, Mornar \& Boticki, 2009; Holbert, \& Karady, 2009; Liu, Lin \& Bhattacharya, 2008; MacíasGuarasa, Montero, San-Segundo, Araujo \& Nieto-Taladriz, 2006; Mallinson \& Nyawo, 2008; Shen, Wang, Gao, Novak \& Tang, 2009). Además, muchos de estos estudios han propuesto incluso marcos de trabajo conceptuales que cubren desde el diseño y soporte tecnológico de estos sistemas hasta su implementación y consecuente evaluación de resultados de cara a maximizar los resultados educativos (Daradoumis, Martínez-Mones \& Xhafa, 2006; Georgouli, Skalkidis \& Guerreiro, 2008; Gomez-Sanchez, BoteLorenzo, Jorrin-Abellan, Vega-Gorgojo, Asensio-Perez \& Dimitriadis, 2009; HoicBozic et al., 2009; Konstantinidis, Tsiatsos \& Pomportsis, 2009; Zurita \& Nussbaum, 2007). Asimismo, es interesante ver cómo la mayoría de ellos se centran en desarrollar actividades que promuevan el aprendizaje colaborativo (Collaborative Learning), como Daradoumis et al. (2006), Gomez-Sanchez et al. (2009), Konstantinidis et al. (2009) o Zurita \& Nussbaum (2007). De hecho, un entorno educativo colaborativo puede jugar un rol importante en la construcción del conocimiento y en la compartición, ya que la colaboración entre los alumnos tiene un impacto muy significativo en los logros educativos (Allen, McAlpine, Hoffman \& Munroe, 2009; Dan \& XinMeng, 2007; Hamada, 2008; Hurtado \& Guerrero, 2009; Valdivia \& Nussbaum, 2007). El aprendizaje colaborativo es un modelo educativo en el que alumnos con diferentes 
capacidades, habilidades e intereses trabajan juntos o en pequeños grupos para resolver un problema o llevar a cabo un proyecto (Hoic-Bozic et al., 2009). A su vez, este tipo de aprendizaje está estrechamente relacionado con el concepto de aprendizaje colaborativo asistido por ordenador (Computer Supported Collaborative Learning, CSCL), que tiene que ver con la adaptación del modelo educativo anterior para su uso en entornos informatizados, con todas las ventajas implícitas que ello conlleva. Algunos ejemplos recientes de implementaciones exitosas de sistemas CSCL se pueden encontrar en Allen et al. (2009), Dan \& XinMeng (2007), Hamada (2008), Hurtado \& Guerrero (2009) y Valdivia \& Nussbaum (2007).

Otro modelo educativo que ha atraído una gran atención en los últimos años es el aprendizaje basado en problemas (Problem-based Learning, PBL) porque ha probado ser un modelo pedagógico muy exitoso en muchos campos. El PBL va más allá de la metodología de enseñanza tradicional a través de la promoción de la interacción de los estudiantes. Por ejemplo, el trabajo práctico resulta de vital importancia para todos los cursos de ciencias de la información y consecuencia de ello es que el PBL esté ampliamente consolidado en este campo. Formalmente, el PBL se define como una metodología de enseñanza que se vale de problemas específicos para motivar a los alumnos hacia su resolución y el consecuente aprendizaje derivado del proceso. En este contexto, la importancia reside en el proceso de resolución más que en la explicación por parte del docente, ya que éste último actúa más como facilitador que como fuente de conocimiento (Garcia-Robles, Diaz-del-Rio, Vicente-Diaz \& Linares-Barranco, 2009). Algunos ejemplos de implantaciones exitosas de PBL en entornos TIC y otros campos de la ciencia se pueden encontrar en Garcia-Robles et al. (2009), Linge \& Parsons (2006), Richardson \& Delaney (2009) y Costa, Honkala \& Lehtovuori (2007), Fitzpatrick (2008), Wattinger, Guggisberg, Burkhart, Nguyen, Gyalog \& Fornaro (2006), respectivamente.

El aprendizaje mixto (formalmente Blended Learning, BL) se está convirtiendo también en una forma cada vez más popular de e-learning, ya que es particularmente adecuado para llevar a cabo el proceso de transición desde las formas tradicionales de enseñanza y aprendizaje hacia el e-learning (Hoic-Bozic et al., 2009). El BL está basado en una combinación de CSCL, PBL y las clásicas clases presenciales (face to face, $f 2 f$ ) con una parte de aprendizaje independiente, todo ello enfocado a la creación de un entorno más eficiente de cara al aprendizaje. Existe mucha literatura reciente al respecto 
que evalúa el despliegue e implementación de sistemas de BL con grupos de estudiantes (Gálvez, Guzmán \& Conejo, 2009; Sancho, Corral, Rivas, Gonzalez, Chordi \& Tejedor, 2006; Shen, R. et al., 2009), mientras que también existen interesantes modelos teóricos y recomendaciones para el diseño e implementación de cursos (Allen et al., 2009; Alonso, Viñes, López \& Manrique, 2005; Hoic-Bozic et al., 2009; Liu et al., 2008).

Finalmente, el aprendizaje móvil (Mobile Learning, mLearning) es quizá la forma de e-learning que más atención y actividad investigadora está atrayendo en la actualidad debido al ingente número de terminales móviles que entran en el mercado cada día. Esta modalidad se basa, de forma genérica, en el uso de dispositivos móviles en el proceso de enseñanza. Como es lógico, se aprovecha de las ventajas y beneficios que se derivan de su naturaleza móvil en términos de, por ejemplo, conectividad ubicua (pudiendo acceder a los recursos educativos desde cualquier ubicación a través de Internet) o flexibilidad horaria (permitiendo a los estudiantes aprender en cualquier momento que lo deseen). Sin embargo, aunque existen varios marcos de trabajo conceptuales para desarrollar actividades de mLearning (Kazi, 2007; Motiwalla, 2007), no existe una metodología de acción clara, como se puede leer en Frohberg, Gothe \& Schwabe (2009) que resalta, hasta 2007, algunos de los cuellos de botella y principales problemas asociados al desarrollo de sistemas de mLearning. Además, varios estudios concretos como Anido-Rifon (2008), Economides (2008), Evans (2008), Mikic, Anido, Valero \& Picos (2007) o Parsons, Hokyoung \& Cranshaw (2006) incluso cuestionan la idoneidad del uso de dispositivos móviles en educación debido principalmente a la falta de estandarización existente y a los problemas de visualización de contenidos en dichos dispositivos, que complican enormemente el desarrollo de sistemas para este tipo de dispositivos. Sin embargo, otros estudios son más optimistas en cuanto a este tema y tratan de aclarar y concretar ciertas asunciones teóricas relacionadas con un hipotético diseño multi-dispositivo, presentando alguno de ellos incluso alguna implementación práctica (De Oliveira \& Da Rocha, 2007; Hongru, Wang, Tong, Shen, Wang \& Gao, 2006). En esta línea, algunos ejemplos de experiencias exitosas de mLearning se pueden encontrar en Liu, Liu \& Yu (2008) y Wang, Novak \& Shen (2008). En este contexto multi-dispositivo, muchos investigadores han encontrado una línea de acción interesante desarrollando sistemas de mLearning auto-adaptativos (self-adaptative) (Kuo \& Huang, 2009; Martín \& Carro, 2009; Yang \& Chen, 2006) y sensibles al contexto (contextaware) (Huang, Kuo, Lin \& Cheng, 2008; Yang \& Chen, 2006). 
Pero en definitiva, cualquiera que sea la modalidad de e-learning escogida, debe cumplir una serie de criterios mínimos de calidad para asegurar que el uso de semejante plataforma innovadora de aprendizaje realmente aporta un valor positivo y favorable al proceso de enseñanza $\mathrm{y}$, por tanto, merece la pena y el esfuerzo. Existen muchos trabajos y artículos que tratan de este tema de la evaluación de la calidad, como Ellis \& Calvo (2007), que trata de cuantificar unos niveles mínimos de calidad en un escenario con un sistema de gestión del aprendizaje, LMS-Supported Blended Learning (LMS, learning management system). Leacock \& Nesbit (2007) presenta por su parte un marco de trabajo para la evaluación de la calidad del contenido multimedia ofrecido en los cursos. Además, es interesante resaltar el trabajo hecho en Bousbia, Labat, Rebai \& Balla (2009), Brown, Brailsford, Fisher \& Moore (2009), Mondi, Woods \& Rafi (2008) o Ozpolat \& Akar (2009), ya que proveen varios modelos y métodos numéricos para identificar e incluso cuantificar el estilo de aprendizaje de los alumnos de cara a la obtención de una información muy útil que pueda contribuir al rediseño y reciclaje de los sistemas actuales de e-learning para aumentar drásticamente su efectividad. Finalmente, en este contexto de evaluación de la calidad, es muy remarcable el trabajo realizado en Toral, Barrero, \& Martinez-Torres, 2007; Roca, Chiu \& Martinez, 2006 y Martinez-Torres et al., 2008, que versa sobre la aplicación del modelo de aceptación tecnológica (Technological Acceptance Model, TAM) a la evaluación de herramientas de e-learning. El TAM es una teoría de los sistemas de información que modela la forma en que los usuarios aceptan y usan una nueva tecnología. En este sentido, estos estudios hacen una importante contribución en la validación y aceptación de herramientas educativas basadas en el uso de ordenadores. Estrechamente relacionado con estos temas del TAM podemos encontrar el tema del diseño de herramientas de elearning. De hecho, el grado de aceptación de una herramienta de e-learning concreta depende directamente de su diseño, por lo que éste representa un papel muy importante en la etapa de desarrollo de la misma. Un trabajo interesante en este campo se puede encontrar en Martinez-Torres, Toral \& Barrero, 2011.

En definitiva, en estos párrafos se han presentado varias formas de e-learning (Cabrera-Lozoya, Cerdan, Cano, Garcia-Sanchez \& Lujan, 2012a). Asimismo, han sido clasificadas atendiendo al agente catalizador que propicia o potencia el aprendizaje de los alumnos (por ejemplo, la resolución de problemas para el PBL o el hecho de trabajar colaborativamente y con ordenadores para el CSCL). Además, se han 
identificado las ventajas de los sistemas mixtos BL mediante varios ejemplos. Por último, está claro que existen diferentes formas y medios de implementar sistemas de elearning exitosos, dependiendo siempre de las habilidades específicas a potenciar en los alumnos.

Sin embargo, aunque todas estas formas especializadas de e-learning han probado ser efectivas en sus respectivos ámbitos de acción (es decir, potenciando ciertas habilidades en los estudiantes, como ya se ha descrito anteriormente), parece que no existe aún ningún sistema de e-learning capaz de abstraer varios principios educativos básicos y llevarlos a la práctica en una plataforma específica de e-learning. El sistema que se presenta en esta tesis trata de arrojar algo de luz en este aspecto. Así, las principales contribuciones de la misma son:

- El diseño y desarrollo de una nueva plataforma multimedia de e-learning capaz de abstraer varias prácticas y metodologías educativas actuales en un único sistema.

- La implementación de esos entornos de aprendizaje heterogéneos (entendidos como una mezcla y combinación de actividades educativas que, aisladas, podrían enmarcarse dentro de otra modalidad de e-learning) con estudiantes usando la plataforma.

- La evaluación del impacto de un entorno altamente interactivo en el rendimiento académico de los estudiantes a través de un análisis estadístico.

\subsection{Ejemplos de plataformas virtuales de docencia}

\subsubsection{SWAD}

Como alternativa a la situación descrita anteriormente, diversas universidades utilizan desarrollos propios pensados para sus necesidades específicas. Un ejemplo es SWAD (Sistema Web de Apoyo a la Docencia, http://swad.ugr.es/info), desarrollada en la Universidad de Granada, y utilizada actualmente por 773 profesores y 31.509 alumnos en 785 asignaturas de 137 titulaciones. Es una plataforma web de teleformación y gestión docente que incluye funciones de apoyo al aprendizaje, a la docencia y a la gestión de estudiantes y profesores. 
Esta plataforma muestra una página donde el profesor incluye respuestas a todas aquellas cuestiones formuladas más frecuentemente (FAQ, Frequently Asked Questions) por los alumnos de la asignatura.

También dispone de una pestaña de información sobre el sistema de evaluación del alumno (por ejemplo, la valoración de los exámenes, las prácticas, etc.) así como fichas del alumno personalizadas para la asignatura donde se introducen calificaciones, observaciones que puedan rellenar los alumnos, etc. Además, permite el envío de los trabajos de los alumnos junto con exámenes de autoevaluación tipo test, servicio muy valorado entre ellos ya que les permite autoevaluarse y llegar al examen con mayor confianza.

\subsubsection{PRADO}

Otro ejemplo es el tablón de docencia del CSIRC (Centro de Servicios de Informática y Redes de Comunicaciones). Este es un servicio centralizado, también de la Universidad de Granada, que pretende facilitar el intercambio de información electrónica entre el profesor y sus alumnos. Simulan un tablón normal en el que el profesor deja mensajes a los alumnos y permite asimismo que el alumno cuelgue sus propios mensajes. Como novedades presenta buzoneo de listas, conferencias vía web, salas de videoconferencia virtuales pudiendo establecerse reuniones entre personas que puedan estar físicamente alejadas, etc. Actualmente, la universidad granadina pretende unificar ambos proyectos en una única plataforma denominada PRADO (Plataforma de Recursos de Apoyo a la Docencia, proyecto del CEVUG, Centro de Enseñanzas Virtuales de la Universidad de Granada, ).

Sin embargo, es evidente que hay todavía una gran infrautilización de todas las potencialidades que técnicamente ya son posibles con estas plataformas. Prácticamente todas las universidades disponen de plataformas virtuales de uno u otro tipo y en casi todas las asignaturas se utilizan, pero apenas como tablón de avisos, tutorías o para descargar archivos con los contenidos subidos por el profesor.

\subsubsection{OCW}

Otro ejemplo también a citar lo encontramos en la plataforma $O C W$ (MIT, Massachusetts Institute of Technology, Open CourseWare, http://ocw.mit.edu), que 
intenta poner a disposición del profesor y los alumnos una gran cantidad de información y conocimientos pero sin potenciar tanto la interacción entre ambos.

Esta iniciativa nació en Abril de 2001 en el Massachusetts Institute of Technology, donde fue conocida como $O C W-M I T$. OCW es conocido en España y América Latina como Universia. A través de esta plataforma se ofrece en abierto el material docente que sus profesores utilizan en las enseñanzas junto con un guía de estudio.

La iniciativa tuvo un gran impacto e impulsó a otras universidades de prestigio internacional a adherirse, generando proyectos propios en coordinación con ellos. La Universidad de Granada antes mencionada se encuentra en el puesto número 22 de las 36 universidades de España que han implantado este método, teniendo 13 asignaturas disponibles en este formato. Por su parte, la Universidad Politécnica de Cartagena $(U P C T)$ posee un portal en OCW cuyo principal objetivo es proporcionar acceso libre, sencillo y coherente a los materiales docentes elaborados por los profesores de nuestra universidad con el fin de que puedan ser compartidos y utilizados por docentes y estudiantes de otras universidades o por cualquier persona que quiera acceder a ellos. OCW es un ejemplo más de las iniciativas que en los últimos tiempos han emergido para promover el acceso libre y sin restricciones a la información y, en este caso, a los materiales docentes.

\subsubsection{CADI}

En la UPCT hemos diseñado una plataforma innovadora denominada CADI (Clase Docente Interactiva) pensada para mejorar la participación del alumnado asistente a clases docentes, presentaciones, mesas redondas, etc. El sistema tiene una arquitectura cliente servidor: por un lado los clientes, que son los dispositivos de los alumnos o público asistente en general y, por otro, el servidor, que incorpora una aplicación web basada en un sistema CMS (Content Management System, sistema gestor de contenidos). El cliente y el servidor se comunican vía WiFi mediante una red propia creada por el servidor e independiente de cualquier otra red de comunicaciones del entorno. Los clientes acceden al contenido a través del navegador web de sus propios dispositivos $\mathrm{WiFi}$, y una vez ahí pueden interactuar con la plataforma haciendo preguntas según sus inquietudes o valorando las ya existentes de otros clientes. El moderador es el profesor / ponente o persona de apoyo a aquél, que se encarga de filtrar 
las preguntas de los clientes antes de hacerlas públicas. Adicionalmente, el sistema permite implementar un control de asistencia, el acceso mediante descarga a recursos docentes y didácticos, la realización de encuestas y exámenes y la integración con la reconocida plataforma de eLearning Moodle entre otras funcionalidades.

La siguiente Figura 1.1 muestra los resultados obtenidos de la realización de un test de concepto sobre CADI llevado a cabo al principio del proyecto de tesis para medir la reacción real de los potenciales usuarios en relación al futuro producto o servicio. El test de concepto, por su parte, es una técnica básica de investigación de mercado que mide si un potencial consumidor está dispuesto a comprar o usar un producto.

Dicho test fue realizado a distintos grupos de alumnos de la UPCT para sondear su grado de aceptación ante la hipotética incorporación de una plataforma como CADI en las clases y en general, en la docencia. Como se puede observar, los resultados a priori del test fueron muy buenos para CADI:

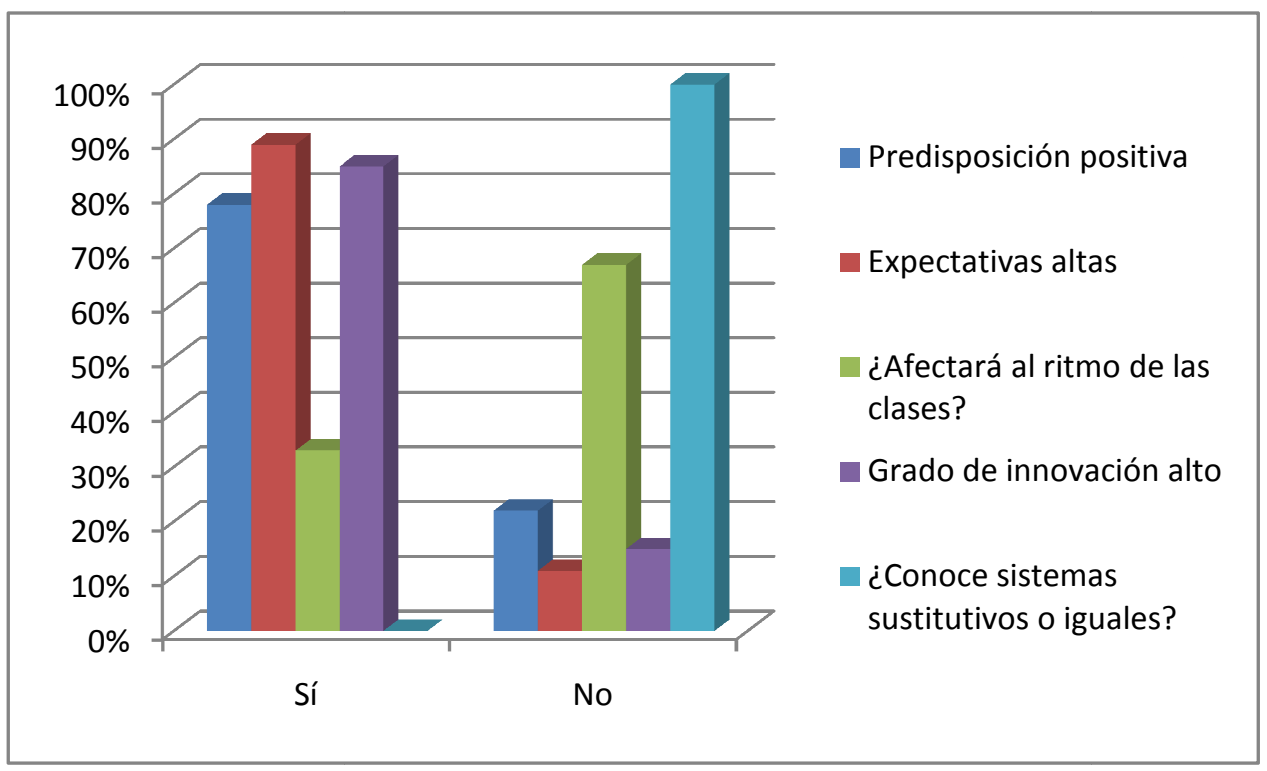

Figura 1.1. Test de Concepto CADI

La plataforma CADI constituye una de las actuaciones desarrolladas dentro del proceso modernizador en el que se encuentran inmersas actualmente las universidades españolas conforme al EEES nacido del denominado acuerdo de Bolonia.

Dicho proceso se puede enmarcar en la necesidad de armonizar y homologar los estudios universitarios que se plantean en el seno de la Unión Europea para facilitar el 
acceso al mundo laboral europeo de todos los ciudadanos miembros. Por tanto, este proceso insta a los países implicados a adaptar sus sistemas educativos al nuevo EEES, lo que ha provocado que en estos años se haya iniciado un cambio que está transformando el panorama universitario europeo.

El cambio es posible. Es posible mejorar y factible hacer las cosas de manera cualitativa y cuantitativamente diferente y mejor. Debemos aprovechar las potencialidades de las tecnologías para flexibilizar el proceso, de forma que la oferta sea adaptada a las necesidades del alumno.

La utilización de CADI también hace posible que el centro educativo donde se aplique se esfuerce por mejorar, trabaje en equipo, se arriesgue, planifique y busque alternativas comprometiéndose con el proceso y los resultados y conforme, en definitiva, una comunidad innovadora. Gracias a la interacción que se produce y la mejora de la calidad de la enseñanza, el esfuerzo de la comunidad educativa se transforma en objetivos alcanzables, realizándose una planificación realista para conseguirlos, implementándose las propuestas, revisándose constantemente el proceso y adaptándose a las demandas de los estudiantes, del entorno, de los mismos docentes y del sistema educativo en general.

\subsubsection{Conclusiones}

En la actualidad, la enseñanza ha de enfrentarse al reto de incrementar los niveles de calidad y equidad de la educación; ha de confrontar los desafíos que supone una sociedad sujeta a rápidos cambios (sociales, culturales, económicos y tecnológicos), desafíos que exigen un docente nuevo, para el que reproducir esquemas aprendidos en sus años de formación inicial ya no es suficiente.

Actualmente se exige a los centros de formación, sobre todo universidades, que formen profesionales bien preparados y comprometidos con su trabajo, personas flexibles, capaces de dar respuesta a las nuevas necesidades y demandas, que sean innovadoras y con recursos para transformar su realidad inmediata.

Hoy día no es suficiente, por ejemplo, que un profesor sepa lo que va a enseñar y posea una buena formación acerca del proceso de enseñanza porque la complejidad de la tarea docente exige un cambio de enfoque. 
Para responder a estos retos, algunos centros de formación docente se plantean propuestas innovadoras, capaces de dar respuesta eficaz a las necesidades del sistema educativo.

\subsection{Contenidos de la tesis}

El resto del presente trabajo de tesis se compone de los siguientes capítulos:

Capítulo 2. Trasfondo pedagógico de la plataforma CADI. En este capítulo se describen una serie de aspectos relacionados con el campo de la psicología y de las teorías del aprendizaje. Dicho capítulo refleja todo el trabajo de documentación preliminar y preparación llevado a cabo en las fases de concepción y diseño de la plataforma CADI para maximizar su impacto didáctico y los beneficios académicos derivados de su utilización.

Capítulo 3. La plataforma docente interactiva CADI. Este capítulo está dedicado a la descripción en profundidad de todos los aspectos de la plataforma desarrollada. Así, en primer lugar se dedican unas páginas a la contextualización el sistema dentro del panorama educativo actual, para dar lugar a la justificación del proyecto. Asimismo, se analiza la plataforma desde un punto de vista cualitativo y posteriormente técnico. Finalmente, se listan los objetivos del sistema y se ponen de manifiesto las ventajas derivadas del uso real de la plataforma.

Capítulo 4. La experiencia piloto con CADI. En este cuarto capítulo se detalla la experiencia llevada a cabo en un escenario de uso real con CADI. Primero se enumeran una serie de experiencias paralelas interesantes, para después pasar a la descripción del escenario real, la metodología empleada durante la misma y, finalmente, los resultados obtenidos, cuyo rigor está avalado por una serie de estudios estadísticos que también se detallan en este capítulo.

Capítulo 5. Conclusiones. Este capítulo resume las aportaciones de este trabajo y se concretan los resultados obtenidos en relación con los objetivos planteados. 


\section{Capítulo 2. Trasfondo pedagógico de la plataforma CADI}

\subsection{Principales teorías del aprendizaje}

Si clasificamos las teorías del aprendizaje según la concepción intrínseca de éste podemos diferenciar entre:

1) Teorías asociacionistas del condicionamiento

a. Condicionamiento clásico (Pávlov, Guthrie)

b. Condicionamiento instrumental operante (Hull, Thorndike)

2) Teorías mediacionales

a. Teorías cognitivas

i. Teoría de la Gestalt (Koffka, Wertheimer)

ii. Psicología genético-cognitiva (Piaget, Bruner, Ausubel, Inhelder)

iii. Psicología genético-dialéctica (Vygotski, Rubinstein, Wallon, etc.)

b. Teorías del procesamiento de la información (Gagné, Néwell, Mayer, Pascual Leone, etc.)

En este capítulo hablaremos de las tres últimas por ser las más relacionadas con el caso que nos ocupa.

\subsubsection{La psicología genético-cognitiva}

Desde la mitad del siglo XX y hasta nuestros días se han impuesto los principios de la psicología genético-cognitiva. Por citar algunos casos de los representantes más significativos encontramos a Piaget, biólogo, psicólogo y pedagogo suizo (1896-1976) que afirmaba que tanto el desarrollo psicológico como el aprendizaje son el resultado de un proceso de equilibración (Piaget, 1975). Según él, los resultados del desarrollo psicológico están predeterminados genéticamente. El aprendizaje modifica y transforma 
las estructuras en el ser humano y, así, éstas permiten la realización de nuevos aprendizajes de mayor complejidad.

El aprendizaje es un proceso de adquisición en un intercambio con el medio, mediatizado por las estructuras (las hereditarias y las construidas). Los mecanismos reguladores son las estructuras cognitivas. Estos mecanismos surgen de los procesos genéticos y se realizan en procesos de intercambio. Recibe el nombre de constructivismo genético. Todo proceso de construcción genética consta de:

- Asimilación: Es el proceso de integración de las cosas y los conocimientos nuevos a las estructuras construidas anteriormente por el individuo.

- Acomodación: Consiste en la reformulación y elaboración de estructuras nuevas debido a la incorporación precedente.

Para Piaget son 4 los factores que intervienen en el desarrollo de las estructuras cognitivas:

- Maduración

- Experiencia física

- Interacción social

- Equilibrio

El conflicto cognitivo provoca el desarrollo del alumno. Para Piaget existe una estrecha vinculación entre la dimensión estructural y afectiva de la conducta. La inteligencia y la afectividad son indisociables. No existe cognición sin una motivación y, por ende, no hay motivación que no esté conectada con un nivel estructural cognitivo.

Ausubel propone otra teoría del aprendizaje hacia el año 1973. Esta teoría toma como elemento esencial la instrucción. Para él, el aprendizaje del alumno alude a cuerpos organizados de material significativo. Le da especial importancia a la organización del conocimiento en estructuras y a las reestructuraciones, que son el resultado de la interacción entre las estructuras del sujeto y las nuevas informaciones.

Tanto Ausubel como Vygotski estiman que para que la reestructuración se produzca y favorezca el aprendizaje de los conocimientos elaborados, se necesita una instrucción formalmente establecida. La instrucción reside en la presentación secuencializada de informaciones que quieran desequilibrar las estructuras existentes y sean las generadoras de otras estructuras que las incluyan. 
Ausubel tiene en cuenta 2 elementos:

- El aprendizaje del alumno va de lo repetitivo-memorístico hasta el aprendizaje significativo.

- La estrategia de la enseñanza, que va desde la puramente receptiva hasta la enseñanza que tiene como base el descubrimiento por parte del propio educando.

El aprendizaje es significativo cuando se incorpora a estructuras de conocimiento que ya posee el individuo. Para que se produzca este aprendizaje significativo deben darse las siguientes condiciones:

- $\quad$ Potencialidad significativa. Se refiere a:

- Lógica: La significalidad lógica se refiere a la secuencia lógica de los procesos y a la coherencia en la estructura interna del material.

- Psicológica-cognitiva: El alumno debe contar con ideas inclusoras relacionadas con el nuevo material, que actuarán de nexo entre la estructura cognitiva preexistente del educando y las ideas nuevas.

- Disposición positiva.

○ Afectiva: Disposición subjetiva para el aprendizaje.

\subsubsection{La psicología genético-dialéctica}

Vygotski (1896-1934) tiene similitudes y diferencias con Piaget. Ambos mantienen la concepción constructivista del aprendizaje pero Vygotski se diferencia de Piaget en el papel que juega en el aprendizaje el medio y la cultura.

Para Vygotski es esencial la consideración de lo social, que contribuye con los mediadores a transformar la realidad y la educación (Vygotski, 2000).

El psiquismo y la conducta intelectual adulta son el resultado de la impregnación social del organismo de cada sujeto, y esto no es un proceso unilateral, sino dialéctico.

Los mediadores serían:

- Las herramientas: elementos materiales

- Los signos: no son materiales, pero actúan sobre los individuos y su interacción con el entorno, por ejemplo, el lenguaje oral. 
El mundo de la cultura aporta las herramientas y los signos y es el que da sentido a la enseñanza y al aprendizaje.

El aprendizaje es el proceso de internalización de la cultura y en cada individuo da significado a lo que percibe en función de su propia posibilidad de significación y a la vez, incorpora nuevas significaciones. El aprendizaje es, por tanto, un proceso interactivo en el que la acción parte del sujeto, pero a la vez está determinada por el mundo exterior.

Vygotski afirma que el aprendizaje engendra un área de desarrollo potencial y estimula procesos internos.

La psicología genético-dialéctica considera que existe una distancia óptima entre lo que se sabe y lo que se puede saber. Recorrer esta distancia necesita de la acción docente y constituye aprendizaje. Esta concepción concede importancia fundamental al lenguaje puesto que la palabra es el instrumento más rico de transmisión social.

La actividad del individuo es el motor fundamental de desarrollo, en su participación en procesos grupales y de intercambios de ideas. Quienes rodean al alumno constituyen agentes de desarrollo, que guían, planifican y encauzan las conductas del alumno.

Vygotski distingue entre nivel de desarrollo potencial y nivel de desarrollo actual. El primero es el conjunto de actividades que el alumno es capaz de realizar con la ayuda de los demás. El segundo es el conjunto de actividades que el alumno es capaz de realizar por sí mismo, sin la ayuda de otras personas.

\subsubsection{Aprendizaje como procesamiento de la información}

Surge a partir de la década de los años 60, en la segunda mitad del siglo XX, integrando el modelo conductista dentro de un esquema cognitivo. Este aprendizaje resalta la importancia de las estructuras internas que mediatizan las respuestas que, por analogía con los ordenadores, tratan de reproducir de forma artificial el funcionamiento de la mente. Las funciones de ésta última con respecto a la información serían:

\section{- Almacenar \\ - Ordenar \\ - Jerarquizar}

Estas teorías reconocen la existencia de: 
- Procesos cognitivos complejos

- Una mente que contiene y da sentido a la información procesada.

Pero existen unas limitaciones didácticas de esta perspectiva, que son:

- La comparación paralela entre el hombre y la máquina. El hombre posee una conciencia, un conocimiento de lo que se conoce y del acto de conocer.

- La importancia del factor afectivo: emociones, sentimientos, personalidad, interacción social, etc., todos de importancia en el aprendizaje.

- En el alumno, ya que entre el conocimiento y la acción hay complejos procedimientos de toma de decisiones, la influencia de las emociones y las expectativas individuales y sociales.

En síntesis, la psicología de la educación no dispone todavía de un marco teórico unificado y coherente. Las distintas teorías brindan datos parciales.

El profesor es un guía y un mediador en el proceso de construcción de conocimientos del alumno. El alumno construye los significados, resultantes de una compleja serie de interacciones con la intervención del:

- Profesor

- Los contenidos del aprendizaje

- Lo más importante, el propio alumno.

\subsection{Principales principios pedagógicos}

El aprendizaje es un proceso de construcción interno, activo, individual e interactivo con el medio social y natural. Para aprender, los estudiantes utilizan estructuras lógicas que dependen de variables como los aprendizajes adquiridos anteriormente y el contexto sociocultural, geográfico, lingüístico y económicoproductivo en el que se encuentran.

La interacción entre el estudiante y sus docentes, sus pares y su entorno se produce sobre todo a través del lenguaje, recogiendo los saberes de los demás y aportando ideas y conocimientos propios que les permitan ser conscientes de qué y cómo está aprendiendo, a la vez que le permite desarrollar estrategias para seguir en su continuo aprendizaje. 
El aprendizaje significativo es posible si se relacionan los nuevos conocimientos con los que ya se poseen, pero además si se tienen en cuenta los contextos, la realidad misma y la diversidad en la cual está inmerso el estudiante. Los aprendizajes deben estar conectados con la vida real y las prácticas sociales de cada cultura.

Las relaciones que se establecen entre los diferentes conocimientos se amplían a través del tiempo y de la oportunidad de aplicarlos en la vida, lo que permite establecer nuevas relaciones con otros conocimientos y desarrollar la capacidad para evidenciarlas.

Los aprendizajes deben abarcar el desarrollo integral de los estudiantes, de acuerdo con las características individuales de cada persona. Por ello, se debe propiciar la consolidación de las capacidades adquiridas por los alumnos en su vida cotidiana y el desarrollo de nuevas capacidades a través de todas las áreas del currículo.

Los estudiantes requieren actividades pedagógicas que les ayuden a reconocer sus avances y dificultades, a acercarse al conocimiento de sí mismos, a autoevaluarse analizando sus ritmos de aprendizaje, sus características personales y estilos a la vez que a aceptarse y a superarse permanentemente para seguir aprendiendo de sus aciertos y errores.

Principios como los del aprendizaje activo, colaborativo y las posibilidades de individualización o autonomía se defienden ahora mucho más que antes como características propias del aprendizaje, pero lo que es verdad es que ahora podemos afirmar que con el uso y aumento de las tecnologías interactivas, estos principios son más alcanzables.

La democratización del acceso a la educación ha venido siendo desde siempre uno de los objetivos básicos para la creación de instituciones y programas de educación, sobre todo de educación a distancia. Reconocemos que, con Internet, se ha democratizado el acceso a la información y, a través de la educación, el acceso al conocimiento.

Por otro lado, la socialización y la interactividad junto con el aprendizaje colaborativo y cooperativo tutelado entre los propios alumnos, denominados entre ellos por Jay \& Perkins (1997) como educación entre pares se ha venido fomentando, por ejemplo, en instituciones a distancia de gran prestigio nacidas en la década de los 70 a través de tecnologías más convencionales tales como el teléfono, videoconferencias, audio conferencias, etc. 
Pero lo que sí es cierto es que la interacción a través de medios telemáticos hace más inmediata, fácil y frecuente esta interacción en las aulas.

El principio de actividad en la educación tiene gran importancia y ahora se ve potenciado con el uso de herramientas tecnológicas más avanzadas. El estudiante, como sujeto activo de su propio proceso de aprendizaje es más protagonista en la educación actual. Este protagonismo se mantiene y se aumenta con la formación en espacios virtuales.

El principio de la individualización tan defendido por la Escuela Nueva a finales del siglo XIX era una clara apuesta en la educación convencional, pero ahora se potencia nuevamente con la libertad e independencia en el estudio, las ventajas del autoaprendizaje y el uso de las nuevas tecnologías de la información y las comunicaciones. La lectura negativa de este principio nos llevaría al individualismo, tan deplorable en cualquier modalidad educativa (recordemos que también se están generando grandes problemas de soledad y escasa socialización cuando tanto se depende de Internet).

\subsection{Rasgos que se han potenciado con el uso de las TIC y posibles peligros}

La siguiente Tabla 2.1 pretende resumir los rasgos y principios pedagógicos que han sido potenciados con la integración de las TIC en la educación (García Aretio, 2002):

\begin{tabular}{|c|l|}
\hline & - A diversa y amplia oferta de cursos. \\
& - A destinatarios dispersos. \\
\hline Apertura & - A diferentes entornos, niveles y estilos de aprendizaje. \\
& - A las necesidades actuales. \\
& - A la segunda oportunidad. \\
\hline \multirow{3}{*}{ Flexibilidad } & - De espacios ¿dónde estudiar? \\
& - De tiempo ¿cuándo estudiar? \\
& - De ritmos ¿a qué velocidad estudiar? \\
& - Para combinar familia, trabajo y estudio \\
\hline
\end{tabular}




\begin{tabular}{|c|c|}
\hline & $\begin{array}{l}\text { - Para permanecer en el entorno familiar y laboral } \\
\text { - Para compaginar estudio con otras alternativas. }\end{array}$ \\
\hline Eficacia & $\begin{array}{l}\text { - Posibilidad de aplicar con inmediatez lo que se aprende } \\
\text { - Integración de medios para aprender. } \\
\text { - Autoevaluación de los aprendizajes. } \\
\text { - Posibilidad de que mejores especialistas elaboren materiales. }\end{array}$ \\
\hline Economía & $\begin{array}{l}\text { - Al obviar pequeños grupos. } \\
\text { - Al ahorrar gastos de desplazamiento. } \\
\text { - Al evitar abandono de puesto de trabajo. } \\
\text { - Al disminuir tiempo complementario de permanencia en trabajo } \\
\text { - Al propiciar la economía de escala }\end{array}$ \\
\hline Formación permanente & $\begin{array}{l}\text { - Al dar respuesta a la gran demanda de formación. } \\
\text { - Al mostrarse como ideal para la formación en servicio. } \\
\text { - Al propiciar la adquisición de actitudes, intereses y valores. }\end{array}$ \\
\hline Privacidad & $\begin{array}{l}\text { - Al propiciar la posibilidad de estudiar en la intimidad. } \\
\text { - Al evitar lo que para muchos puede suponer la presión del grupo. } \\
\text { - Al invitar a manifestar conocimientos o habilidades que ante el } \\
\text { grupo se evitarían. }\end{array}$ \\
\hline Interactividad & $\begin{array}{l}\text { - Al hacer posible la comunicación total, bidireccional y } \\
\text { multidireccional. } \\
\text { - Al hacerla más próxima e inmediata. } \\
\text { - Al posibilitar la interactividad síncrona o asíncrona. }\end{array}$ \\
\hline Aprendizaje activo & $\begin{array}{l}\text { - Estudiante es sujeto activo de aprendizaje. } \\
\text { - El autoaprendizaje exige en mayor medida la actividad }\end{array}$ \\
\hline Aprendizaje colaborativo & $\begin{array}{l}\text { - El aprender con otros, de otros y para otros, sea este aprendizaje } \\
\text { de forma más o menos guiada (cooperativo). }\end{array}$ \\
\hline Macro-Información & $\begin{array}{l}\text { - Al poner a disposición la mayor biblioteca jamás imaginada. } \\
\text { Ninguna biblioteca de aula, centro o universidad alberga tantos } \\
\text { saberes como los depositados en la red. }\end{array}$ \\
\hline Recuperación inteligente & $\begin{array}{l}\text { - Al propiciar que el estudiante pase de receptor de información a } \\
\text { poseer la capacidad de buscar, seleccionar y recuperar } \\
\text { inteligentemente la información, }\end{array}$ \\
\hline
\end{tabular}




\begin{tabular}{|c|c|}
\hline $\begin{array}{l}\text { Democratización de la } \\
\text { educación }\end{array}$ & $\begin{array}{l}\text { - Al superar el acceso limitado a la educación por razones laborales, } \\
\text { de residencia, familiares, etc. }\end{array}$ \\
\hline $\begin{array}{l}\text { Democratización de la } \\
\text { información }\end{array}$ & $\begin{array}{l}\text { - Al hacer realidad la universalidad de la información. } \\
\text { - Todos pueden acceder a todo tipo de documentos textuales y } \\
\text { audiovisuales. }\end{array}$ \\
\hline Diversidad y dinamismo & $\begin{array}{l}\text { - La información es diversa, variada y complementaria. } \\
\text { La web ofrece múltiples maneras de acceder al conocimiento de } \\
\text { forma variada y dinámica. }\end{array}$ \\
\hline Inmediatez & $\begin{array}{l}\text { - La respuesta ante las más variadas cuestiones se ofrece a gran } \\
\text { velocidad, al margen de la hora y el lugar. }\end{array}$ \\
\hline Permanencia & $\begin{array}{l}\text { - La información no es fugaz como la de la clase presencial, la } \\
\text { emisión de radio o televisión. } \\
\text { - Los contenidos están disponibles siempre para su consulta y } \\
\text { acceso. }\end{array}$ \\
\hline Multiformatos & $\begin{array}{l}\text { - La diversidad de formatos en los que puede ofrecerse la } \\
\text { información estimula el interés por aprender y puede ofrecer } \\
\text { ángulos diferentes del concepto, idea o acontecimiento. }\end{array}$ \\
\hline Multidireccionalidad & $\begin{array}{l}\text { - Existe gran facilidad para que documentos, opiniones y respuestas } \\
\text { tengan simultáneamente diferentes y múltiples destinatarios, } \\
\text { seleccionados a golpe de "click". }\end{array}$ \\
\hline Teleubicuidad & $\begin{array}{l}\text { - Todos los participantes en el proceso de enseñanza y aprendizaje } \\
\text { pueden estar virtualmente presentes en muchos lugares a la vez. }\end{array}$ \\
\hline $\begin{array}{l}\text { Libertad de edición y } \\
\text { difusión }\end{array}$ & $\begin{array}{l}\text { - Todos pueden editar sus trabajos y difundir sus ideas que pueden } \\
\text { ser conocidas por multitud de internautas. }\end{array}$ \\
\hline Interdisciplinariedad & $\begin{array}{l}\text { - Todos los ángulos, dimensiones y perspectivas de cualquier } \\
\text { cuestión pueden ser contemplados desde diferentes áreas } \\
\text { disciplinares y presentados de manera inmediata. }\end{array}$ \\
\hline
\end{tabular}

Tabla 2.1. Resumen de los rasgos y principios pedagógicos que han sido potenciados con la integración de las TIC en la educación (García Aretio, 2002)

No podemos olvidar que existen algunos peligros en la aplicación de las nuevas tecnologías. No podemos olvidar asimismo que la pedagogía tradicional está muy arraigada en algunos docentes y que no es fácil propiciar cambios verdaderos e innovadores basados en las TIC. Son muchos los que piensan que por el hecho de 
utilizar las tecnologías están renovando las propuestas pedagógicas cuando esta renovación siempre va a sustentarse en el saber, el saber hacer pedagógico y el saber actuar de los propios docentes.

Los saberes, intenciones y prácticas del docente serán antes y más importantes que el soporte tecnológico, pero lo que sí es cierto es que según el uso que haga el docente del recurso tecnológico, el resultado puede mejorar sustancialmente la enseñanza de forma cualitativa y cuantitativa. Todavía hoy en día la realidad nos muestra que la mayoría de los docentes no están totalmente preparados para usar las nuevas tecnologías en la enseñanza, ya que fueron educados sin ordenador y sin Internet y piensan "que no fueron mal formados". Por eso, actualmente se está procediendo a un plan de formación atractivo bien diseñado $\mathrm{y}$, naturalmente, a través de herramientas electrónicas con el fin de que esos docentes se conviertan en los artífices esenciales de la transformación educativa que propugna el EEES (García Aretio, 2002).

No cabe duda de que se ha hecho un esfuerzo en formar a los docentes sobre las herramientas tecnológicas. Sin embargo, se ha hecho muy poco por formar a esos mismos docentes sobre prácticas pedagógicas innovadoras (Comisión Europea, 2000). El cambio pedagógico no vendrá con la mera aplicación de las tecnologías; vendrá cuando los docentes sean conscientes de todas sus posibilidades y vinculen adecuadamente las tecnologías a la práctica pedagógica de cada una de las disciplinas del currículo.

El énfasis no ha de ponerse sólo en la disponibilidad y potencialidad de las tecnologías sino también en los cambios de estrategias didácticas de los docentes en cuanto al diseño y estructura de su clase, sus contenidos, y a los sistemas de comunicación tanto verticales como horizontales, es decir, profesor-alumno y alumnoalumno, respectivamente (Salinas, 2000).

Así, surgirían de forma natural nuevas competencias docentes con la integración de las tecnologías en el proceso educativo como serían:

- Diseñador o, al menos, gestor de la clase.

- Planificador y organizador de recursos (Inglis, 2002).

- Proveedor de fuentes de información, lo que supone una cualificación para buscar, seleccionar, procesar, valorar y estructurar informaciones $\mathrm{y}$ conocimientos además de informar a los alumnos en estas técnicas. 
- Facilitador, que descubre caminos, apunta estrategias de aprendizaje y soluciona problemas y dudas.

- Promotor de temas de debate, trabajos colaborativos, estudio de casos, guía y moderador de debates (escritos y verbales).

- Evaluadores, con incidencia en la modalidad formativa de la evaluación.

- Orientador, tutor y creador de un ambiente agradable para el aprendizaje. Esto supone el seguimiento del progreso del estudiante, la permanente disponibilidad y motivación y la atención a la configuración de diversos grupos de trabajo, etc. (García Aretio, 2006).

\subsection{Métodos didácticos}

Con método didáctico nos referimos al conjunto lógico y unitario de los procedimientos didácticos que tienden a dirigir el aprendizaje, incluyendo en él desde la presentación y elaboración de la materia hasta la verificación y competente rectificación del aprendizaje. Así, y en cuanto a los métodos didácticos de la educación, a modo de síntesis podríamos resumir los más importantes cuyos principios son tan universales que no sólo se limitan a las escuelas sino también a la educación de adultos y a las universidades.

A comienzos del siglo XX surge el método de Decroly, médico y psicólogo que tomó como base la realidad de su momento para diseñar un método didáctico basado en la ideología de la psicología americana de John Dewey.

Los principios básicos de este método se podrían resumir en:

- "Escuela para la vida por la vida", que partía de sus concepciones pedagógicas de respeto por el alumno y por su personalidad.

- El principio de la libertad (también propuesto por Rousseau y manifestado por Dewey) mantenido hasta nuestros días.

- Partir del educando, teniendo en cuenta sus intereses y que cada alumno alcance el grado de perfección de que sea capaz.

- Oposición a la disciplina rígida, que sometía al alumno a una actitud pasiva.

- Proposición de grupos lo más homogéneos posible y con una ratio de 20 a 25 alumnos / aula. 
- Defiende la actividad en el alumno.

Por otro lado, para llegar a la finalidad formativa del conocimiento, John Dewey enunciaba tres etapas fundamentales:

1. Hechos y acontecimientos científicos.

2. Ideas y razonamientos.

3. Aplicación de los resultados a nuevos hechos específicos (Dewey, 2004).

Según el psicopedagogo estadounidense, cuando se han recorrido estas tres etapas, se ha completado la enseñanza de una lección. Sus ideas están íntimamente ligadas a su pragmatismo y a su instrumentalismo. Para Dewey, se debe aprender haciendo, resolviendo problemas concretos y personales, y no escuchando. Dice Dewey: "Toda educación deriva de la participación del individuo en la conciencia social de la especie".

En este recorrido sobre métodos didácticos no podemos dejar a un lado al gran pedagogo del siglo XIX Pestalozzi (Zúrich 1746 - Brugg 1827). Su método estaba basado en la intuición. Pestalozzi fue el primer pedagogo que trató de entender la educación como un proceso de autoformación. Para él, todo saber surge de la íntima experiencia del individuo. Para Pestalozzi, la naturaleza humana significa conocimiento y racionalidad, autonomía y ética. El fin de la educación no consiste en un determinado contenido impuesto desde el exterior. Por lo tanto, la educación tiene como tarea el desarrollo armónico de las facultades del individuo y el dominio del espíritu sobre la animalidad.

\subsection{Importancia del aprendizaje activo}

El método y la teoría más actual es el aprendizaje activo. Este tipo de aprendizaje fue introducido por la doctora Lilli Nielsen en Dinamarca en la década de los 90, educando al alumno según sus capacidades y habilidades, con un desarrollo autónomo de todo su potencial.

El aprendizaje activo conlleva seguir el flujo natural del proceso de aprendizaje de cada persona en lugar de imponer la secuencia de enseñanza que quiere el educador. 
Esencialmente, el aprendizaje activo es un método que pretende alcanzar el desarrollo de las capacidades del pensamiento crítico y del pensamiento creativo. La actividad del aprendizaje está centrada en el educando.

Algunos objetivos de este tipo de aprendizaje serían:

- Aprender en colaboración.

- Organizarse.

- Trabajar de forma grupal.

- Fomentar el debate y la crítica.

- Responsabilizarse de tareas.

- Desarrollar la confianza, autonomía y experiencia directa.

Con el aprendizaje activo, el alumno adopta una actitud crítica, fomenta el debate y propicia una actitud reflexiva atendiendo a la diversidad de los alumnos y de los conocimientos. Además investiga las posibles respuestas y soluciones aprendiendo a utilizar la razón. También es importante aprender a pensar de modo autónomo y a fundamentar lo que decimos o escribimos. La plataforma CADI nos ayuda a propiciar y utilizar más el diálogo para constatar y debatir diferentes puntos de vista.

En este tipo de aprendizaje activo, el docente es quien asume el rol de mediador en el proceso de enseñanza, y no sólo como instructor de contenidos conceptuales, sino que debe poseer el perfil de orientador de los procesos de formación integral del alumnado. El perfil docente debe presentar dos aspectos básicos:

- Mediador: atiende al concepto de diversidad.

- Orientador: el eje vertebrador de la acción educativa es el individuo y no los contenidos.

La autonomía en la enseñanza requiere que los alumnos asuman algunas responsabilidades acerca de su propio aprendizaje, planteando iniciativas propias ante algunas tareas.

El aprendizaje con autonomía e independencia ofrece la posibilidad de una educación sin la presencia física del docente. Éste último puede asesorar, brindar tutorías o aclarar dudas mediante guías de trabajo y de forma no presencial, lo que posibilita y da lugar a una educación a distancia. 


\section{Capítulo 3. La plataforma docente interactiva CADI}

\subsection{Principales cambios que se están produciendo en la formación universitaria: CADI}

Uno de los principales cambios que se están produciendo en la formación universitaria es el paso de la universidad como mero vehículo para transmisión de saberes a una nueva visión, en la que se plantea como uno de los ejes principales el desarrollo de competencias profesionales. Por ello, el proceso de enseñanza-aprendizaje ahora gira en torno al aprendizaje valorado en base a un amplio abanico de actividades a realizar por el alumno, entre las que se encuentran prácticas, seminarios,... así como actividades de evaluación.

Todo esto implica un cambio en el rol del profesor y un replanteamiento de las metodologías docentes, en las que la participación del alumnado se contempla como básica durante todo el proceso.

La plataforma CADI conlleva importantes beneficios tanto en las tareas del profesorado como en el proceso de aprendizaje del alumnado, ya que aumenta el grado de atención de éste, permitiendo una mayor interacción docente-discente y mejora el grado de comprensión de la materia a estudiar (Cabrera-Lozoya, Cerdan, Cano, Garcia-Sanchez \& Lujan, 2012b).

Asimismo, cabe resaltar dos particularidades propias de esta plataforma de comunicaciones interactiva, como son:

1. Permitir al alumnado participar en las clases de forma anónima, venciendo una de las principales barreras que dificultan la relación profesor-alumno.

2. Plantear el proceso clases-evaluación como una actividad más dinámica, logrando incentivar al alumnado por encima del modo tradicional de enseñanza y venciendo así la posible apatía de éste. 
Con el proyecto CADI nos plateamos conseguir un acercamiento del alumnado de la Universidad Politécnica de Cartagena a las nuevas tecnologías y al profesorado, de forma que los considere como algo necesario y útil para su crecimiento intelectual y la adquisición de competencias y habilidades propias de la titulación a la que aspire.

\subsection{Justificación del proyecto CADI}

\subsubsection{La trayectoria de CADI}

La telefonía móvil a la que accede la mayor parte de la población en los países desarrollados y en vías de desarrollo se ha convertido en un vehículo imprescindible para la formación de individuos que se mueven constantemente de un lugar a otro "colgados" de su teléfono móvil. Similar impacto es el producido por las Personal Digital Assistants, PDAs, organizadores, agendas electrónicas personales, ordenadores portátiles, smartphones, etc., que con sus diminutas dimensiones se están convirtiendo en auténticas oficinas de bolsillo que integran todas las posibilidades que ofrece el Internet de hoy y las que previsiblemente seguirá ofreciendo en los próximos años.

Del mismo modo, el desarrollo de estándares para el diseño de materiales de estudio e instrumentos para el aprendizaje y las plataformas o entornos virtuales para la gestión del conocimiento y el aprendizaje existentes hoy tendrán que depurar sus prestaciones y ofrecer las máximas facilidades a docentes y alumnos. En este escenario descrito se ha diseñado y desarrollado CADI.

En las primeras fases de la tesis se pensó en aprovechar las potencialidades de los recursos TIC para mejorar el proceso de enseñanza-aprendizaje universitario. Esta práctica ofrecía la posibilidad de reflexionar sobre el uso de este sistema y su idoneidad para facilitar la construcción del conocimiento y así conseguir la responsabilidad del propio estudiante en su proceso de formación. Así, el concepto de docencia que implementa CADI no es trivial, sino que es fruto del desarrollo constante de esta idea innovadora a lo largo del tiempo. Los primeros pasos en esta línea se dieron en 2008 (Estrems-Amestoy, Sanchez-Reinoso, Franco-Chumillas, Cerdan, Garcia-Sánchez \& Cabrera-Lozoya, 2008).

También en la fase de diseño se propuso la exploración y explotación de las posibilidades que ofrece el trabajo colaborativo entre los propios estudiantes y entre 
éstos con el docente (Cabrera-Lozoya, Lujan \& Cerdan, 2008). Así, este canal de comunicación facilitaría un aprendizaje más autónomo, permitiendo una mayor participación en el aula y en las actividades grupales y aumentando la actividad, el interés y la motivación en los alumnos.

El sistema interactivo CADI ayudaría al alumno a convertirse en el verdadero protagonista de su proceso de aprendizaje además de promover y generalizar diferentes principios metodológicos actuales como:

- La participación activa del alumno en la construcción de su propio conocimiento.

- La promoción de la colaboración entre iguales.

- El establecimiento de dinámicas de debate, argumentación y negociación.

- El hecho de aprender bajo colaboración.

- El empleo de múltiples fuentes de información.

- La promoción de procesos de autoevaluación.

- La introducción de nuevas pruebas de evaluación, tanto cuantitativas como cualitativas, basadas en la reflexión y en la valoración práctica.

Hoy no podemos conformarnos con saber, sino que resulta cada vez más necesario desarrollar un tipo de conocimiento vinculado a los profundos cambios sociales y económicos en convivencia con los nuevos avances tecnológicos en un mundo creciente y complejo.

Por eso, con la puesta en marcha de metodologías innovadoras, se consigue que el alumnado se sienta más implicado y muestre (como así ha sido) una actitud positiva hacia el trabajo, con índices de asistencia y participación mucho más altos. Promoviendo un aprendizaje mucho más centrado en el alumnado hemos conseguido dos tipos de evaluación del proceso educativo: por un lado, la auto-reflexión del estudiante sobre el trabajo que va elaborando, su participación en el aula y el proceso de desarrollo de la asignatura o materia; por otro, la reflexión del docente sobre el trabajo de los alumnos, pero sobre todo sobre su propia labor (Cabrera-Lozoya, Cerdan, Cano, Garcia-Sanchez \& Lujan, 2012b).

Buena parte de los alumnos que forman parte del sistema educativo español pertenecen a lo que se ha dado en llamar "Net Generation" o generación de Internet. La inmensa mayoría han nacido rodeados de los dispositivos tecnológicos que hacen 
posible el acceso a las grandes autopistas de la información. Videoconsolas, teléfonos móviles u ordenadores personales forman parte del paisaje cotidiano de estos alumnos, conformando un ecosistema digital del que les resulta casi imposible sustraerse.

El uso generalizado de las TIC en tareas educativas puede ofrecer herramientas didácticas más atractivas y próximas al alumnado, reforzando incluso el interés y grado de motivación en determinadas materias (Cabrera-Lozoya, Cerdan, Cano, GarciaSanchez \& Lujan, 2012a).

El empleo de las nuevas herramientas tecnológicas ha de estar incluido en un amplio programa de actuación consecuente con las principales teorías del aprendizaje en las que se asienta el sistema educativo. Por tanto, el enfoque constructivista anteriormente mencionado es el fundamento teórico en la mayor parte de las actuales reformas educativas, que reclama a los docentes estrategias mediacionales activas en las que los procesos de construcción del conocimiento sean articulados tanto a nivel cognitivo como social. Con este nuevo método importa más el cómo enseñar que el qué enseñar.

El papel activo del alumno resulta central en la elaboración de las categorías lógicas y estructuras simbólicas que les permitan elaborar su particular modo de ser en el mundo. La formación del alumno se convierte en un proceso de adaptación permanente (longlife learning) en el que las habilidades intelectuales, la reflexión crítica, el análisis, la síntesis, la generalización y la resolución de problemas importan más que los conocimientos en sí.

En el actual marco educativo, la plataforma CADI reúne todas las características para ser un método ideal para la docencia contemporánea. CADI potencia la actividad del alumno, la interacción con los compañeros y los docentes además de caracterizarse por su facilidad de uso y versatilidad ya que no se requieren conocimientos de diseño web para su uso. El estándar de comunicaciones WiFi convierte a los móviles u ordenadores en un "micrófono individual" para lanzar mensajes escritos, realizar votaciones, responder encuestas o registrar exámenes, visualizando todos los resultados de forma inmediata. Además, resulta ser un eficiente navegador de contenidos. Las aportaciones aparecen con un orden cronológico inverso: lo último que se publica es lo último que se ve (Cabrera-Lozoya, Cerdan, Cano, Garcia-Sanchez \& Lujan, 2012b). 
Fue usado en el $1^{o}$ Congreso Internacional de Innovación Docente (CIID) celebrado en la UPCT en Julio de 2011 demostrando su alto grado de interactividad, lo que lo convierte en una de las estrategias docentes con mayor potencial didáctico. Las publicaciones resultantes cuando se aplicó resultaron vivas e inacabadas y constituyeron auténticas invitaciones a la participación, enriqueciéndose de manera permanente con las aportaciones de todo el grupo. Los comentarios quedaron anexados de forma ordenada y facilitaron el seguimiento de la secuencia conversacional.

Asimismo, durante la fase final del desarrollo del sistema CADI se tuvo la oportunidad de colaborar con otros proyectos paralelos de innovación docente como el descrito en Cano, Martínez-Rojo, Sánchez-Iborra, Cabrera-Lozoya \& Cerdán (2012), con el que se generaron interesantes sinergias y posibles ideas para mejoras del sistema en un futuro. Por último, también se tuvo la oportunidad de utilizar la plataforma a través de varias redes inalámbricas experimentales para evaluar su grado de rendimiento sobre ellas inyectando distintos flujos de tráfico multimedia suministrados por la plataforma (García-Sánchez, Cerdán, Cano, Cabrera-Lozoya, Luján-Fernández, \& AlmagroCarrión (2010), Cabrera-Lozoya, Cerdan, Lujan, \& Garcia-Sanchez (2011) y Cabrera-Lozoya, Cerdan, Lujan \& Garcia-Sanchez (2012)).

\subsubsection{Potenciales beneficios de CADI}

Estudios realizados sobre las tasas de retención y compresión de los contenidos en alumnos que reciben información por diferentes canales e interactúan con el profesor en tiempo real (como en el caso de CADI), muestran que se retiene un $10 \%$ de lo que lee, un $30 \%$ de lo que ve, un $50 \%$ de lo que ve y oye, un $70 \%$ de lo que se dice o escribe y un $90 \%$ de lo que hace (Felder \& Silverman, 1988). La figura 3.1 siguiente muestra esta afirmación de forma gráfica. 


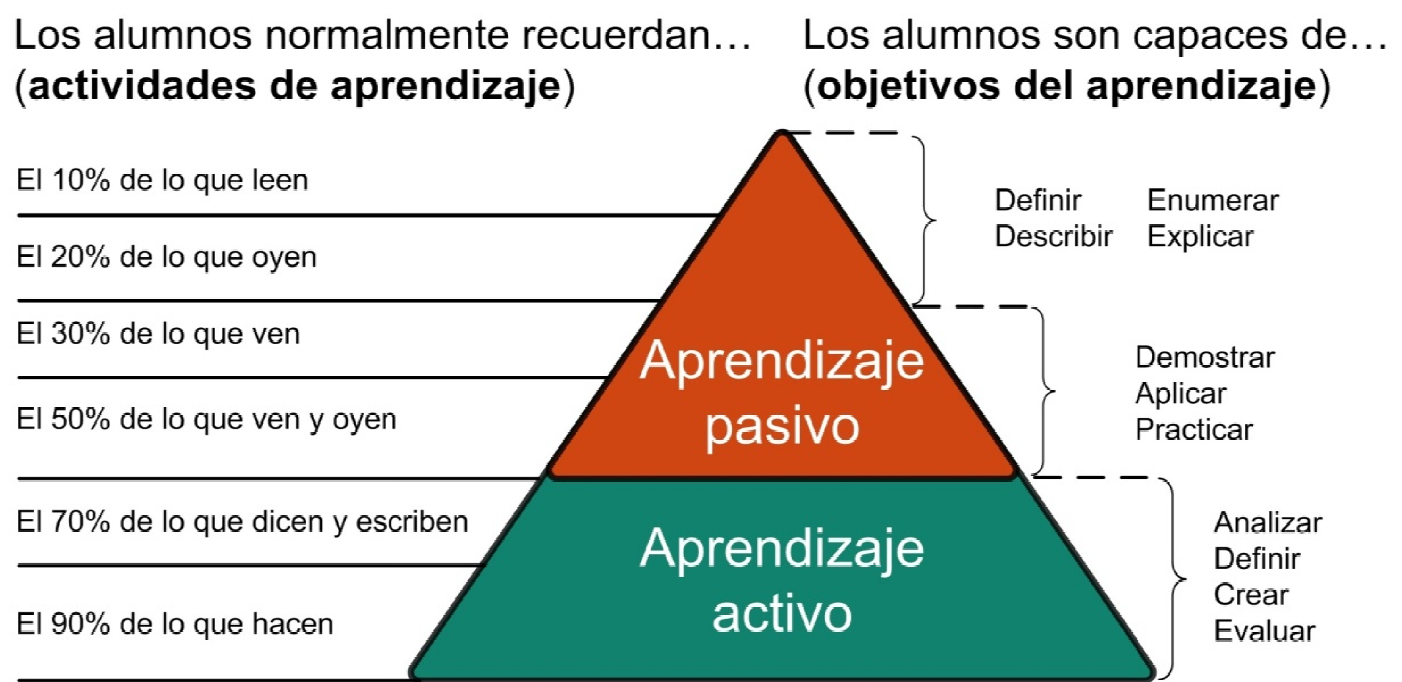

Figura 3.1. Principales diferencias entre el aprendizaje pasivo y activo (Felder \& Silverman, 1988)

También, pero aunque no de forma tan concluyente, parece quedar demostrado que el grado de compresión del alumno está directamente relacionado con el formato en que se le presente la información y con el uso que se haga de ella, aspecto en el que la plataforma CADI resulta inmejorable (Cabrera-Lozoya, Cerdan, Cano, Garcia-Sanchez \& Lujan, 2012b).

Por otro lado, la comprensión del alumno en conformidad con la psicología cognitiva está firmemente relacionada con los procesos de representación mental, que dan soporte a la asignación de significados (redes semánticas) y a las pautas de acción individual y social.

Datos obtenidos en Gardner (2001) nos revelan con un bello ejemplo hasta qué punto el uso práctico de una teoría y la acción del alumno son determinantes para su comprensión. Un día un estudiante le preguntó al Dr. Gardner: “¿Cómo puedo aplicar la teoría si no la comprendo?". El doctor pensó durante un momento y respondió: "Nunca entenderás la teoría si no la aplicas... y la vuelves a aplicar". Como vemos, este ejemplo nos obliga a resaltar la actividad y la actuación del alumno en clase ya que no sólo se estimula su consumo activo de material de clase, sino que también se refuerza la comprensión de este material. 
Con la plataforma CADI se potencia la autorregulación del alumno en el aprendizaje. Existen numerosos estudios (Schunk, 2001; Zimmerman, 1989; Zimmerman, Kitsantas \& Campillo, 2005) que ponen de manifiesto el valor de la participación activa del alumno en los procesos motivacionales e intelectivos que subyacen en todo proceso de formación. En general, los alumnos que saben autorregular su aprendizaje consiguen mejor rendimiento académico y saben orientar mejor su esfuerzo individual hacia la consecución de metas personales bien definidas y más duraderas.

La alta interactividad de algunas plataformas web (Printrich, 1995) parecen facilitar la ejercitación eficiente de los aspectos metacognitivos que conducen a la construcción significativa e interactiva del conocimiento. Gracias a la interactividad, los límites de una asignatura o área de conocimiento se alternan con intereses y motivaciones personales en los que el alumno asume claramente el control sobre lo que desea aprender.

Las discusiones que se generan en el aula con el uso de la plataforma CADI van asociadas a cada pregunta que se haga en clase, perfilando y modulando los intereses objetivos y fines que se pretendan conseguir. El autocontrol del alumno adquiere un nuevo grado de refinamiento, convirtiéndose en inter-control, en donde todos pueden participar de manera anónima y desinteresada. Este inter-control de la clase requiere una negociación entre ellos, un consenso y un sentido de la responsabilidad además del sometimiento de los partícipes al conjunto de normas tácitas no escritas que nacen de manera espontánea en el grupo.

\subsection{Descripción cualitativa de la plataforma}

El sistema que se presenta en esta tesis permite el establecimiento de un nuevo canal de comunicación genérico y en tiempo real entre el profesor y los alumnos. De forma general, ofrece una amigable interfaz gráfica de usuario (GUI) para que los estudiantes puedan preguntar, comentar, valorar, votar en encuestas o incluso realizar cuestionarios entre otras muchas cosas con la única necesidad de sus dispositivos móviles compatibles con WiFi. De esta manera, ignorando por el momento todos los aspectos técnicos relativos al despliegue de la red WiFi (detallada en la Sección 3.4 más adelante) y asumiendo que todo el hardware y software está listo y operativo, imaginemos un aula donde se está dando una clase como ejemplo para poder ilustrar las 
ventajas derivadas del uso de la plataforma sobre el escenario clásico en el que usa una de las metodologías de enseñanza tradicionales.

Imaginemos, por tanto, que en un momento determinado de la clase, a un alumno le surge una duda sobre algo de lo que el profesor está explicando. Entonces, en lugar de interrumpir al profesor para preguntarle o simplemente quedarse callado y dejarlo pasar, el estudiante coge su dispositivo móvil e interactúa con la plataforma desarrollada a través de su interfaz para introducir una nueva pregunta. Instantáneamente, el docente (quien está equipado con un ordenador portátil) es notificado de dicho evento a través de la plataforma y podría entonces proceder a resolver la duda en tiempo real.

Desde un punto de vista pedagógico, este rápido y simple proceso de interacción estimula, entre otros, dos importantes principios: primero, promociona la participación de todos los estudiantes durante las clases (incluso la de los más tímidos) y segundo, aumenta de forma drástica la interactividad de los métodos de enseñanza tradicionales. Además, cuando el sistema registra un pregunta, automáticamente entra en un estado pendiente de moderación / validación por parte del profesor. Así, si el docente considera que cierta pregunta es interesante o apropiada, es libre de publicarla y difundirla de forma inmediata al resto de estudiantes; en cualquier otro caso, tiene la potestad de descartarla (ambas opciones sólo implican un clic de ratón).

Por otro lado, el sistema permite configurar esta simple interacción de forma más avanzada en términos de anonimidad. De esta manera, podemos definir dos etapas cuando trabajamos con preguntas: en primer lugar, la transacción llevada a cabo entre el estudiante que pregunta y el docente actuando de "moderador" y en segundo, la que se origina entre la pregunta una vez aprobada y publicada y el resto de estudiantes. El carácter anónimo de estas dos etapas por separado puede ser configurado fácilmente por el profesor, permitiendo (o no) la interacción anónima de los estudiantes con la plataforma.

Otra característica que aporta la interfaz desarrollada es la que permite que los estudiantes sean capaces de "valorar" para, de alguna manera, "unirse" a las preguntas publicadas en un momento determinado a través de una puntuación (es decir, asignar una puntuación a las preguntas publicadas). A través de este enfoque, el docente es capaz de obtener una instantánea del número de estudiantes que, por ejemplo, 
apreciarían positivamente una explicación más detallada sobre cierto tema, y así actuar en concordancia... todo ello en tiempo real.

En este punto, y conociendo el funcionamiento de la herramienta, la adopción de metodologías de trabajo innovadoras por parte de los profesores (por ejemplo, alternando la explicación de nuevos conceptos con intervalos de tiempo en los que los estudiantes puedan realizar preguntas sobre el tema o puedan discutir en grupos sobre lo explicado para luego preguntar, etc.) podría conducir hacia nuevos e interesantes modelos de enseñanza apoyados en la plataforma.

De igual forma, los docentes que logren ver la plataforma desarrollada como una herramienta más disponible en sus clases e integrarla con éxito en su estilo de enseñanza, pueden llegar a conseguir importantes mejoras educativas. En este sentido, la inclusión de la plataforma abre un amplísimo abanico de posibilidades para dinamizar las clases y sacar el máximo rendimiento académico al sistema.

Sin embargo, es muy importante destacar en este punto que el sistema desarrollado no pretende en ningún caso actuar como un sustituto de las tradicionales interacciones cara a cara entre profesor y alumnos (que de hecho, permanecen intactas aún con el sistema), sino todo lo contrario: como ya se ha comentado anteriormente, el sistema provee un canal de comunicación adicional (no excluyente) para la realización de preguntas que podría incluso ser usado muy fácilmente para incentivar la participación oral de los estudiantes, por ejemplo, utilizando ciertas preguntas hechas a través de la plataforma para comenzar un debate o propiciando la interacción entre ellos, por grupos, antes de lanzar una "pregunta grupal" a través de la plataforma... Aquí, una vez más, las habilidades e imaginación del profesor para utilizar y gestionar los recursos que le provee el sistema podrían desembocar en importantes mejoras en el proceso educativo.

Imaginemos ahora que el docente quiere conocer la opinión de los estudiantes sobre determinado asunto o que simplemente quiere someter a votación varias propuestas como, por ejemplo, la fecha del examen, el horario de clases al principio de curso o cualquier otra situación susceptible de votación. En este escenario, el profesor podría crear una nueva encuesta, definiendo la cuestión y todas las posibles opciones asociadas a la misma. Una vez creada, la encuesta sería mostrada en todos los dispositivos móviles de los estudiantes de forma automática y, como es lógico, podrían proceder a expresar su opinión o votar de forma instantánea. La interacción descrita 
acelera de forma considerable los tediosos métodos tradicionales de votación. Además, gracias a los módulos desarrollados, los datos generados durante las votaciones se almacenan en la base de datos interna de la plataforma y el propio sistema es capaz de procesar dicha información para proveer al profesor de estadísticas e informes que incluyen gráficos de barras, histogramas, diagramas de sectores, informes en formato texto, etc.: las posibilidades de este módulo son ilimitadas dada su naturaleza genérica y la gran cantidad de usos posibles en el aula. Así, este potente subsistema de estadísticas e informes registra las interacciones de cada usuario (es decir, estudiante) con la plataforma. De hecho, es capaz de generar un log de casi cada pulsación o clic de ratón de los usuarios en la base de datos interna, incluyendo la hora y un conjunto de parámetros adicionales de cada evento. Los informes son, por su parte, totalmente personalizables (ya que toda la información es almacenada en una base de datos relacional $\mathrm{y}$, por tanto, puede ser fácilmente recuperada y filtrada según múltiples criterios). El profesor puede así obtener un importante feedback a través de estos informes textuales, tablas y gráficas, y usar toda esa completa información en beneficio de los estudiantes... a tiempo: este módulo implementa sobre la plataforma desarrollada el conocido concepto de evaluación formativa (formative assessment), permitiendo proveer al docente de información en tiempo real acerca del progreso de los estudiantes. Además, esta información se puede exportar fácilmente a varios formatos de datos conocidos como .CSV o .XLS para permitir su procesamiento alternativo a través de software de terceros. En este sentido, el sistema también implementa estrategias de evaluación acumulativa (summative assessment) al permitir la generación de forma automática de informes del progreso de cada estudiante por separado. Por ejemplo, consideremos ahora un aula en la que el profesor desea sondear el nivel de conocimiento general de los estudiantes en relación a cierto tema o materia. Para llevarlo a cabo, tan sólo tiene que definir diferentes cuestiones en el sistema (antes del comienzo de la clase, si se desea, para optimizar el tiempo) y publicarlas... Desde ese momento, el cuestionario estará disponible para todos los estudiantes, quienes procederán a responderlo. En este punto es interesante destacar la importancia de este módulo desde una perspectiva pedagógica, ya que si se usa concienzudamente, puede mejorar sustancialmente la cantidad de información que llega al profesor, todo ello en tiempo real (por ejemplo, y como ya se ha comentado anteriormente, para tener una instantánea del progreso de los estudiantes en cada caso, etc.). A partir de ahí, si estos resultados son considerados de forma reactiva, el docente podría enfocar las clases para 
minimizar el fracaso de los estudiantes de forma muy eficiente. Consideremos, por ejemplo, una situación en la que el profesor acaba de explicar en clase un concepto que "suele ser difícil de entender" para los estudiantes, pero a la vez crítico para comprender los que siguen. En ese punto, el profesor podría realizar uno de estos cuestionarios para evaluar el nivel de comprensión de los estudiantes con respecto a ese preciso concepto en lugar de lanzar una pregunta abierta (cosa que se suele hacer con frecuencia) esperando una respuesta por parte de los estudiantes para seguir con la explicación... De hecho, si se hiciera las respuestas de muchos alumnos serían afirmativas aún cuando realmente no comprenden el concepto (Hoic-Bozic et al., 2009). Usando este sistema, el profesor obtendría una idea objetiva de la situación, y podría volver atrás sobre la marcha para repasar dicho concepto incomprendido para rellenar el hueco en los estudiantes, si fuera necesario.

Por último, el sistema implementa un módulo que pretende promover aún más el contacto entre los estudiantes y el profesor, a modo de foro, en el que cualquiera puede hacer comentarios o sugerencias, siempre relacionadas con la materia en cada caso.

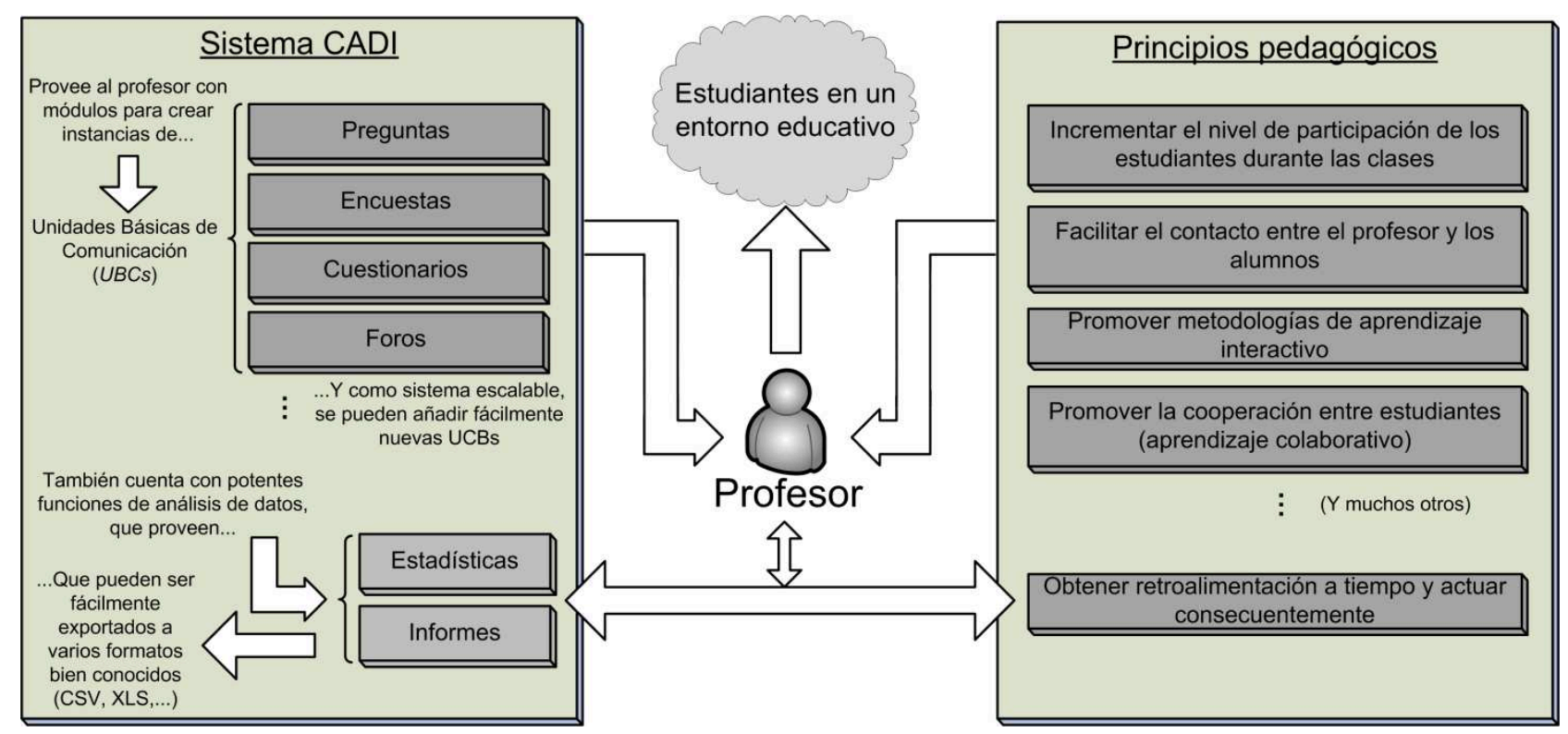

Figura 3.2. Esquema funcional de un escenario donde se está usando el sistema.

En resumen, el sistema desarrollado ofrece diversos recursos para favorecer la comunicación (que han sido enfatizados en cursiva en los párrafos anteriores) y que, desde una perspectiva funcional, han sido denominados unidades básicas de 
comunicación, UBCs. Así, la arquitectura del sistema es capaz de gestionar estas UBCs de forma aislada (como instancias independientes), permitiendo su creación y combinación de muchas formas distintas dependiendo del ámbito u objetivo que se pretenda con cada actividad concreta, y para conseguir unos $\mathrm{u}$ otros beneficios pedagógicos en los alumnos (Figura 3.2). En este escenario, el profesor juega un papel crítico, ya que es el responsable de elegir la configuración de recursos correcta de entre las unidades básicas de comunicación disponibles (es decir, el número de instancias de cada una, su tipo y la metodología de uso) y de poblarlas de información para crear entornos de aprendizaje eficientes con los estudiantes. Cada configuración específica deberá estar enfocada a maximizar el logro de ciertos principios pedagógicos y, en este sentido, y como ya se ha comentado, el grado de experiencia del docente será crucial para alcanzarlos en mayor o menor medida. Así, por ejemplo, se podría utilizar un número de cuestionarios en un momento dado para llevar a cabo una competición entre varios grupos de estudiantes (para promover el aprendizaje colaborativo, como en el CSCL). Del mismo modo, las encuestas se podrían utilizar para, por ejemplo, formular un problema matemático y dar una serie de posibles soluciones numéricas. Se les pediría entonces a los estudiantes que lo resolvieran, por ejemplo, en grupos (motivándolos así e involucrándolos en su propio proceso de aprendizaje, como en un entorno de PBL).

Resumiendo, el sistema puede verse, por tanto, como un marco innovador para la creación, desarrollo y despliegue de actividades de aprendizaje completamente heterogéneas. Como se ha mostrado, existen muchas posibilidades y combinaciones, solamente limitadas por la imaginación del profesor.

Finalmente, como el sistema incorpora potentes módulos de análisis y procesado de datos (con estadísticas e informes de casi cada evento en la clase), el profesor puede (y, de hecho, debe) evaluar la idoneidad de cada iniciativa que lleve a cabo para obtener una importante (e instantánea) retroalimentación para corregir rápidamente los aspectos deficientes de su práctica docente y, en definitiva, mejorar la calidad de su enseñanza y el grado de eficiencia. 


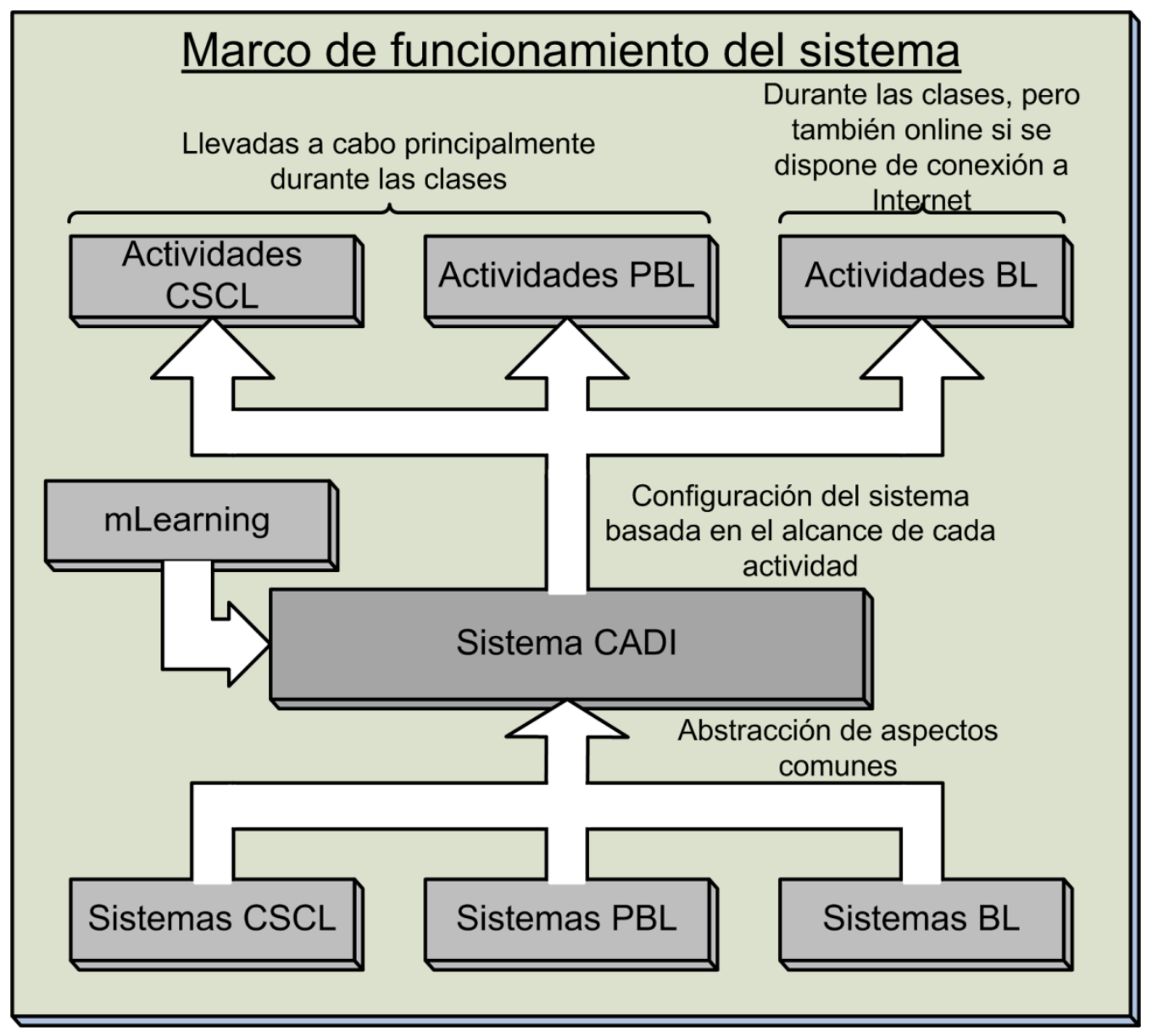

Figura 3.3. Marco de funcionamiento conceptual del sistema. El diagrama de bloques muestra la posición del sistema comparado con otros sistemas de e-learning. En CADI, el nivel de abstracción es mayor y, gracias a ello, es posible llevar a cabo un abanico más amplio de actividades educativas.

Este sistema podría ser encasillado de forma errónea como un sistema de mLearning porque trabaja con tecnologías móviles y es capaz de mostrar los contenidos en dispositivos fijos y móviles. Sin embargo, el sistema CADI va un paso más allá: su diseño innovador permite abstraer los aspectos comunes de los sistemas de CSCL, PBL o incluso BL ya que puede ser configurado para soportar toda clase de actividades (Figura 3.3). Por ejemplo, resulta extremadamente sencilla la realización de actividades enmarcadas dentro de las modalidades de CSCL y PBL durante las clases (como ya se ha comentado en los párrafos anteriores), pero también de actividades de BL, ya que la plataforma se apoya directamente en tecnologías web y, por tanto, puede ser configurada para ser accedida desde Internet (como se describe en la Sección 3.4 a continuación). 


\subsection{Hardware y software involucrado}

Las características y mecanismos descritos en la sección anterior han sido implementados usando los elementos hardware y software que se detallan a continuación.

\subsubsection{Arquitectura hardware}

En primer lugar, la arquitectura hardware que soporta el sistema implementa todas sus comunicaciones haciendo uso de una red inalámbrica basada en el estándar IEEE 802.11 (WiFi). El hecho de usar esta tecnología para las comunicaciones dota a la plataforma de una estupenda flexibilidad y compatibilidad con infinidad de dispositivos móviles, ya que la omnipresencia de este estándar de comunicaciones ha hecho que hoy día sea muy fácil adquirir dispositivos compatibles a un precio razonable.
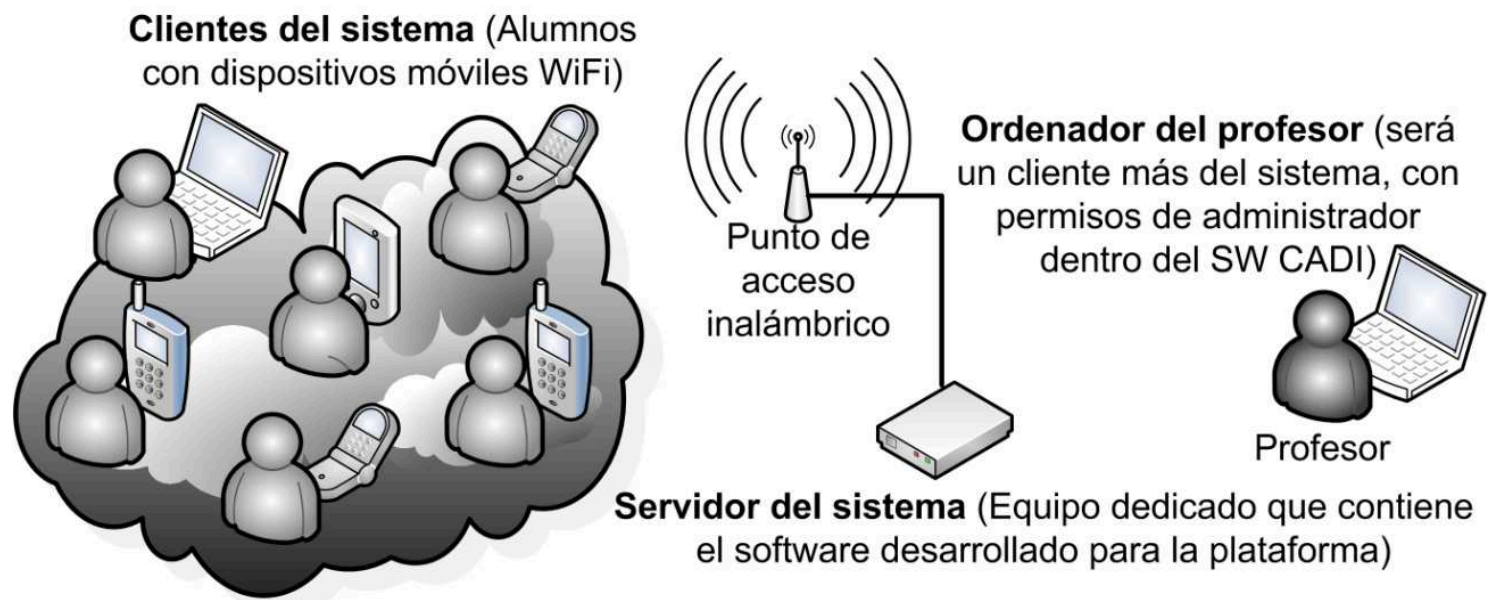

Servidor del sistema (Equipo dedicado que contiene el software desarrollado para la plataforma)

Figura 3.4. Esquema de la infraestructura hardware que requiere el sistema.

La topología de la red desplegada responde al esquema clásico de sistema de información centralizado, en el que están presentes los siguientes elementos (Figura 3.4):

- Un ordenador (portátil, empotrado, o de sobremesa) con conectividad, como es lógico, a la red WiFi del sistema (ya sea de forma inalámbrica o cableada a través del punto de acceso). Esta máquina será la que albergue el software desarrollado de la plataforma y actuará como servidor del sistema en el modelo 
de red propuesto. Será, a su vez, fuente y destino de toda la información que maneje la plataforma.

- Un dispositivo compatible con WiFi para permitir la interacción del profesor con la plataforma (normalmente, un ordenador portátil, aunque puede ser también un smartphone o PDA). El profesor lo utilizará para conectarse a la plataforma y acceder, aportando sus credenciales a la interfaz de administración de la plataforma. Podría asemejarse a un cliente administrador (con permisos especiales) en el modelo de red propuesto.

- Varios dispositivos móviles compatibles con WiFi (PDAs, smartphones, portátiles o cualquier otro dispositivo equivalente y compatible). Son las interfaces de los estudiantes con la plataforma y los clientes del sistema en el modelo de red propuesto.

- Un punto de acceso inalámbrico, que es a su vez el único hardware de red necesario. Será el encargado de mantener la red inalámbrica (WLAN) que conectará todos los dispositivos de la arquitectura propuesta (servidor y clientes).

Como ya se ha comentado anteriormente, el despliegue del sistema implica la creación de una red WiFi propia. En este sentido, es importante destacar que el sistema no requiere de conexión a Internet para funcionar, ya que todos los actores de la comunicación (estudiantes y profesor, todos ellos clientes del sistema, véase la Figura 3.4), interactuarán en cualquier caso con el servidor. El sistema se despliega, por tanto, de forma local cada vez que se usa en una clase. Esta concepción hace que el sistema sea una solución robusta e independiente, compuesta únicamente por el servidor y el punto de acceso (véase el Anexo II de este documento, Breve manual de usuario del sistema CADI).

\subsubsection{Arquitectura software}

El escenario descrito en el apartado anterior puede considerarse como la típica arquitectura web cliente-servidor. Por tanto, las tecnologías en las que se basa son web $\mathrm{y}$, como es lógico entonces, todas las transferencias de datos se llevan a cabo usando el protocolo HTTP de transferencia de hipertexto (HyperText Transfer Protocol). Además, como la interacción entre los estudiantes y sus respectivos dispositivos móviles es a través del navegador web, no es necesaria la instalación de ningún software adicional en 
estos últimos para poder usar la plataforma de forma activa (lo que constituye una importante ventaja en términos de despliegue rápido y sencillo).

Otra ventaja derivada del hecho de utilizar tecnologías web radica en la posibilidad de usar el sistema online si se configura previamente para ser accedido desde Internet (ya que integra un servidor web). Esta característica podría ser interesante si el sistema se usara para realizar actividades en entornos de Blended Learning, en los que los estudiantes pueden realizar distintas actividades tanto durante las clases como posteriormente, por ejemplo, desde sus casas. Además, el diseño de la plataforma es compatible y totalmente interoperable con otras conocidas plataformas de eLearning como Moodle.

Sin embargo, uno de los principales objetivos del sistema, desde su concepción y etapa de diseño, fue la promoción de la interacción y la participación entre el profesor y los alumnos en el aula, es decir, durante las clases, por lo que aunque una configuración online como la descrita anteriormente es posible, no es el principal motivo de estudio de esta tesis.

La arquitectura software del sistema está implementada sobre una instalación estándar del famoso gestor de contenidos web Typo3 WCMS (Web Content Management System, http://www.typo3.org) en el servidor. Dicho gestor está escrito en el lenguaje PHP y usa una base de datos MySQL para almacenar de forma persistente toda la información que maneja. El hecho de usar un software open source como Typo3 como base para el software desarrollado reporta diversas ventajas, entre las que destacan:

- Separación del contenido, la estructura y el diseño (lo que constituye un principio básico de cualquier gestor de contenidos o content management system, CMS).

- Producción de contenido ágil (para editar y refrescar los contenidos existentes de forma rápida).

- No se requieren habilidades de programación para generar o editar contenidos (esto es importante desde el punto de vista de los docentes, ya que muy probablemente no sepan programar).

- Restricciones de acceso configurables (por ejemplo, para definir los perfiles de profesor y alumno dentro del sistema). 
- ... y, en definitiva, la posibilidad de cambiar cualquier mínimo aspecto del gestor en unos cuantos clics de ratón.

Además, Typo3 provee varios mecanismos para expandir su funcionalidad básica, a través del gestor de extensiones, el denominado Extension Manager. Este módulo del CMS permite la adición de nuevas características y módulos al sistema siguiendo un proceso de importación e instalación de ficheros llamados extensiones (extensions). Por otro lado, Typo3 cuenta con un framework para la creación de extensiones llamado kickstarter (que, a su vez, es una extensión) y que ha sido usado en esta tesis para desarrollar cada una de las UBCs del sistema CADI (es decir, las preguntas, encuestas, cuestionarios, foros y el módulo de estadísticas e informes). De esta manera, una vez que se instala cada extensión en el gestor, se pueden crear y poblar con información ilimitadas instancias de la UBC correspondiente. Además, existe la posibilidad de agrupar un número de UBCs de distinto tipo en una entidad de nivel superior para ajustarse a las necesidades específicas de cada actividad educativa o situación (por ejemplo, agrupando varias encuestas simples para conformar un concurso entre los estudiantes, etc.). La arquitectura software del sistema desarrollado cumple con los principios clásicos de diseño software en términos de extensibilidad (ya que se pueden desarrollar e instalar como extensiones otras UBCs en cualquier momento), escalabilidad y reusabilidad (ya que se pueden crear de forma estable y fácil ilimitadas instancias de las UBCs instaladas).

\subsection{Objetivos de CADI}

Con CADI nos proponemos conseguir una serie de objetivos, que serían:

1. Conseguir, por parte del alumno, el conocimiento y uso en profundidad de la plataforma y sus posibilidades.

2. Aumentar la interacción de los alumnos entre ellos y con los propios docentes usando las diversas posibilidades que la plataforma permite a través de cuestionarios, participación en clase, valoraciones,...

3. Mejorar la información que se da al alumno en clase, permitiendo aclarar los contenidos más importantes de forma que estén disponibles a todos, minimizando el posible aislamiento de no poder participar en la clase o en una actividad concreta. 
4. Ampliar el conocimiento adquirido en las clases teóricas por medio de preguntas, respuestas y contenidos relacionados con la materia impartida.

5. Conseguir una vía fluida de comunicación entre el alumnado y el profesor en tiempo real y con tutorías virtuales personales o grupales.

6. Obtener un feedback por medio de cuestionarios con preguntas tipo test y preguntas abiertas tanto de la docencia impartida como de los métodos empleados para la misma, desde el punto de vista de los alumnos y así poder evaluar de esa forma el trabajo de los profesores pudiendo realizar los cambios oportunos para mejorar las posibles carencias.

7. Permitir al alumno optimizar tanto su tiempo como su capacidad de aprendizaje, haciéndose éste más autónomo, práctico y adaptable. Con ello, el alumno adquiere la capacidad y las habilidades necesarias para su futura actividad laboral y la interacción con otros profesionales.

8. Completar la docencia clásica, ya que no sólo conseguimos mejorar y ampliar la información que recibe el alumno, sino que se abre un abanico de posibilidades mucho mayor del que se tenía hasta este momento.

9. Permitir el análisis de la asistencia a clase de los alumnos de la asignatura, pudiendo conocer el nivel de asistencia, a la vez que se determina si el uso de la plataforma puede contribuir a incentivarla.

10. Permitir el análisis del rendimiento académico en función de esta metodología interactiva comparada con el sistema tradicional (basado en clases magistrales con la posterior realización de un examen final) con un sistema de evaluación continua, más acorde con los requisitos del nuevo marco europeo de enseñanza. Los resultados de este análisis nos servirán para diseñar e implantar la estrategia a seguir en la docencia de las diversas materias.

\subsection{Medidas de mejora}

La plataforma CADI nos permite una serie de medidas de mejora que persiguen un mayor rendimiento del alumnado (Cabrera-Lozoya, Cerdan, Cano, Garcia-Sanchez \& Lujan, 2012b). Entre ellas, y a modo de resumen, destacaríamos: 
1. Los alumnos tímidos no participaban en clase, lo que les crea una situación importante de estrés que se logra reducir o incluso eliminar en su totalidad.

2. Quedaban algunas lagunas tras la exposición y explicación de los contenidos por parte del profesor. Con CADI, se pueden plantear y resolver directamente en clase, en tiempo real.

3. Se mejora y amplía la información y los contenidos a impartir en el aula gracias a todas las sugerencias de los alumnos a través de los cuestionarios.

4. Se ha potenciado y mejorado la interacción con los profesores y con los mismos alumnos de forma sencilla.

5. CADI permite la creación subida y posterior descarga de contenidos multimedia.

6. Otra mejora tiene que ver con el sistema de evaluación del alumnado. Los alumnos comprueban sus conocimientos, reforzando las partes de la asignatura que no han comprendido o entendido bien e informando al profesor si lo ven conveniente.

7. Se propicia el uso de foros "virtuales", pudiéndose crear en clase varias sesiones donde, de forma ordenada, los alumnos y profesores van planteando sus dudas, opiniones, noticias, o cualquier otro punto de interés común. Estos “foros" ayudan mucho a fomentar el compañerismo.

Además, las encuestas son la vía más útil para valorar las actuaciones del profesor y los grados de satisfacción del alumno. Por ejemplo, el alumno podría valorar la docencia recibida en función de su grado de comprensión, de dificultad ante lo expuesto, etc.

8. Otra mejora de la plataforma reside en la potenciación de la interactividad y el compañerismo ya que con la ayuda de las encuestas podemos conseguir que los alumnos que son reacios a explicar sus ideas a otros compañeros y a pedir ayuda, al final, al tener más confianza con el grupo y crearse un clima más distendido en clase, se invierta esta tendencia.

El método resulta muy eficaz, por ejemplo, en el primer curso universitario donde el alumnado procede de institutos donde se conocen todos, llegando a un ámbito universitario completamente distinto donde interactúan con otros compañeros procedentes de múltiples localizaciones y de caracteres muy distintos. En estas circunstancias es normal que al principio les pueda costar a algunos alumnos relacionarse con los demás. 
9. En cuanto a la forma de impartir la docencia, con la plataforma interactiva CADI se consigue una mejor comprensión de los temas a estudiar y una mayor dinamización de las clases. Recordemos que es muy importante que el alumno aprenda nuevas formas de interactuar y crecer no sólo como profesional sino también como persona, aprendiendo a perder el miedo a plantear preguntas para luego, a lo largo de su vida, poder expresarse mejor en público y con más espontaneidad.

10. Una de los aspectos más interesantes derivados de la experiencia con CADI es la valoración por parte del alumno de la optimización de su tiempo de estudio al poder resolver dudas de forma inmediata y en tiempo real.

Este feedback es una de las mejoras que buscamos con el proyecto CADI, ya que son los propios alumnos, los que de primera mano nos pueden dar información fidedigna de cómo se ha realizado la experiencia y qué aspectos se pueden optimizar y mejorar aún más.

Por parte del profesorado, la plataforma CADI pretende la mejora de su relación con el alumno para que, siendo más fluida, personal y directa, se consiga una mayor conexión entre ambos, haciendo las clases más prácticas y amenas y pudiéndose enfocar al día a día que tendrán cuando finalicen sus estudios. Gracias a la plataforma, el alumno participa en clase de forma activa dejando de ser un mero espectador u oyente para convertirse en un elemento activo que, en muchas ocasiones, decidirá la mejor forma de abordar un tema determinado.

\subsubsection{Evaluación continua}

La creación del EEES está vinculada a la innovación docente puesto que el esfuerzo por centrar la formación en los resultados del aprendizaje supone reflexionar y replantearse los modos de aprender en sí mismos y las metodologías más adecuadas a seguir en la docencia universitaria (Ariño, 2009). Este proceso de innovación académica involucra también a los sistemas de evaluación de la enseñanza. Como señala (Delgado \& Oliver, 2006), en el nuevo modelo educativo derivado del EEES la evaluación se convierte en un elemento clave como consecuencia de que el alumno pasa a ser el centro del proceso de enseñanza, surgiendo la necesidad de la aplicación de un enfoque en la educación basado en la adquisición de competencias. 
Los sistemas de evaluación tradicionales tenían como objetivo simplemente evaluar al alumno, pero ante las necesidades actuales y con la ayuda de las nuevas plataformas interactivas, el sistema de evaluación continua, además de evaluar la asimilación de los conocimientos, evalúa el desarrollo de competencias a lo largo de todo el proceso (González-Rosende, Vega, Girbés, Ortega, Segura \& Hernández, 2008).

La evaluación continua que CADI nos permite realizar nos facilita la recogida de información y la evaluación del trabajo que el alumno realiza dentro y fuera de clase, es decir, tanto en las clases presenciales como en las no presenciales. Coincido con MartínLaborda (2005), entre otros, en que las TIC son una vía para mejorar la calidad de la enseñanza. De hecho, como señala Bates (2002), las razones más frecuentes para la introducción de las TIC en la enseñanza universitaria son mejorar la calidad del aprendizaje, ofrecer a los alumnos las destrezas cotidianas de las tecnologías de la información que necesitan en el trabajo y en la vida, ampliar el acceso a la educación y la formación, responder al imperativo tecnológico, reducir los costes de la enseñanza y mejorar la relación entre costes y eficacia de dicha enseñanza.

Sabemos que son muchos los factores de los que depende la incorporación de las tecnologías a la educación, pero uno de ellos es la actitud de los docentes, de los que dependerá que su uso suponga verdaderamente un aumento en la calidad de la enseñanza (Martín-Laborda, 2005).

Una de las principales ventajas derivadas del uso de estas plataformas para la realización de evaluaciones está relacionada con la accesibilidad de los alumnos a las mismas, tanto en términos geográficos como temporales. Este sistema de evaluación proporciona al profesor información a partir de la cual puede conocer las dificultades y los progresos de los alumnos para finalmente calificar su rendimiento. No obstante, como señala Sacristán et al. (2009), esto supone a su vez una serie de riesgos añadidos, ya que no es posible comprobar aspectos cruciales tales como: qué materiales consultan los alumnos durante la realización de estas actividades, si se llevan a cabo de forma individual o en grupo, o incluso si verdaderamente el alumno en cuestión es el autor de las mismas.

Con CADI podemos evaluar el trabajo del alumno durante el curso y realizar un seguimiento continuo del mismo en la asignatura donde sea utilizado. A partir de la información recogida por la plataforma se realiza un control permanente y a lo largo del 
curso del aprendizaje que está desencadenándose en el alumno, de forma que se puede intervenir cada vez que sea necesario para así mejorar y reorientar dicho proceso.

\subsubsection{Cambios en el alumno}

La plataforma CADI supone un cambio en la educación tanto a nivel de alumnos como a nivel de profesores.

En la sociedad actual, caracterizada por su complejidad y diversidad, la educación se enfrenta a continuos retos debiendo solventar las dificultades y los cambios en los que se ve envuelta. En este contexto, el alumno universitario precisa de nuevas necesidades formativas encaminadas a la adquisición de conocimientos más especializados, contemplando en ellos la presencia de las TIC.

Dado que cada persona es única, su forma de aprender es también diferente. Investigaciones de las últimas décadas concluyen que la forma de aprender está muy relacionada con los aspectos de la personalidad del individuo de tal manera que cada persona posee un estilo característico o preponderante sobre cómo adquiere los conocimientos, es decir, el alumno normalmente se apoya en estrategias particulares para alcanzar mejores resultados en su aprendizaje. Partiendo de este hecho surge la idea de establecer estrategias didácticas originales donde los docentes contemplen los estilos de aprendizaje de los alumnos para potenciar al máximo sus habilidades mentales y lograr un aprendizaje más significativo y útil. Para ello, el profesor debe ser capaz de crear "entornos de aprendizaje" en el aula, con resoluciones de problemas reales, formulando interrogantes, buscando respuestas a los mismos, indagando, reflexionando, aplicando una crítica constructiva y, en definitiva, buscando la cooperación entre los alumnos.

En la universidad, si el alumno (ayudado por el profesor) aprende a descubrir su propio estilo de aprendizaje podrá obtener mejores resultados académicos y de enriquecimiento personal. Es el típico y famoso "aprenda a aprender".

La plataforma interactiva CADI ayuda al alumno con todos sus beneficios a (Cabrera-Lozoya, Cerdan, Cano, Garcia-Sanchez \& Lujan, 2012b):

- Controlar su propio aprendizaje.

- Diagnosticar sus puntos fuertes y débiles como estudiante.

- Descubrir su estilo de aprendizaje. 
- Conocer en qué condiciones aprende mejor.

- Aprender de la experiencia diaria.

- Superar las dificultades que se presenten en el aula.

- Admitir que no tienen todas las respuestas.

- Estar dispuesto a indagar, preguntar, probar y crear nuevas combinaciones.

De esta manera se contribuye a potenciar en el alumno un estilo de aprendizaje activo, interactivo y participativo, donde éste se implique plenamente y con entusiasmo en el aula y en las nuevas tareas.

Así, el alumno va formando una mente más abierta, afrontando experiencias nuevas y creciéndose ante ellas gracias a la interactividad que se logra potenciar con el sistema. Al mismo tiempo, el aprendizaje adquiere un matiz reflexivo: el alumno contempla diferentes perspectivas, recoge información y la analiza con detenimiento, volviéndose más prudente y escuchando a los demás. Así, de forma indirecta se potencia la tolerancia en los alumnos y en el ambiente.

En el ámbito de la enseñanza universitaria ha predominado tradicionalmente la clase magistral. La actuación docente se ceñía a la mera transmisión de contenidos teóricos y se dejaban a un lado aspectos didácticos como el ambiente de clase y el estilo de enseñar a aprender a pesar de ser factores que influyen directamente en el proceso de aprendizaje. Ahora bien, sabiendo que los alumnos presentan distintas formas de aprender, las estrategias didácticas de los docentes deben considerar el uso de las TIC para permitir adaptar los contenidos a los diferentes estilos de aprendizaje de los alumnos.

En la actualidad se está originando un cambio en las metodologías pedagógicas que están dando paso a entornos de aprendizaje virtuales caracterizados, sobre todo, por la interactividad entre el conocimiento y el estudiante lo que va permitiendo el desarrollo de nuevas habilidades prácticas y mentales en los alumnos.

Una de las principales razones que impulsa al profesor a utilizar la plataforma CADI es su gran capacidad motivadora en aras de una educación de calidad. Por eso, dentro del EEES se ha puesto de manifiesto la necesidad que tiene el estudiante universitario de conocer su propio estilo de aprendizaje para lograr un proceso formativo de mayor calidad y mejor rendimiento académico. Este autoconocimiento del alumno debe completarse en el contexto del aula y en la formación de actitudes 
positivas hacia la tecnología más adecuada a su estilo. El proceso de enseñanzaaprendizaje de los alumnos de la UPCT que aplicaron el uso de la plataforma en el aula mejoró notablemente (Cabrera-Lozoya, Cerdan, Cano, Garcia-Sanchez \& Lujan, 2012b), ya que este nuevo planteamiento permitió a cada alumno desarrollar sus propias estrategias (marcó su ritmo, disipó sus dudas, se sintió más motivado, etc.) permitiéndole desarrollar capacidades para manejar una situación específica. A través de este proyecto piloto, el alumno logró activar los conocimientos que ya poseía y aprovechar nuevas fuentes utilizando capacidades adquiridas anteriormente.

Con el uso de la plataforma se repercute directamente en la forma en que se imparten los contenidos de las asignaturas. Éstos ya no se definen por la gran cantidad de información a ser transmitida o acumulada, sino por la sistematización para lograr un proceso de aprendizaje más amplio.

La plataforma CADI desarrollada en la UPCT es un proceso innovador en cuanto que se define por los procesos implicados y los resultados obtenidos pero, sobre todo, se define por la actitud de la comunidad educativa, actitud que lleva a buscar alternativas frente a los constantes desafíos planteados en el marco del EEES. Esta actitud de la Universidad Politécnica de Cartagena se refleja en la búsqueda de una propuesta nueva para formar personas capaces de dar respuestas a las necesidades de la sociedad actual.

\subsubsection{Cambios en el profesor}

Pero como hemos mencionado anteriormente, la plataforma CADI también pretende servir de ayuda al docente. Actualmente, la observación de que la actividad docente genera en algunos profesores desánimo y agotamiento mientras otros siguen manteniendo la motivación y la ilusión, lleva a muchos autores a establecer relaciones entre buenas prácticas y bienestar docente. Con frecuencia, los profesores innovadores muestran satisfacción profesional y placer con sus iniciativas. Por tanto, tal vez en las buenas prácticas docentes es en donde radiquen las claves para prevenir el malestar docente e incentivar las emociones positivas. El modelo interaccionista que propone la plataforma CADI interpreta el bienestar subjetivo como una relación entre factores personales (mejora de la autoestima, la superación personal, etc.) y características situacionales (ambiente de trabajo estimulante y receptivo, relaciones fluidas docente- 
discente, clima de confianza en el aula, respeto para aclarar conceptos, expresión de lo que pensamos, etc.).

El reto de este sistema es favorecer un perfil profesional en el que el docente tenga la información necesaria para generar intervenciones de forma inteligente e innovadora con acceso a sistemas de ayuda eficaces que le apoyen en su tarea. CADI aporta un potencial destacado como ayudas significativas para la enseñanza.

La actividad del alumno es el medio para movilizar el entramado de comunicaciones que se pueden establecer en clase (entre profesor, alumno y contenidos) (Zabala Vidiella, 1998).

La perspectiva denominada "tradicional" era coherente con la creencia de que el aprendizaje consistía en la reproducción de la información que recibíamos del profesor sin cambios, pero en la concepción "constructivista”, enseñar comporta establecer una serie de relaciones que deben conducir a la elaboración por parte del alumno de representaciones personales sobre el contenido objeto de aprendizaje. Promover esta actividad mental supone que el alumno entienda lo que hace y por qué lo hace y tenga conciencia del proceso que está siguiendo. Pero que el alumno comprenda lo que hace depende en buena medida de que el profesor sea capaz de ayudarlo a comprender, a dar sentido a lo que tiene entre las manos. También está en función del grado en que el profesor le ayuda a recuperar lo que posee al igual que de la organización de los contenidos. Es todo un conjunto de interacciones basadas en la actividad conjunta de ambos. Un ejemplo actual y de gran importancia hoy es el profesor Eric Mazur, del que hablaremos más adelante.

\subsection{CADI como ejemplo de pedagogía activa e interactiva}

Hoy en día, la pedagogía activa concibe la educación como el desarrollo de la conciencia crítica por medio del análisis y de la transformación de la realidad. Este movimiento pedagógico acentúa el carácter activo del alumno en el proceso de aprendizaje, interpretándolo como búsqueda de significados, crítica, etc. concediendo gran importancia a la motivación del alumno. Este movimiento, al igual que la plataforma, identifica al docente como animador, orientador y catalizador del proceso 
de aprendizaje. CADI permite concebir la relación teoría-práctica como procesos complementarios y la relación docente-alumno como un proceso de diálogo, cooperación y apertura permanente, enriquecidos con un intercambio comunicativo entre el grupo y el profesor. Dentro de este enfoque de la educación, el uso de la plataforma CADI considera la actividad del alumno como un elemento fundamental, ya que las diversas concepciones educativas del mundo contemporáneo postulan que las acciones prácticas conducen más rápidamente al aprendizaje.

La pedagogía activa permite establecer una organización docente dirigida a eliminar la pasividad del alumno (utilizando una didáctica de respuesta), necesidades internas que enseñan entre otras cosas a vencer de manera consciente las dificultades.

Con el uso de CADI, el profesor facilita la actividad, observa y despierta el interés, convirtiendo al alumno en un sujeto activo. Uno de los aportes más significativos de CADI ha sido plantear las necesidades que van surgiendo en el proceso de aprendizaje. Así, se logra despertar el interés del alumno mediante la utilización de métodos activos y conseguir que los alumnos se formen desarrollando un carácter indagador. CADI también ayuda a que el alumno tenga experiencias directas que estimulen su pensamiento. Ayuda a adquirir más información y a que se realicen más observaciones. También puede ayudar a que las soluciones se le ocurran al alumno, teniendo más oportunidades de comprobar y constatar sus ideas y opiniones. El alumno adopta una posición activa frente al aprendizaje (Activismo pedagógico, Dewey, 2004) y la docencia se centra más en los intereses del alumno (número de preguntas realizadas, que se repitan, etc.).

CADI garantiza un sistema educativo más flexible; es como una enseñanza "más a la medida". Además, la plataforma permite enfatizar la enseñanza cooperativa, colaborativa y socializada como complemento a la individualizada (Cabrera-Lozoya, Cerdan, Cano, Garcia-Sanchez \& Lujan, 2012b).

Aspectos que también se potencian en los alumnos con este sistema son:

- El orden

- El respeto a los otros y por uno mismo

- Las iniciativas

- La capacidad de elegir

- El desarrollo de la voluntad 
- La autodisciplina

- Favorecer la responsabilidad

En algunos casos (alumnos tímidos), la plataforma permite la oportunidad de participar en clase y sentirse así más integrado e incluso aceptado.

CADI es un método fundamentalmente interactivo. La pedagogía interactiva consiste básicamente en un trabajo conjunto entre profesor y alumno, intercambiando ideas y desarrollando actividades compartidas. Aprender sería una actividad coherente que se construye y desarrolla gracias a las ideas que surgen entre compañeros. La dinámica interactiva que se desarrolla en un grupo está hecha de observaciones mutuas, revelaciones, invitaciones, comentarios, preguntas, explicaciones, reactivación de pensamientos y coordinación de ideas y acciones.

Este método interactivo es también una parte esencial del trabajo del profesor que ha de presentar con eficacia el saber que estima que debe transmitir y que, para responder a esta misión con efectividad, es decir, que todos los alumnos adquieran estos saberes, se apoyará en la pedagogía interactiva y en todo aquello que el alumno conoce ya. El profesor buscará situaciones en las que, gracias al intercambio y a la interacción, el alumno utilice sus adquisiciones y desarrolle sus competencias. Por todo ello, una parte esencial del trabajo del profesor no es otra que la provocación de tales situaciones. En todo caso, el profesor tiene que cuidar sus modos de intervención para ayudar al alumno a avanzar en su aprendizaje sin intervenir en su dinámica o ritmo.

\subsection{Otros usos de CADI}

\subsubsection{Ponencias}

Una ponencia es una propuesta o comunicación sobre un tema específico, que es analizado y examinado en una asamblea. La ponencia puede generar una resolución por parte de la asamblea en cuestión.

En el lenguaje cotidiano suele utilizarse el concepto de ponencia para hacer referencia a cualquier discurso o presentación que una persona realiza frente a un auditorio. El lanzamiento de productos en el marco de un evento, las exposiciones científicas y la argumentación académica serían, en este sentido, distintos tipos de 
ponencias. Toda ponencia debe tener una introducción (para llamar la atención de la audiencia), un cuerpo central (donde se desarrolle el mensaje que se quiere transmitir) y una conclusión (que suele resumir lo expresado en el cuerpo central).

Es importante que la ponencia cuente con un adecuado soporte audiovisual que refuerce los conceptos que se presentan o que ayude a la comprensión de los términos. Por ejemplo, el ponente puede apoyarse en diapositivas mientras habla, hacer pausas para mostrar pequeños vídeos, etc. Pero al final de la ponencia resulta necesario dejar espacio para las preguntas o el diálogo.

Actualmente, la intervención del público asistente en un auditorio se realizaba con la costosa instalación de una red de micrófonos fijos o bien con la preexistencia de un número de azafatas provistas de micrófonos inalámbricos que facilitarían al público la labor de intervenir.

El ponente debe invitar al auditorio a realizar consultas y tiene que ser claro en sus respuestas. Ahí es donde el sistema CADI hace su aportación, evitando problemas como el de entablar diálogos personales dejando a un lado al resto de personas presentes o resignar al público asistente a no intervenir con el consiguiente deslucimiento del acto. CADI resuelve estos problemas a través de despliegue de una red $\mathrm{WiFi}$, convirtiendo el dispositivo portable de los asistentes a la ponencia en una especie de "micrófono individual" capaz de lanzar mensajes escritos o realizar votaciones y valoraciones, responder encuestas, etc., todo ello en tiempo real.

Además, teniendo en cuenta que algunas ponencias de diversos autores son a veces publicadas conjuntamente en libros o informes que intentan divulgar las discusiones llevadas a cabo en los congresos o seminarios ante los que han sido presentadas, el sistema podría ser especialmente útil ya recoge de forma nativa las intervenciones, valoraciones y votaciones del personal asistente sobre ciertos aspectos de la ponencia que luego podrían resultar de importante valor añadido.

Así, ante las respuestas y el debate, el ponente con la ayuda de CADI puede:

1. Contestar a las preguntas más solicitadas y valoradas por el auditorio, quedando su actuación más clara y precisa para el público en general.

2. Responder mirando a todo el público en general ya que las preguntas pueden ser lanzadas de forma anónima, evitando así confrontaciones entre los 
asistentes y pudiendo poner punto y final a un debate que pudiese resultar acalorado.

En toda ponencia, la habilidad para hablar y realizar presentaciones en público debe ser entendida como un proceso de mejora continua. Por ello, una vez finalizado el acto el ponente debe y, con la ayuda de CADI, puede evaluar el nivel de satisfacción del público detectando posibles errores o vías de mejora.

Un buen ponente debería considerar que cada participación en público es un ensayo para la siguiente ocasión. Por ello, resulta muy interesante la oportunidad que CADI le brinda de poder solicitar a la audiencia que rellenen un cuestionario de evaluación de la misma sobre su actuación a la vez que esta respuesta del público también nos informaría sobre si se ha conseguido o no el objetivo que se perseguía con la ponencia, por ejemplo, vender un producto, obtener la aprobación de una plan de marketing de una empresa, obtener financiación para un nuevo proyecto, etc.

\subsubsection{Ruedas de prensa}

Como ya sabemos, las ruedas de prensa son reuniones convocadas por una fuente para dar cuenta de una determinada información a los medios de comunicación. $\mathrm{Su}$ importancia radica en que esta iniciativa facilita el contacto directo de la entidad con los profesionales de la información (periodistas) constituyendo un medio idóneo para comunicar mensajes corporativos (previamente definidos por el departamento o gabinete de comunicación correspondiente) a la opinión pública.

Las ventajas que posee esta forma de comunicación informativa radican en que posee un carácter interactivo en tanto que permite el feedback inmediato de los periodistas que, a su vez, obtienen datos oficiales de forma directa.

Según la conferencia de prensa de que se trate podemos encontrarnos con un número determinado de periodistas invitados, es decir, con un grupo escaso o especialmente amplio. En este último caso, el uso de la plataforma CADI resolvería totalmente el tradicional problema que hay con la participación con grupos numerosos evitando así que quedasen preguntas sin contestar, repetidas o pérdidas de tiempo inútiles. Toda conferencia de prensa precisa de un acondicionamiento del escenario donde se va a desarrollar como, por ejemplo, garantizar la presencia de elementos de comunicación multimedia para la exposición de los portavoces así como teléfonos, 
faxes y terminales online por si los periodistas pudieran precisarlos o dispositivos y personal de traducción simultánea. Todo ello requiere una cuidada y costosa instalación que podría reducirse con el uso de la plataforma.

Además, existe otro aspecto relacionado con los gastos mínimos que habría que considerar a la hora de organizar la conferencia de prensa, como la contratación de un número de azafatas que portasen dispositivos inalámbricos para realizar las posibles preguntas que pudieran surgir y así poder garantizar la total participación de todos los asistentes al acto. 


\section{Capítulo 4. La experiencia piloto con CADI}

\subsection{Introducción. Experiencias paralelas}

El origen de los sistemas de respuesta interactiva lo encontramos en el ámbito empresarial. En este sentido, podemos decir que son numerosas sus aplicaciones, entre ellas: asambleas, reuniones de consenso, elecciones, sondeos de opinión, toma de decisiones, convenciones de empresas, seminarios de ventas, etc. A las mismas, indudablemente, hay que añadir su uso en el ámbito educativo. Pues bien, la utilización de estos sistemas en la enseñanza superior se remonta a la década de los 60, principalmente en las universidades de EEUU (Chafer, 2009), aunque ha sido en la mitad de los años 90 cuando se ha extendido su uso (Judson \& Sawada, 2002). Fue entonces cuando los profesores se sintieron atraídos especialmente por la capacidad de estos sistemas, que proporcionan información de forma inmediata, aspecto que hoy en día sigue animando su utilización.

La aplicación de estos sistemas ha tenido lugar en diversas ramas del conocimiento (ingeniería, ciencias de la salud, ciencias sociales, etc.) como se observa en la Tabla 4.1 siguiente, en la que se han recogido algunos de los estudios consultados indicando la universidad en la que se ha desarrollado la experiencia y la materia impartida en cada caso (Ruiz Jiménez et al., 2010).

\begin{tabular}{|l|l|l|}
\hline ESTUDIO & UNIVERSIDAD & MATERIA \\
\hline Berry (2009) & University of Wisconsin & Enfermería \\
\hline $\begin{array}{l}\text { Bode, Drane, Kolikant, \& } \\
\text { Schuller (2009) }\end{array}$ & Northwestern University & Matemáticas \\
\hline Clearly (2008) & Colorado State University & Psicología \\
\hline Freeman et al. (2007) & University of Washington & Biología \\
\hline Gauci, Dantas, Williams, \& & University of Melbourne & Psicología \\
\hline
\end{tabular}




\begin{tabular}{|l|l|l|}
\hline Kemm (2009) & & \\
\hline $\begin{array}{l}\text { Hanson, Graham \& Seawright } \\
\text { (2008) }\end{array}$ & Brigham Young University & Ciencias \\
\hline Huh, Lee, \& Jin (2008) & California State University & $\begin{array}{l}\text { Administración de } \\
\text { empresas (Contabilidad) }\end{array}$ \\
\hline Johnson \& Robson (2008) & University of Wisconsin & $\begin{array}{l}\text { Económicas } \\
\text { (Microeconomía) }\end{array}$ \\
\hline Len (2006-07) & Cuesta College & Astronomía \\
\hline Matesic \& Adams (2008) & York University & Gestión de empresas \\
\hline Medina et al. (2008) & University of Oklahoma & Farmacia \\
\hline $\begin{array}{l}\text { Morling, McAuliffe, Cohen \& } \\
\text { DiLorenzo (2008) }\end{array}$ & University of Delaware & Psicología \\
\hline Nelson \& Hauck (2008) & Illinois State University & Sistemas de Información \\
\hline Shaffer \& Collura (2009) & Ohio State University & Psicología \\
\hline Stowel \& Nelson (2007) & Eastern Illinois University & Psicología \\
\hline Weerts, Miller \& Altice (2009) & University of North Florida & Nutrición \\
\hline
\end{tabular}

Tabla 4.1. Experiencias con sistemas de respuesta interactiva (Ruiz Jiménez et al., 2010).

La inmediatez que caracteriza la información obtenida a través de las plataformas interactivas ha sido valorada en los trabajos publicados por estas universidades. Así, a modo de resumen, podemos resaltar que:

1) Aumenta la participación de los estudiantes (Berry, 2009; Chafer, 2009; Silliman \& McWilliams, 2004; Weerts, Miller \& Altice, 2009) e incluso en grupos de gran tamaño (Beatty, Gerace, Leonard \& Dufresne, 2006).

2) Se mejora la atención de los estudiantes (Berry, 2009).

3) Se mejora el rendimiento de los estudiantes e incluso sobre otros sistemas de aprendizajes activos (DeBord, Aruguete \& Muhlig, 2004; Pemberton, Borrego \& Cohen, L. M. ,2006).

4) Se mejora la comprensión de los temas (Chafer, 2009).

5) Se fomenta la asistencia a clase y la preparación de éstas por parte de los alumnos (Chafer, 2009). 
6) Se aumenta la interacción profesor-alumno (Silliman \& McWilliams, 2004; Shaffer \& Collura, 2009).

7) Se proporciona una retroalimentación inmediata (Chafer, 2009; Weerts, Miller \& Altice, 2009).

8) Se permite un seguimiento individual de cada estudiante (Draper, Cargill \& Cutts, 2002).

9) Se permite conocer el grado de asimilación de los contenidos y aquellos aspectos en los que este es menor (Berry, 2009).

10) Se posibilita la enseñanza y la evaluación en tiempo real, lo que permite evaluar la comprensión del estudiante en el momento en que se imparten los contenidos (Wit, 2003).

11) Se fomenta la discusión en grupo (Weerts, Miller \& Altice, 2009) y la facilita cuando los grupos son de gran tamaño (Greer \& Heaney, 2004).

12) Se aumenta la creatividad para el desarrollo de las clases (Weerts, Miller \& Altice, 2009).

13) Se amenizan las clases (Beekes, 2006; Shaffer \& Collura, 2009) y aumenta la satisfacción del alumno (Chafer, 2009).

14) Se mejora la calificación del estudiante (Berry, 2009; Kennedy \& Cutts, 2005).

15) Se reduce la gestión administrativa por parte del profesor (Chafer, 2009).

Todos estos estudios concluyen que los alumnos valoran globalmente estos sistemas como positivos, por muchos de los aspectos mencionados anteriormente y señalan, además, que les gustaría la utilización de sistemas interactivos de respuesta en otras asignaturas (Berry, 2009).

Los sistemas de respuesta interactiva se pueden utilizar con diversos objetivos en la enseñanza. En este sentido, la retroalimentación inmediata permite a los alumnos comprobar el grado en que están asimilando los contenidos, y a los profesores les aporta la información acerca de la efectividad de la docencia impartida. Además, constituye una excelente herramienta para dinamizar las clases, de forma que se fomenta la atención, la participación y el debate. Sin embargo, una de las aplicaciones más importantes estará en su utilización como herramienta de apoyo en la evaluación del alumnado. 


\subsubsection{Eric Mazur}

Una experiencia paralela a la plataforma CADI de la UPCT la encontramos en Eric Mazur, experto en física aplicada de la universidad de Harvard y científico e investigador. En la actualidad dirige un programa de investigación en física óptica y supervisa distintos grupos de investigación en su universidad. En 1990 comenzó el desarrollo de un método de enseñanza para grandes aulas de forma interactiva y en 2006 ayudó a producir el premiado DVD de enseñanza interactiva (Mazur, 2006).

Este autor se descubre a sí mismo como un profesor convertido, pues está convencido de que su rol como formador es mucho más que dictar una cátedra magistral. Hace tiempo se dio cuenta de que su modelo tradicional de enseñanza no funcionaba, por lo que empezó a explorar nuevas formas de enseñanza. A través de su experiencia, comprendió que el proceso de enseñanza implicaba más que una mera transferencia de información ya que dependía de la capacidad de los alumnos para asimilar lo aprendido y transferirlo a la propia experiencia, y por eso cambió su metodología. En la actualidad realiza en sus clases presentaciones breves y favorece la discusión grupal, lanzando continuas preguntas e invitando a los estudiantes de Harvard a expresar y sustentar sus criterios. Mazur dedica actualmente parte de su tiempo a la investigación docente porque sostiene que "sirve de poco hacer ciencia si la sociedad no la entiende" (Mazur, 1997). Para cambiar esta situación, su grupo de trabajo ha desarrollado modelos de aprendizaje colaborativo (tipo CADI) que responden a las necesidades diversas de los alumnos.

"La educación es interacción, se necesita dotar de destrezas a los alumnos para que puedan resolver problemas", apuntó Mazur cuando participó en la $3^{a}$ Jornada de Vanguardia Tecnológica 2011, organizada por el Instituto de Ciencias y Tecnología IC y TDF. Su método interactivo consiste en tomar uno de los temas considerados difíciles para después realizar una pregunta a los alumnos. Tras esperar unos momentos, si recibe el $70 \%$ de respuestas correctas, la hace pública. Sin embargo, si no es así, invita a los alumnos a buscar con alguien de su alrededor una respuesta distinta para que interactúen y usen sus argumentos para convencerles de que la respuesta que tienen es la correcta. Mazur explica que con este método percibe el grado de conocimiento de sus estudiantes y una vez que los alumnos entienden los conceptos, no los olvidan. 
En Mazur (1997) afirma: "Esta forma de enseñar hace que la gente deserte menos de las carreras", "la mejor forma de enseñar es cuestionar, no sólo hablar, hay que invitar a los alumnos a buscar información de otras fuentes". "Pensaba que era un buen profesor hasta que descubri a mis estudiantes memorizando información en lugar de aprender a entender los contenidos. Creí que debía ajustar mi enfoque de la enseñanza para conseguir mejorar el rendimiento de mis alumnos de forma significativa".

Esta tendencia de Mazur hacia el aprendizaje activo puede derrocar al estilo de enseñanza que ha gobernado durante 600 años las universidades. Mazur sostiene que el aprendizaje le interesa mucho más que la enseñanza y anima a un cambio de la "enseñanza para ayudar a los estudiantes a aprender".

Mazur especula con la naturaleza verbal de las personas y la colaboración entre los compañeros como herramientas para propiciar un mejor ambiente de aprendizaje para los estudiantes. Para él, con este método existe "una mejor retención del conocimiento". A través de su experiencia observó que los estudiantes que activamente argumentaban determinados conceptos se aferraban a este conocimiento por más tiempo. En una de sus conferencias alude anecdóticamente a las clases magistrales como "una manera de transferir las notas del instructor a los cuadernos de los estudiantes sin pasar por los cerebros de ambos". De igual modo, en dichas conferencias alude con frecuencia a una cita de Albert Camus: "Some people talk in their sleep. Lecturers talk while other people sleep" ("algunas personas hablan mientras duermen. Los profesores hablan mientras otros duermen"). Sentado pasivamente y tomando notas, el alumno no aprende y sin embargo las clases son un $99 \%$ de forma magistral en la actualidad.

Mazur también afirma que casi todos los estudiantes tienen ordenadores portátiles, teléfonos móviles y otros dispositivos, y que los usan constantemente, lo que hace muy fácil la aplicación de este método interactivo en clase, ya que no supone ningún despliegue tecnológico especial, como el sistema CADI desarrollado en la UPCT. Mazur inicia las clases con una pregunta al estudiante, después pide que la piensen y se comprometan a una respuesta a través del móvil y un ordenador central las recoge. Si entre el 30 y el $70 \%$ de la clase tienen la respuesta correcta, Mazur busca la controversia. Los estudiantes encuentran un compañero con otra respuesta diferente y empieza la interacción entre ellos tratando de convencerse y defender su postura. 
Durante el caos, Mazur circula por el aula escuchando las conversaciones. Escucha razonamientos incorrectos pero tras dos o tres minutos, los alumnos votan de nuevo y, por lo general, el porcentaje de respuestas correctas mejora de forma espectacular. Mazur quiere ayudar a sus alumnos a resolver problemas reales y afirma irónicamente: "Ahora, si doy a mis alumnos un problema en un examen que no han visto antes no hay quejas del tipo: nunca hemos hecho un problema de esta clase... ya que les contestaba: si hubierais hecho ya problemas de este tipo, por definición, esto no sería un problema...”.

Mazur defiende que el profesorado debe de capacitar a sus alumnos para hacer frente a situaciones que no han encontrado resueltas antes. Esta situación recibió al principio una gran resistencia estudiantil además de arquitectónica, ya que la mayoría de las aulas de los campus universitarios son auditorios construidos con el sólo propósito de centrar la atención de todos en la figura del profesor o ponente, siendo éste el representante activo, y el resto de personas los sujetos pasivos que sólo reciben información.

En el año 2011, Eric Mazur fundó la empresa Learning Catalytics, que ofrece soluciones interactivas para mejorar el aprendizaje en el aula. Además, es el Consejero Jefe en Asuntos Académicos de Turning Technologies, una compañía de desarrollo de sistemas electrónicos de respuesta para el mercado de la educación.

Para él, la educación es algo más que la transferencia de información y, sin embargo, esto es lo que se hace. Pocos estudiantes tienen la capacidad, la motivación y la disciplina para sintetizar toda la información que les es dada en el aula.

Marzu opina que la síntesis es quizá el aspecto más importante de la educación. Demuestra con sus experiencias que cambiar el enfoque en el aula mejora significativamente el aprendizaje de los alumnos. Se trata de cómo los estudiantes pueden asimilar la información para transferirla a su propia experiencia.

Este profesor cambia el enfoque de la educación desarrollando una estrategia que permite tener una retroalimentación por parte de los alumnos en tiempo real con conferencias cortas interrumpidas por cuestiones conceptuales que él mismo plantea a los alumnos utilizando métodos de respuesta en el aula que se apoyan en las TIC. 
Esta es la base de lo que él llama el "método de enseñanza por pares", que involucra a los estudiantes, es interactivo, proporciona una evaluación continua y permite a los alumnos aprender unos de otros.

\subsubsection{Universidad de Sevilla}

Otra experiencia similar a nuestra plataforma interactiva CADI es la llevada a cabo por un grupo de profesores de la universidad de Sevilla también sobre la enseñanza interactiva en la docencia universitaria.

Este equipo de profesores son defensores de metodologías docentes que incrementen la participación y motivación del alumnado considerando ambos aspectos necesarios para el adecuado proceso de enseñanza-aprendizaje en la universidad así como para la consecución de excelentes resultados académicos.

Esta iniciativa que desarrolló el profesorado de la universidad sevillana consistía en la utilización de un sistema de mandos electrónicos de respuesta comercial llamado Educlick, que permitía realizar preguntas colectivas a una audiencia y recoger las respuestas individuales emitidas, en este caso, por los alumnos.

La experiencia se llevó a cabo en distintas asignaturas de la Escuela Universitaria de Estudios Empresariales y en la Facultad de Ciencias Económicas y Empresariales. Su objetivo era evaluar la utilización de este sistema en la docencia universitaria. Para ello, se realizó un proceso de encuesta a más de 300 alumnos, quienes tuvieron que evaluar aspectos relacionados con su uso, sobre cómo influye en el desarrollo de las clases, las ventajas en el proceso de aprendizaje, sus potencialidades, etc.

Tradicionalmente, los sistemas de evaluación continua se han asociado, por su facilidad de adopción, a grupos poco numerosos o más bien reducidos. Sin embargo, la experiencia sevillana aplicó este método en un curso académico con 374 alumnos matriculados, repartidos en 4 grupos, lo que pone de manifiesto el entorno masificado en el que se ha desarrollado este sistema de evaluación. Este hecho no supuso ningún hándicap ya que estaban apoyados en una herramienta interactiva que facilitaba la recogida de información y la evaluación del trabajo que el alumno realizaba dentro y fuera de clase. 
La experiencia se llevó a cabo durante el primer cuatrimestre del curso académico 2009/2010, en una materia optativa en la asignatura de Dirección y Gestión de la Producción II, del tercer curso de la diplomatura en Ciencias Empresariales de la Universidad de Sevilla.

Su objetivo principal era saber si la introducción de sistemas interactivos aumentaba la participación en clase de los alumnos, saber en qué grado se veía alterada la atención de los mismos durante la clase, en qué grado se favorecía la asimilación de los contenidos y, en general, evaluar el proceso de aprendizaje y la calidad de la enseñanza. Además, pretendía conocer en qué medida la retroalimentación inmediata era valorada positivamente por los alumnos.

El proyecto consistía en la recogida de información mediante mandos electrónicos de respuesta personalizados. El sistema constaba de un software, un receptor de radiofrecuencia y un conjunto de mandos electrónicos dedicados. Cada alumno tenía asignado un mando para todo el curso, identificado numéricamente. Dichos mandos se encontraban en unos armarios casilleros en las respectivas aulas donde se impartía la docencia. Al comienzo de la clase, el profesor abría el armario con los mandos y cada uno recogía el suyo, depositando como medida de control el carné universitario. El software necesario se encontraba instalado en los ordenadores de las aulas y bastaba con iniciar una sesión en el mismo y seleccionar la presentación de PowerPoint correspondiente a ese día. En algunas de las transparencias que se utilizaban, el profesor insertaba preguntas acompañadas de algunos componentes que proporcionaban la capacidad para entablar un diálogo interactivo. Las transparencias tenían un formato similar, pero incluían un cuadro de control donde se reflejaban las respuestas de los alumnos.

La metodología utilizada consistía en intercalar en las presentaciones del profesor dichas diapositivas interactivas, con preguntas sobre el tema expuesto en ese momento, obteniéndose así una retroalimentación inmediata tanto del grado de atención como del grado de comprensión de los alumnos. Se utilizaron dos tipos de preguntas durante la experiencia: unas tipo test y otras tipo encuesta. En estas últimas se introducían tantas opciones de respuesta como se consideraban necesarias y las utilizaban básicamente para discutir conceptos y fomentar el debate en clase. Sin embargo, las cuestiones tipo test se centraban en la materia impartida, ofreciéndose a los alumnos 4 alternativas posibles, de las que sólo una era válida. El número de preguntas 
en una clase normal variaba según la naturaleza de la materia, aunque todas las clases comenzaban con tres preguntas tipo test de repaso sobre la materia explicada en la sesión anterior. Tras exponer cada pregunta, se visualizaba una gráfica con estadísticas al objeto de que los alumnos, a su vez, conocieran su grado de acierto y sobre todo, pudieran plantear las dudas que la cuestión en sí o el tema tratado les suscitaran.

Las puntuaciones obtenidas en estas preguntas y en las que se podían lanzar durante la clase se tenían en cuenta para la evaluación final del alumno, lo que permitía al profesor tener un registro diario de datos por alumno, con información relativa a aspectos tan importantes como la asistencia a clase, la participación, el grado de comprensión, el nivel de aciertos, etc. Adicionalmente, utilizaban el sistema como método de evaluación al finalizar cada tema.

Este método de evaluación continua también suponía una ventaja ya que como señalan (Delgado \& Oliver, 2006), cuando las actividades son evaluables lo habitual no es facilitar al estudiante la calificación enseguida, sino al final del periodo académico, con lo que no se ofrecen elementos para rectificar a tiempo con el enfoque de las actividades.

La Universidad de Sevilla valoraba mucho en este proyecto la posibilidad de intervenir y reconducir el proceso de enseñanza siendo además el feedback inmediato.

Por su parte, el sistema Clase Docente Interactiva (CADI) desarrollado en la UPCT también estimula la comunicación. Es través de ella como se aprende. Para ello es fundamental instaurar en el aula un clima o ambiente de confianza tal que cada alumno no tenga ningún temor a expresar sus ideas, cualquiera que sea su modo de expresarlas y cualesquiera que sean sus características individuales o socioculturales.

Con CADI se favorece la comunicación entre el grupo. El alumno emprende iniciativas, expresa sus intereses y pone a prueba sus capacidades a la vez que el profesor observa estas manifestaciones y puede tenerlas en consideración para proponer nuevas situaciones e ir así obteniendo poco a poco la participación de todos.

Las intervenciones del docente se convierten con CADI en estimulantes, con situaciones seleccionadas incitando a la comunicación, participación, estimulando al alumno a la actividad, a desarrollar actitudes de investigación, aportando conocimientos y manteniendo una dinámica interactiva que al final empuja a éste a la reflexión. 
Gracias a la interacción, ciertas intervenciones son a veces necesarias para alentar el diálogo, retomar las proposiciones que llegan de los alumnos, solicitar la escucha de otros compañeros y remarcar que todas las ideas son dignas de ser tenidas en cuenta. Todo ello es un conjunto de poderosos estimulantes que hacen que el alumno se sienta valorado, se interese y mantenga de forma sostenida su atención sobre el trabajo.

Gracias a los cuestionarios y a la participación activa de todos, se instala en el proceso educativo una actitud mental de "reflexionar para aprender".

La plataforma permite asimismo la realización de diferentes prácticas de autoevaluación y regulación, balances puntuales del docente sobre los procesos de los alumnos, debates de los docentes con ellos, etc.

Todo esto significa una apuesta por la reflexión, de manera que si alumno dedica su tiempo a actuar y a reflexionar en el aula, sí experimenta, descubre, crea y comunica, podemos estar seguros de que está aprendiendo y construyendo estructuras de conocimiento útiles en todos los dominios del saber (Legrand, 1992).

Aprender es, en efecto, un largo proceso en el que la reflexión constante y la continua interactividad ocupan un lugar fundamental. La plataforma CADI permite intercambiar y confrontar las ideas, potenciando de esta forma una pedagogía interactiva consistente en el desarrollo de un auténtico intercambio intelectual que permita compartir el saber entre todos cuantos participan en el proceso educativo: alumnos entre ellos, profesores y alumnos y profesores entre ellos.

Todos los principios que se mencionan están conectados con los trabajos de Piaget (1975) y las pedagogías activas de Wallon, Vygotski (2000), Cousinet y Freinet, entre otros de los autores comentados anteriormente.

A modo de conclusión podemos decir que en la actualidad existe un deseo y una necesidad de cambio en el proceso educativo.

Antes, la enseñanza de centraba más en los contenidos que en los métodos. Se trataba de un esquema en el que resultaba fundamental la exposición del docente, la atención, la memorización y la repetición por parte del alumno, quien sólo era un receptor pasivo de conocimientos, siendo el resultado la evaluación de la memoria. Sin embargo ahora todo ha cambiado: el alumno ha dejado de ser un ser pasivo, involucrándose en su propio proceso de enseñanza aprendizaje a la vez que el docente va adquiriendo un rol de facilitador cuya misión es coordinar dicho proceso. Con todo 
ello, hoy están surgiendo modelos pedagógicos basados en sistemas interactivos (recordemos a Eric Mazur). Estos modelos buscan desarrollar en los alumnos (al igual que CADI) la capacidad de autogestión y autodesarrollo como fundamentos de la excelencia profesional. Se trata de un saber producto de la corresponsabilidad entre alumnos y docentes a través del estudio personal, la investigación, la cooperación grupal, la vinculación con el campo de trabajo, las tutorías personalizadas y, por último, el manejo de tecnologías altamente especializadas.

En la actualidad es esta pedagogía interactiva la que se está imponiendo ya que constituye una forma de enseñanza en la que tanto profesor como alumno están dispuestos a trabajar y a aprender juntos. El mayor propósito es formar personas que tengan la dedicación de aprender y saber más, por lo que es un proceso de crecimiento y, de esta manera, los alumnos harán suyos los conocimientos aprendidos. Debido a las potencialidades de las nuevas tecnologías y específicamente a Internet, el aprendizaje puede centrarse en el sujeto que aprende, concebido como un ente procesador de información, capaz de dar significación y sentido a lo aprendido.

El aprendizaje es el producto de una aplicación reflexiva e intencional de estrategias para abordar la información. El alumno desarrolla estas estrategias y con ello adquiere conciencia del propio proceso para aprender, es decir, que sepa qué tipo de recursos debe emplear, en qué momento y ante qué contenidos de manera que sea capaz de planear, supervisar y autoevaluar su proceso de aprendizaje e incluso de proponer formas de corregir sus resultados en una perspectiva de mayor autonomía.

El proceso de enseñanza interactivo supone la utilización de procedimientos que tratan de lograr aprendizajes significativos en los alumnos. Así, estos estudiantes aprenden a aprender, lo cual supone enseñarles a pensar.

Sin duda, los aprendizajes de contenidos son indispensables pero los alumnos deben procurar además adquirir habilidades generales y específicas que les permitan convertirse en aprendices activos, capaces de manejar y acceder eficazmente a diferentes tipos de contenidos curriculares.

Actualmente, el alumno se convierte en un sujeto activo que aprende, inicia y aprovecha experiencias, además de buscar información para resolver problemas y reorganizar los que ya sabe para lograr nuevos aprendizajes. 
Con nuestra plataforma interactiva hemos logrado conseguir en el proyecto piloto que los alumnos pasen del esfuerzo al interés, es decir, los alumnos comprenden mejor cuando están envueltos en tareas y temas que cautivan su atención. Nuestra plataforma también nos permitió pasar de la obediencia a la autonomía ya que el docente dejaría de exigir sumisión y fomentaría en cambio la libertad responsable. Al mismo tiempo, la experiencia nos permitió pasar de la coerción a la cooperación, ya que se obtuvo la participación de todos y se potenció las relaciones entre alumnos y, a través de ellas, se desarrollaron conceptos de igualdad, justicia y democracia. Todo ello ayudó a que la experiencia resultara un éxito.

\subsection{CADI: El proyecto piloto}

En esta sección se describe la experiencia llevada a cabo con el sistema CADI. En primer lugar se describen el escenario y la asignatura donde se realizó el caso de estudio. Después, la metodología seguida para incorporar CADI como herramienta docente adicional. Finalmente, se muestran los resultados académicos de los estudiantes de forma detallada junto con las encuestas y los resultados de las mismas tras la experiencia. Es importante destacar cómo esta información resultó ser muy significativa para evaluar la utilidad de la herramienta desarrollada.

\subsubsection{Escenario de uso}

La experiencia fue llevada a cabo en Ingeniería de la Calidad, una asignatura optativa impartida durante en el último de los cinco años de la carrera de Ingeniería Industrial (actualmente en extinción con la implantación de los grados) de la Escuela Técnica Superior de Ingeniería Industrial, ETSII, de la Universidad Politécnica de Cartagena. La asignatura contaba con tres horas de clases y una hora y media de actividades de laboratorio a la semana. El objetivo general de la asignatura era mostrar a los estudiantes situaciones reales de ingeniería, prestando especial atención a los procesos de calidad y su gestión. Los proveía de las herramientas necesarias para lograr la calidad en los procesos industriales, sin perder el enfoque de la productividad y competitividad que debe prevalecer en los ingenieros a la hora de diseñar, implementar y gestionar cualquier sistema. La tabla 4.2 a continuación muestra un breve resumen de los contenidos de la asignatura distribuidos a lo largo de las quince semanas de curso. 


\begin{tabular}{|c|c|c|c|c|}
\hline \multirow[b]{2}{*}{$\begin{array}{l}\mathbf{N}^{\circ} \\
\text { Semana }\end{array}$} & \multirow[b]{2}{*}{ Clase } & \multicolumn{2}{|c|}{ CADI } & \multirow[b]{2}{*}{ Actividad laboratorio } \\
\hline & & $\begin{array}{l}\text { Resol. } \\
\text { dudas }\end{array}$ & Otros & \\
\hline 1 & Calidad total. Conceptos básicos & $\mathrm{X}$ & $\begin{array}{c}\text { Encuesta } \\
\text { inicial }\end{array}$ & \multirow{3}{*}{$\begin{array}{l}\text { Gestión y regulación de la } \\
\text { calidad (GRC) }\end{array}$} \\
\hline 2 & Herramientas de provisión de calidad & $\mathrm{X}$ & - & \\
\hline 3 & El círculo de calidad & $\mathrm{X}$ & $\begin{array}{l}\text { Actividad } \\
\text { en equipo }\end{array}$ & \\
\hline 4 & $\begin{array}{l}\text { Provisión de calidad. } \\
\text { Metodología y pasos para la implementación }\end{array}$ & $\mathrm{X}$ & $\begin{array}{l}\text { Actividad } \\
\text { en equipo }\end{array}$ & \multirow{2}{*}{$\begin{array}{l}\text { Desarrollo de un manual de } \\
\text { calidad }\end{array}$} \\
\hline 5 & Técnicas alternat. para conseguir calidad total & $\mathrm{X}$ & - & \\
\hline 6 & La técnica $5 S$ & $\mathrm{X}$ & - & \multirow{3}{*}{$\begin{array}{l}\text { Auditoría de un sistema de } \\
\text { gestión de la calidad }\end{array}$} \\
\hline 7 & La técnica "Seis Sigma, $6 S$ " & $\mathrm{X}$ & - & \\
\hline 8 & Los 14 puntos de Deming para salir de la crisis & $\mathrm{X}$ & - & \\
\hline 9 & $\begin{array}{l}\text { Sistemas de calidad. Uso e implementación. } \\
\text { Estándares ISO } 9000\end{array}$ & $\mathrm{X}$ & $\begin{array}{l}\text { Actividad } \\
\text { en equipo }\end{array}$ & $\begin{array}{l}\text { Herramientas para la } \\
\text { mejora de la calidad }\end{array}$ \\
\hline 10 & Base estadística para control de la calidad (I) & $\mathrm{X}$ & - & $\begin{array}{l}\text { Diagramas de causa-efecto. } \\
\text { Diagramas de nubes de } \\
\text { puntos. Histogramas }\end{array}$ \\
\hline 11 & Base estadística para control de la calidad (II) & $\mathrm{X}$ & - & $\begin{array}{l}\text { Análisis de gráficos de } \\
\text { control }\end{array}$ \\
\hline 12 & Control estadístico de procesos & $\mathrm{X}$ & - & $\begin{array}{l}\text { Estudio de los gráficos de } \\
\text { unidades defectuosas }\end{array}$ \\
\hline 13 & Planes de aceptación de muestras & $\mathrm{X}$ & - & \multirow{3}{*}{$\begin{array}{l}\text { Análisis de los planes de } \\
\text { muestreo }\end{array}$} \\
\hline 14 & Procedimientos de muestreo (I) & $\mathrm{X}$ & - & \\
\hline 15 & Procedimientos de muestreo (II) & $\mathrm{X}$ & $\begin{array}{l}\text { Encuesta } \\
\text { final }\end{array}$ & \\
\hline
\end{tabular}

Tabla 4.2. Programación semanal de la asignatura

En esta asignatura, la nota de los alumnos se calculaba a partir de la obtenida en un examen final que constaba de cuatro partes: cuestiones sobre las actividades de laboratorio, cuestiones teóricas, preguntas cortas de teoría y problemas. La proporción de cada parte para el cálculo de la nota final se muestra en la Tabla 4.3 siguiente.

\begin{tabular}{ccccc}
\hline Año académico & $\begin{array}{c}\text { Actividades } \\
\text { Laboratorio }\end{array}$ & $\begin{array}{c}\text { Cuestiones } \\
\text { teóricas }\end{array}$ & $\begin{array}{c}\text { Cuestiones } \\
\text { cortas }\end{array}$ & Problemas \\
\hline $2006 / 2007$ & $15 \%$ & $25 \%$ & $25 \%$ & $35 \%$ \\
\hline $2007 / 2008$ & $15 \%$ & $25 \%$ & $25 \%$ & $35 \%$ \\
\hline $2008 / 2009$ & $15 \%$ & $25 \%$ & $25 \%$ & $35 \%$ \\
\hline $\mathbf{2 0 0 9 / 2 0 1 0}$ & $\mathbf{1 5 \%}$ & $\mathbf{2 5 \%}$ & $\mathbf{2 5 \%}$ & $\mathbf{3 5 \%}$ \\
\hline
\end{tabular}

Tabla 4.3. Pesos aplicados en la evaluación final de los alumnos 
Para este trabajo se recopilaron las notas de los estudiantes en las cuatro partes del examen, desde el curso académico 2006/2007 hasta el 2009/2010. Durante todo este último año, se desplegó una instancia del sistema CADI y se incorporó a la clase como una herramienta adicional para el docente de la asignatura, con el objetivo de constatar el impacto y utilidad de la plataforma desarrollada en un entorno real. De esta manera, tanto el profesor como los alumnos disfrutaron de un canal de comunicaciones adicional durante el curso... En cada caso, los estudiantes interactuaron con la interfaz de usuario mostrada en la Figura 4.1. Cabe resaltar en este punto que los contenidos que se brindaron a los estudiantes fueron adaptados con éxito a cada uno de los dispositivos móviles, atendiendo en cada caso a las capacidades de los mismos.

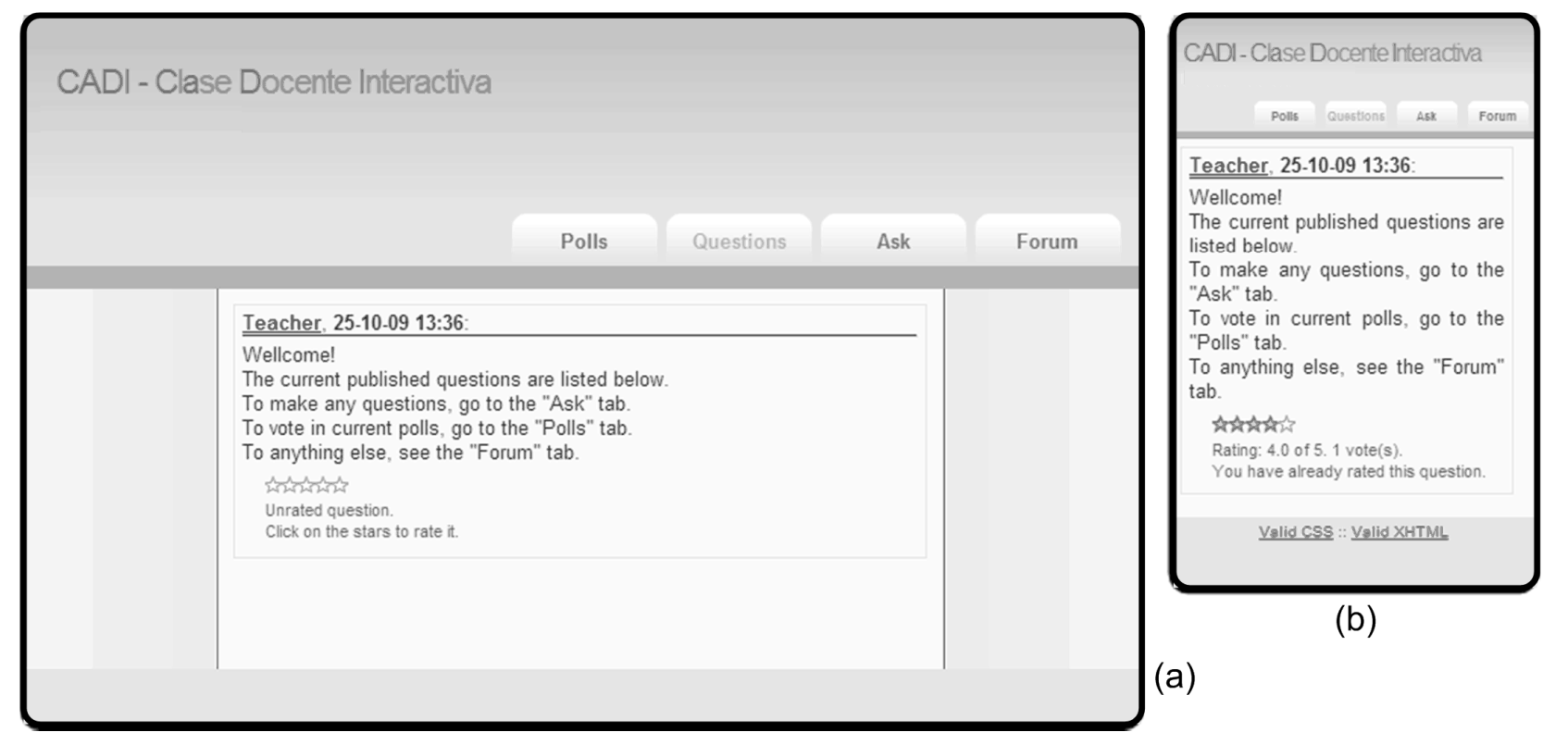

Figura 4.1. Capturas de pantalla de la interfaz gráfica de usuario (GUI) desarrollada para la plataforma. (a) Interfaz del sistema accedido desde un PC u ordenador portátil. (b) Interfaz del sistema accedido desde un dispositivo móvil. La resolución de la pantalla de este dispositivo en concreto es de 240 x 320 píxeles. Nótese cómo los contenidos se adaptan en función del tipo de dispositivo que accede al sistema de forma automática.

En total, y en el curso académico 2009/2010, el número de estudiantes matriculados en la asignatura de Ingeniería de la Calidad fue de 27, 5 mujeres y 22 hombres. Todos ellos participaron activamente en la experiencia con el sistema CADI. En los 3 años anteriores, la suma de los estudiantes matriculados en la asignatura ascendía a 81, manteniéndose los porcentajes por sexos similares a los del curso 
2009/2010. Además, los profesores de la asignatura fueron los mismos durante los 4 cursos académicos incluidos en este estudio.

\subsubsection{Metodología usada (materiales y métodos)}

Durante los tres primeros cursos académicos incluidos en este estudio, los profesores siguieron una metodología tradicional de enseñanza para la asignatura de Ingeniería de la Calidad, con las clásicas clases presenciales. Tal y como apuntaron los propios profesores, el nivel de interacción y participación de los estudiantes era muy bajo. Por tanto, uno de los objetivos que se propusieron con esta experiencia fue el de incrementar ese nivel de participación, incorporando una manera diferente de interactuar con los profesores durante las clases, a la vez que se evaluaba el impacto que tendría la inclusión de una plataforma interactiva sobre el rendimiento académico de los estudiantes en un entorno de educación superior.

Así, la nueva herramienta, CADI, se usó principalmente de dos maneras diferentes durante el curso (véase la Tabla 4.2):

En primer lugar, se mantuvo siempre disponible para que los estudiantes pudieran realizar preguntas de forma anónima (si así lo deseaban) al profesor sobre las clases en tiempo real. En concreto, la metodología utilizada contemplaba que el profesor comprobaría las preguntas realizadas a través de CADI tres veces a lo largo de cada clase, reservando el tiempo necesario para las correspondientes aclaraciones $\mathrm{o}$ explicaciones derivadas de dichas preguntas.

En segundo lugar, el sistema CADI también se uso para desarrollar actividades complementarias tales como "concursos" (para probar el grado de conocimiento de los estudiantes de forma global, no individualmente) o pequeñas competiciones entre grupos de estudiantes en clase. Aparte de esto, y para ciertas explicaciones puntuales, los profesores también usaron CADI para obtener información adicional, por ejemplo, proponiendo la resolución de problemas para después dedicar algo más de tiempo a la explicación cuando fuera necesario...

En este punto resulta interesante destacar que el sistema CADI no se usó en las sesiones de laboratorio. La razón principal reside en la propia naturaleza de estas sesiones, en las que los grupos de estudiantes son mucho más reducidos que en las clases. Este hecho favorece la comunicación entre los docentes y los estudiantes y, por 
tanto, en nuestra opinión, el uso de CADI aquí era mucho más prescindible... De todas maneras, no deja de resultar curioso el hecho de que los profesores notaran ese mismo año un aumento de la participación de los alumnos también en las sesiones de laboratorio, quizá propiciado de forma indirecta por el aumento de implicación por parte de ellos con el uso del sistema en las clases...

Por último, y aunque resultó posible incluir algún aspecto relacionado con el uso de la plataforma en la nota final de los estudiantes, se optó por no variar los criterios de evaluación que se venían aplicando en la asignatura a lo largo del tiempo para poder evaluar más objetivamente el impacto de la plataforma en el rendimiento académico de los estudiantes. Por ello, las notas finales del curso 2009/2010 fueron calculadas de la misma forma que en años anteriores (véase la Tabla 4.3).

\subsubsection{Resultados}

Para la evaluación de la plataforma se utilizaron tanto las notas de los estudiantes en la asignatura como las encuestas realizadas por ellos mismos acerca de su experiencia con el sistema:

Por un lado, y como ya se ha comentado anteriormente, las notas se correspondían con el resultado de cuatro contribuciones independientes que sumadas y ponderadas formaban la nota final (cuestiones de laboratorio, cuestiones teóricas, preguntas cortas y problemas, véase la Tabla 4.3).

Por otra parte, las encuestas realizadas sirvieron para recopilar las opiniones de los alumnos sobre el sistema antes y después de la experiencia. Así, antes de la experiencia se les preguntó por su grado de aceptación acerca de los sistemas de elearning en general y por su predisposición personal hacia dichos sistemas en concreto (véase la Tabla 4.4).

Encuesta inicial

¿Piensa que es interesante la incorporación de sistemas de e-learning en la metodología docente de esta asignatura?

¿Dispone de algún dispositivo portable compatible con WiFi durante las clases?
Respuestas

Sí: 27 (100\%), No: 0 (0\%)

Sí: 16 (59.3\%); No: 9 (40.7\%)

¿Alguna vez antes ha usado una plataforma de e-learning?

Sí: 15 (55.5\%); No 12 (44.5\%)

Tabla 4.4. Resultados de la encuesta inicial. 
Sorprendentemente, la totalidad de los encuestados (100\%) consideraron que una experiencia así podría ser interesante. Este hecho ratifica una vez más la gran predisposición de los estudiantes hacia la incorporación de sistemas basados en TIC en la educación (Mondi, Woods \& Rafi, 2008). Además, la mayoría de los estudiantes respondieron que normalmente llevaban dispositivos compatibles con WiFi durante las clases (en este caso, contaban con tres ordenadores portátiles y 13 smartphones): una tendencia que en estos últimos años hemos visto que es totalmente al alza debido al crecimiento exponencial de dispositivos como smartphones, tablets, portátiles, etc.). De todas formas, para aquellos que no contaban con un dispositivo WiFi entre sus enseres, se distribuyeron smartphones para que todo el mundo tuviera acceso a la plataforma. Un detalle curioso en este momento es que el reducido número de estudiantes en clase (27) se convirtió en una "ventaja natural" que resultó ser crítica para el éxito final de la experiencia: por un lado, el ambiente relajado entre los estudiantes (que se conocían entre ellos) ayudó a maximizar el número de sugerencias y flujo de información hacia los profesores... Por otra parte, fueron capaces de aportar un feedback muy valioso ya eran estudiantes veteranos que contaban con una relativamente extensa experiencia docente (recordemos que la asignatura correspondía al quinto y último curso de su carrera). Del mismo modo, no deja de ser curioso que 15 de los 27 alumnos (55.5\%) ya conocían otros sistemas de enseñanza basados en TIC o habían incluso trabajado alguna vez con ellos a lo largo de sus estudios, brindándonos la valiosa oportunidad de obtener opiniones no sólo cargadas de experiencia, sino también críticas acerca de la plataforma.

Una vez que se recopilaron las opiniones e impresiones iniciales de los alumnos a través de la encuesta inicial, se procedió a la recopilación de las calificaciones al final del curso académico. La Figura 4.2 muestra la media de las notas finales de los estudiantes junto con sus correspondientes intervalos de confianza $(\alpha=0.05)$. Se puede observar cómo la nota media obtenida por los estudiantes el año de la experiencia mejoró casi un punto en una escala de 0 a 10 (de 0 a 4.99: suspenso; de 5 a 6.99: aprobado; de 7 a 8.99: notable; de 9 a 10: sobresaliente), lo que repercutió de forma positiva en el porcentaje de aprobados mostrado en la Figura 4.3, que pasó del 59.92\% en media en los años anteriores hasta el $70.4 \%$ en el último año... 


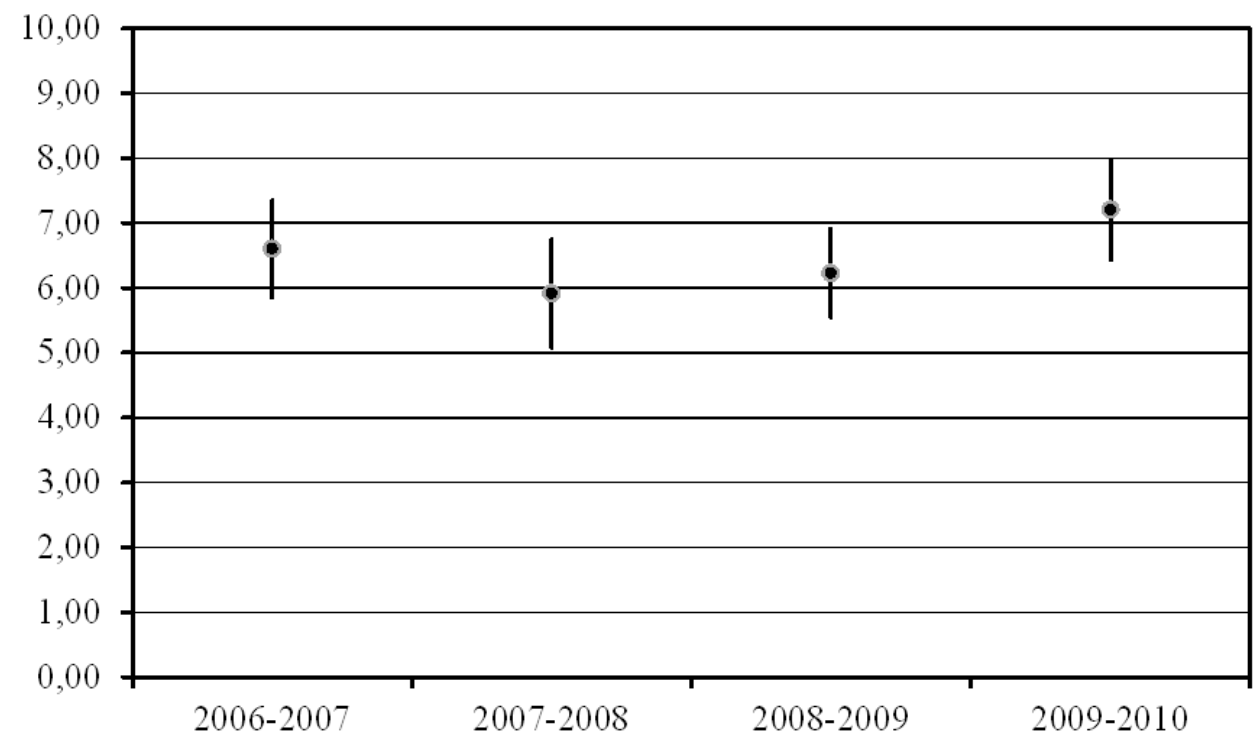

Figura 4.2. Notas medias finales e intervalos de confianza asociados (CADI se usó durante el curso académico 2009/2010).

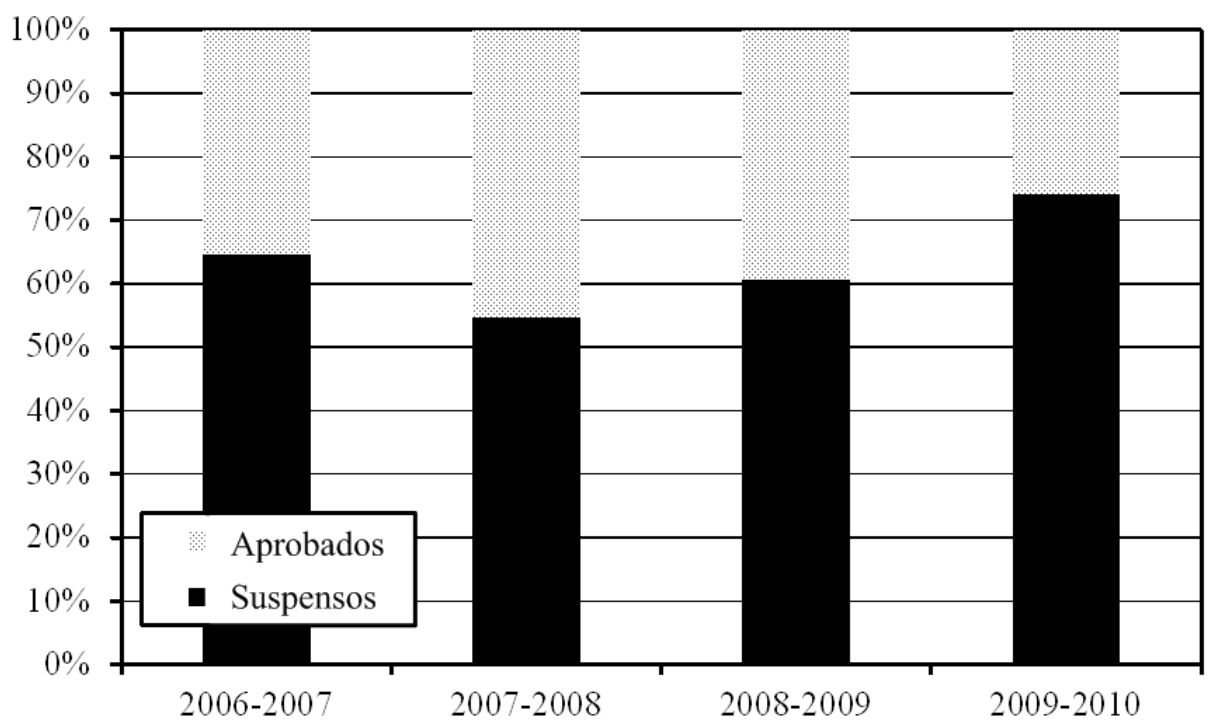

Figura 4.3. $\mathrm{N}^{\mathrm{o}}$ de aprobados y suspensos entre los alumnos (CADI se usó durante el curso académico 2009/2010).

Para determinar más concretamente la influencia de la plataforma CADI en las notas finales de los alumnos, se realizó un análisis de la varianza (one-factor Analysis of Variance, ANOVA) sobre los datos recopilados. La hipótesis nula considerada fue que 
no existía diferencia en la media de las notas finales sin tener en cuenta el uso de CADI durante las clases. Teniendo en cuenta las calificaciones obtenidas por los alumnos en los cuatro últimos cursos académicos hasta el de la experiencia, se obtuvo un valor de 4.09 para la distribución $\mathrm{F}$ de Snedecor. Como el valor crítico calculado, $\mathrm{F}_{0.05 ; 106}$, resultó ser 3.93, se rechazó la hipótesis nula: existía una diferencia estadística entre las notas de los estudiantes de los años anteriores sin CADI y los resultados académicos obtenidos el año de la incorporación del sistema. Concretamente, la diferencia estadística fue detectada en las calificaciones referentes a las preguntas, problemas y notas finales, como se muestra en la Tabla 4.5. Como era de esperar, el uso de CADI no supuso cambios estadísticos en las notas de los estudiantes en lo que se refiere a las actividades de laboratorio (ya que no se usó) ni en las correspondientes a las cuestiones teóricas (memorización de definiciones, conceptos o procesos...). Resumiendo, podemos considerar que la integración del sistema CADI como herramienta para aportar un nuevo canal de comunicación con las metodologías tradicionales ayudó a mejorar el rendimiento académico de los estudiantes involucrados.

\begin{tabular}{cccc} 
Elementos de la nota final de los alumnos & $\mathbf{F}\left(\mathbf{F}_{\mathbf{0 . 0 5}} ; \mathbf{1 0 7}=\mathbf{3 . 9 3}\right)$ & $\mathbf{p}$ & Hipótesis nula \\
\hline Preguntas sobre las actividades de laboratorio & 3.74 & 0.05 & Aceptada \\
\hline Cuestiones teóricas & 1.38 & 0.24 & Aceptada \\
\hline Cuestiones cortas & 6.83 & 0.01 & Rechazada \\
\hline Problemas & 4.00 & 0.04 & Rechazada \\
\hline Puntuación final & 4.09 & 0.04 & Rechazada \\
\hline
\end{tabular}

Tabla 4.5. Resultados del test ANOVA que determinan la diferencia estadística entre los cursos académicos con y sin el uso CADI

Al observar otra vez la Tabla 4.5 anterior, resulta interesante aclarar el resultado correspondiente a las sesiones de laboratorio: como ya se discutió en la Sección 4.2.2, CADI no fue usado durante estas sesiones, pero el hecho de usar el sistema en las clases incrementó la participación y, de alguna manera, la comunicación entre el profesor y los estudiantes. Este hecho tuvo su impacto indirecto también en las calificaciones de laboratorio, aumentándolas ligeramente. Así, aunque los resultados del test ANOVA muestran esta mejora en las notas de laboratorio (8.22 sobre 10 para el curso 2009/2010, cuando se llevó a cabo la experiencia), la diferencia no es estadísticamente relevante 
comparada con las notas de los cursos anteriores $(7.74,7.23$ y 7.79 sobre 10 para los cursos 2006/2007, 2007/2008 y 2008/2009 respectivamente) y, por tanto, se acepta la hipótesis nula...

Después de la experiencia, ya al final del cuatrimestre, se les pasó a los estudiantes otra encuesta final para conocer su opinión sobre el sistema CADI (véase el Anexo I de este documento, Encuesta final sobre la utilización del sistema CADI). El formato de las respuestas fue modulado en una escala de 1 a 5 , donde 5 significaba que estaban muy de acuerdo, 4 que estaban de acuerdo, 3 que su opinión era neutra (ni de acuerdo ni en desacuerdo), 2 si estaban en desacuerdo y 1 en fuerte desacuerdo con cada argumento. La Tabla 4.6 muestra de forma resumida los argumentos de esta encuesta final.

\begin{tabular}{|c|c|}
\hline $\mathbf{N}^{\circ}$ Pregunta & Pregunta \\
\hline $\mathrm{P} 1$ & Valore la calidad de la docencia que ha recibido con la incorporación de CADI \\
\hline $\mathrm{P} 2$ & $\begin{array}{l}\text { Valore la necesidad de usar este tipo de sistemas de apoyo a la docencia por parte de las } \\
\text { instituciones educativas }\end{array}$ \\
\hline $\mathrm{P} 3$ & ¿Cómo cree que CADI ha afectado a sus resultados académicos? \\
\hline $\mathrm{P} 4$ & Por favor, valore CADI en términos de SIMPLICIDAD. \\
\hline P5 & Por favor, valore CADI en términos de FACILIDAD DE USO. \\
\hline P6 & Por favor, valore CADI en términos de ACCESIBILIDAD. \\
\hline P7 & Por favor, valore CADI en términos de DISEÑO. \\
\hline $\mathrm{P} 8$ & Por favor, valore CADI en términos de UTILIDAD. \\
\hline P9 & Por favor, valore CADI en términos de OPERATIVIDAD. \\
\hline $\mathrm{P} 10$ & Por favor, valore CADI en términos de ADECUACIÓN / IDONEIDAD. \\
\hline P11 & Por favor, valore CADI en términos de CALIDAD. \\
\hline $\mathrm{P} 12$ & Exprese su grado de satisfacción en cuanto a FACILIDAD DE DESPLIEGUE. \\
\hline $\mathrm{P} 13$ & Exprese su grado de satisfacción en cuanto a FACILIDAD PARA RESOLVER DUDAS \\
\hline $\mathrm{P} 14$ & Exprese su grado de satisfacción en cuanto a TRANSPARENCIA EN LA OPERACIÓN \\
\hline $\mathrm{P} 15$ & $\begin{array}{l}\text { Exprese su grado de satisfacción en cuanto a MEJORA DE LA COMUNICACIÓN CON } \\
\text { EL PROFESOR }\end{array}$ \\
\hline $\mathrm{P} 16$ & Exprese su grado de satisfacción en cuanto a FLEXIBILIDAD Y FACILIDAD DE USO \\
\hline $\mathrm{P} 17$ & ¿Ha satisfecho CADI sus expectativas como plataforma de docente interactiva? \\
\hline P18 & $\begin{array}{l}\text { ¿En qué medida la existencia de CADI ha afectado al ritmo normal de las clases? (observe } \\
\text { que } 5 \text { significa "afectado de forma positiva" and 1, "de forma negativa") }\end{array}$ \\
\hline P19 & Por favor, valore de forma global esta experiencia con CADI \\
\hline $\mathrm{P} 20$ & Por favor, valore CADI de forma global como plataforma de apoyo en entornos docentes \\
\hline
\end{tabular}

Tabla 4.6. Contenidos de la encuesta final. 
La Figura 4.4 siguiente incluye las puntuaciones medias de los estudiantes hacia cada argumento junto con los intervalos de confianza correspondientes $(\alpha=0.05)$. Podemos observar cómo, en general, las opiniones de los alumnos hacia la plataforma fueron muy positivas. En concreto, varios argumentos obtuvieron una puntuación con una media superior a 4: P2, P8, P14, P16, P18 y P19.

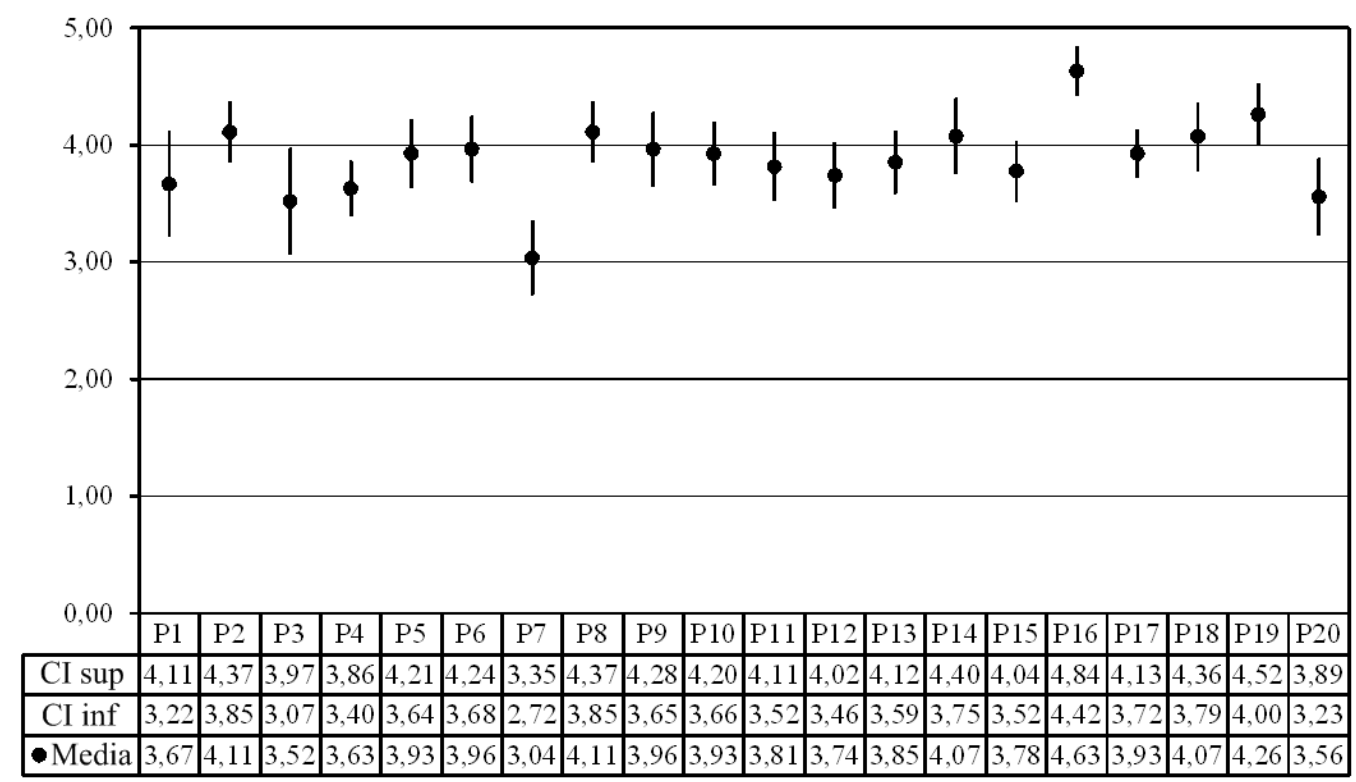

Figura 4.4. Puntuaciones medias e intervalos de confianza asociados a la encuesta final.

En concordancia con lo anterior, los estudiantes se mostraron de acuerdo ante la necesidad e idoneidad de la inclusión de nuevos métodos de enseñanza para incrementar su motivación y participación (nótese cómo estas cuestiones son las que menos varianza tienen). Pero aparte de todo, los estudiantes disfrutaron con la experiencia. La peor puntuación se obtuvo en el argumento P7, lo que dejó entrever que el diseño "visual" de la interfaz de la herramienta podía ser mejorado. Asimismo, es curioso resaltar que los estudiantes no fueron conscientes del efecto positivo que tuvo usar la plataforma en su rendimiento académico (véase el argumento P3 en la Figura 4.4).

Los argumentos P13, P15 y P17 estaban relacionados con la comunicación con el profesor. Se puede verificar en la Figura 4.4 cómo los resultados obtenidos fueron muy motivadores para continuar mejorando el sistema CADI. Por último, los 
estudiantes se mostraron de acuerdo ante la afirmación de que el ritmo de la clase no se había alterado debido a la incorporación de CADI (véase el argumento P18 de la Figura 4.4). Este hecho será abordado más profundamente en la siguiente sección.

Por otra parte, también se calculó la oblicuidad o falta de simetría (skewness), que mide el grado de asimetría de los datos en torno a la media de una distribución de muestras y la curtosis (kurtosis), que mide cuan proclive a datos atípicos es una distribución cualquiera de muestras. La oblicuidad de las respuestas de la encuesta final se muestra en la Figura 4.5. El error estándar en la oblicuidad se puede evaluar como el doble de la raíz cuadrada de $6 / \mathrm{N}$, ignorando el signo, y donde $\mathrm{N}$ es el número de encuestados. En este trabajo, por tanto, podemos considerar que se trata de una distribución normal de datos, en la que el valor de la oblicuidad ha de estar por debajo de 0.94 .

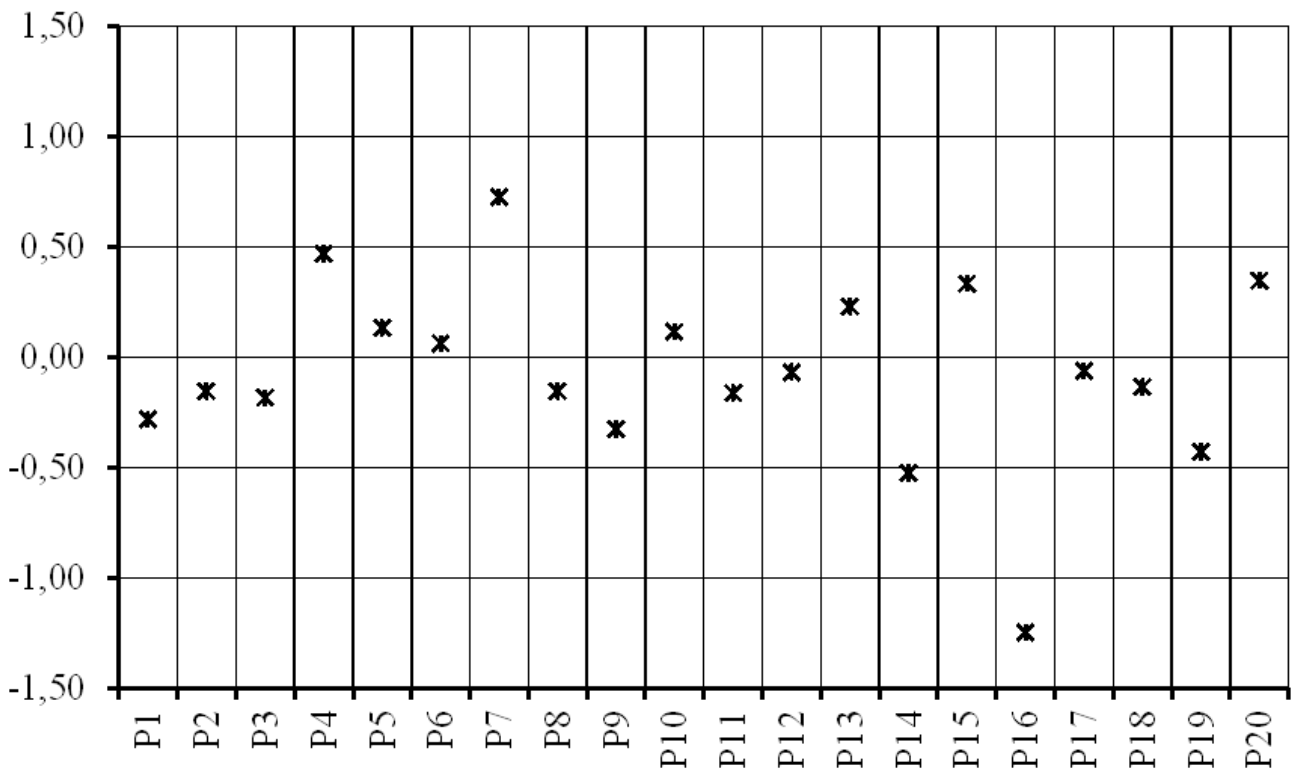

Figura 4.5. Asimetría de las respuestas de la encuesta final. 


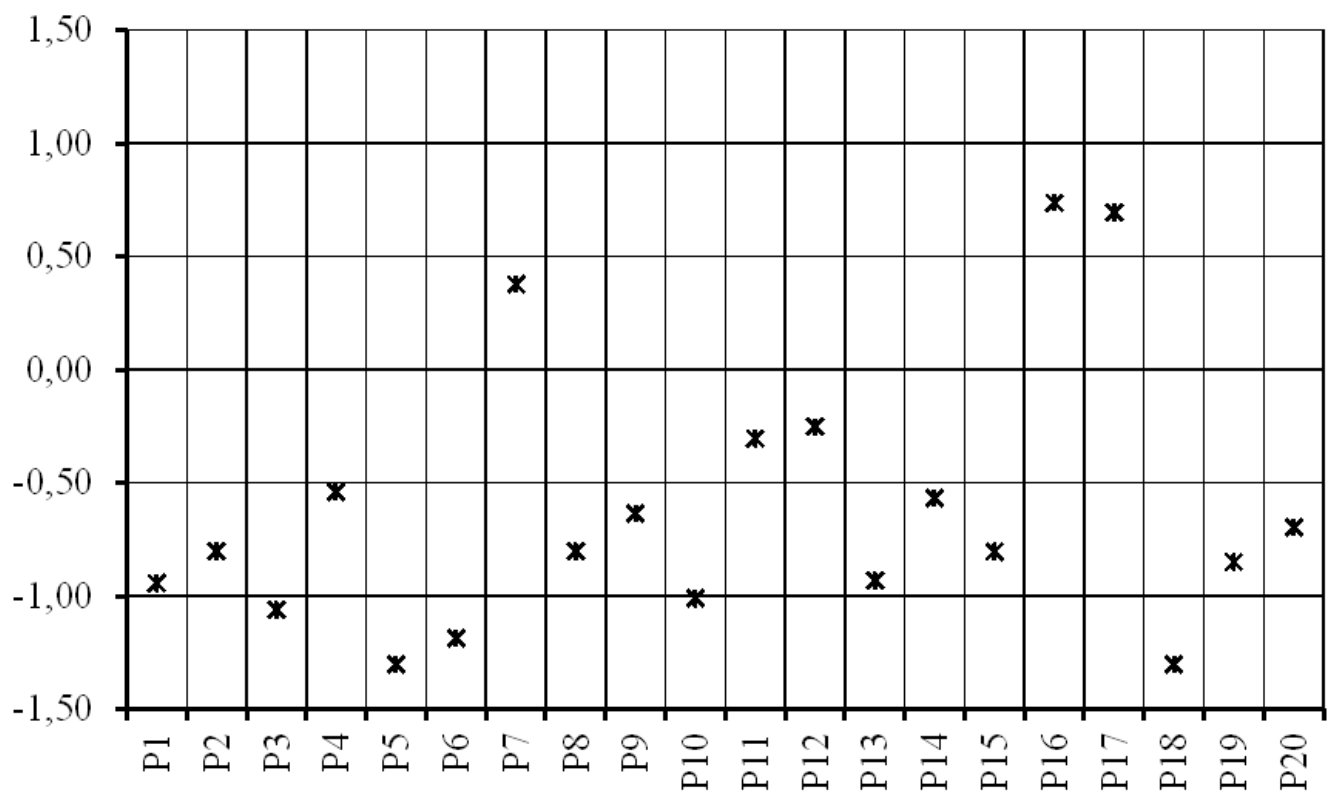

Figura 4.6. Curtosis de las respuestas de la encuesta final.

Si observamos la Figura 4.5, podemos ver como todas las puntuaciones son relativamente simétricas, comprendidas en el rango de una distribución normal. El argumento P7 (con oblicuidad positiva) y los argumentos P14 y P16 (con oblicuidad negativa) fueron los que presentaron un mayor grado de asimetría. En el caso del argumento P7, la oblicuidad positiva revela que las puntuaciones estaban asimétricamente dispersas hacia valores más pequeños que la media, lo que refuerza la necesidad detectada de mejorar el diseño de la interfaz de CADI. Sin embargo, para los argumentos P14 y P16, la oblicuidad negativa muestra el comportamiento contrario al caso anterior, ya que las puntuaciones se encuentran asimétricamente dispersas hacia valores más grandes que la media, lo que nos asegura que las valoraciones de los estudiantes fueron más positivas que las observadas en media en relación a esos argumentos (transparencia de operación, operatividad y facilidad de uso de CADI), lo que concuerda con las puntuaciones dadas por los estudiantes a los argumentos P5 y P9.

Por otra parte, los resultados del análisis de curtosis se muestran en la Figura 4.6 En este caso, todos los valores obtenidos se encuentran por debajo de dos veces el error estándar (1.88), calculado como la raíz cuadrada de 24 dividido por N. Por ello, podemos asegurar que en la distribución no existen datos atípicos y que, por tanto, todos los encuestados rellenaron de forma concienzuda la encuesta... 


\subsubsection{Perspectiva de los profesores respecto a la experiencia}

Uno de las principales preocupaciones de los docentes antes de comenzar la experiencia era que el ritmo de las clases pudiera verse afectado debido al uso de la plataforma durante las mismas, provocando largos parones o retrasando las explicaciones. En principio se pensó que estos retrasos serían principalmente debidos a la lenta interacción de los estudiantes con sus dispositivos o incluso a la falta de entrenamiento de los docentes con este tipo de plataformas sobre cómo explotar sus recursos. Sin embargo, después de realizar la experiencia cambiaron por completo esas concepciones iniciales: en primer lugar, los estudiantes mostraron una enorme capacidad de interacción con sus dispositivos desde el inicio, lo que promovió indirectamente su aprendizaje activo. Es más, no sólo no tuvieron problemas en interactuar con los dispositivos de forma rápida y ágil, explotando desde el principio todos los recursos que les brindaba el sistema CADI, sino que propusieron nuevas funcionalidades muy interesantes para futuros desarrollos de la plataforma. Como se ha comentado, las interacciones fueron rápidas y eficientes y, en ese sentido, el ritmo de las clases se mantuvo intacto.

Debido a la naturaleza genérica del sistema desarrollado, la experiencia pudo ser llevada a cabo obedeciendo a distintos modelos de enseñanza que promovían el aprendizaje activo en los estudiantes (Alonso et al., 2005; Hoic-Bozic et al., 2009; Holbert \& Karady, 2009), obteniéndose particularmente buenos resultados con el descrito en Holbert \& Karady (2009). En este modelo concreto, se introducen brevemente los conceptos teóricos y entonces los alumnos se familiarizan con ellos y con algunas herramientas matemáticas básicas (básicamente, ecuaciones) para finalmente aplicar lo aprendido usando ordenadores y sistemas basados en TIC.

$\begin{array}{lllll}2006 / 2007 & 2007 / 2008 & 2008 / 2009 & 2009 / 2010\end{array}$

Puntuación de los alumnos para los profesores (sobre 10)

7.27

6.58

7.05
9.2

Tabla 4.7. Resultados de la encuesta del Gabinete de Calidad de la UPCT.

Finalmente, la Tabla 4.7 muestra cómo los profesores involucrados en este proyecto piloto (que fueron los mismos que en los años anteriores) recibieron una puntuación sustancialmente más alta en las encuestas realizadas de forma anual por el 
Gabinete de Calidad de la UPCT. Este hecho ratifica una vez más la gran predisposición de los estudiantes hacia la incorporación de sistemas de enseñanza apoyados en las TIC $\mathrm{y}$, en particular, hacia el sistema CADI, que aportó un nuevo canal de comunicación entre profesor y alumnos en la experiencia. 


\section{Capítulo 5. Conclusiones}

En este documento se ha dado una perspectiva del trabajo realizado en la línea del desarrollo de herramientas docentes innovadoras basadas en las TIC y su aplicación práctica. Así, basados en un estudio del estado del arte y una extensa documentación anterior (para identificar las líneas de acción actuales, los problemas comunes y los cuellos de botella de esta área de investigación), se ha diseñado y desarrollado un sistema interactivo llamado CADI. Su elaborado diseño permite que sobre él se dé la unificación de muchos aspectos comunes de varias modalidades de e-learning. El resultado es una plataforma de comunicaciones cuya funcionalidad se solapa con la de muchos de estos sistemas, abarcándola. Así, como si de una moderna librería software se tratara, el profesor puede seleccionar y escoger de entre los recursos desarrollados (llamados Unidades Básicas de Comunicación, UBCs en este documento) para crear infinidad de actividades y experiencias didácticas diferentes con los estudiantes. Además, estas UBCs se pueden usar de forma independiente o mezclarse en tipo o número y agruparse como se desee para dar lugar a entidades de nivel superior para componer recursos más complejos y específicos... En definitiva, el sistema provee un framework completo para la creación, desarrollo e implementación de actividades docentes heterogéneas.

Desde su concepción y su diseño, se ha prestado mucha atención a maximizar la compatibilidad del sistema con dispositivos móviles completamente heterogéneos y, en este sentido, su desarrollo representa una importante contribución a esta área de investigación porque el sistema se encarga de lidiar con la falta de estandarización existente en cuanto a las capacidades de los dispositivos móviles actuales. Así, la plataforma es capaz de identificar de forma automática el agente de usuario y el hardware de cada dispositivo conectado para proveerlo de la versión correcta de los contenidos de la plataforma, adaptados a cada dispositivo para su correcta visualización por parte de los estudiantes.

Finalmente, el subsistema de estadísticas e informes desarrollado para la plataforma brinda al docente información útil y en tiempo real que puede (y debe) ser usada de forma activa en cualquier momento para ir rellenando las lagunas detectadas 
en el proceso de aprendizaje de los alumnos o para prevenir el fracaso de los mismos, entre otros muchos aspectos.

El trabajo presentado en esta tesis demuestra, a través de la realización de un proyecto piloto, que el despliegue e implementación de este sistema de e-learning genérico ha tenido éxito en su objetivo principal de mejorar la calidad de la enseñanza ofreciendo, a su vez, una serie de ventajas también en el proceso de aprendizaje de los estudiantes.

El impacto pedagógico resultante ha sido considerable en los estudiantes involucrados en el proyecto piloto, tal y como demuestran los resultados académicos obtenidos con respecto a años anteriores y las puntuaciones del sistema en la encuesta final realizada. Todos estos resultados son muy motivadores para continuar con el desarrollo y la constante mejora del sistema CADI. Además, la realización del proyecto piloto ha ayudado de hecho a reafirmar algunos conceptos iniciales: los beneficios teóricos esperados en un principio del uso de una plataforma como CADI se corresponden muy estrechamente con los beneficios empíricos observados en los alumnos involucrados, ya que la calidad de la enseñanza recibida aumentó sustancialmente. El proyecto piloto también puso de manifiesto que el sistema desarrollado puede ser usado eficientemente en un rango más amplio de actividades y situaciones que cualquiera de las plataformas existentes y encuadradas dentro de una modalidad de e-learning concreta, ofreciendo así una experiencia más rica a los usuarios.

El sistema CADI, al igual que cualquier plataforma de e-learning moderna, cumple con todas las especificaciones esperadas en este tipo de sistemas, como la integración de mecanismos de feedback para el profesor, la usabilidad, el nivel de eficiencia o el control de la calidad, entre muchos otros. Así, la consecución exitosa del proyecto piloto con CADI en la UPCT sin duda acerca a esta plataforma hacia el desarrollo de un nuevo tipo de sistema de e-learning. Este proyecto y el análisis realizado con él constituyen un buen punto de partida para el estudio de los efectos que tienen estos sistemas sobre los estudiantes en entornos docentes.

Para terminar, y como líneas futuras, se proponen aquí una serie de funcionalidades o características para el sistema CADI. Curiosamente, la mayoría de ellas surgieron a partir de las sugerencias de los propios estudiantes: la integración de recursos multimedia a la plataforma (por ejemplo, transparencias con los contenidos, e- 
books, manuales y tutoriales, imágenes y vídeos asociados a cierta pregunta en una competición, etc.) o la creación de un foro genérico para cada asignatura específica que permita compartir puntos de vista, información, opiniones, materiales, etc. entre los estudiantes. Esta última característica es especialmente interesante ya que CADI se sirve de tecnologías web (concretamente en un servidor web), y podría ser fácilmente configurado para ser accedido a través de Internet, permitiendo a los estudiantes interactuar con él desde cualquier ubicación y en cualquier momento (como si se tratara de un sistema de BL).

Sin embargo, existen ciertas funcionalidades identificadas por los profesores y por el propio autor a partir del uso extensivo de la plataforma como el enriquecimiento del subsistema de estadísticas e informes, que tanta importancia tiene por proporcionar una valiosa información a los docentes. De hecho, se están desarrollando en la actualidad nuevos módulos estadísticos y de procesamiento de los datos de la plataforma. Además, el CMS Typo3 cuenta con una extensión que permite importar contenidos SCORM (Sharable Content Object Reference Model) sin procesar. En pocas palabras, SCORM consiste en una colección de estándares y especificaciones sobre el elearning basado en tecnologías web. Define las comunicaciones entre los contenidos del lado del cliente y un sistema host llamado entorno de ejecución (una función común en los LMSs). En este sentido, se está desarrollando también una extensión que importa contenidos SCORM sin procesar para directamente poblar con información UBCs. Esta extensión actuará de interfaz entre el contenido SCORM (extrayendo la información) para importarla procesada en la nueva UBCs de forma transparente para el profesor / administrador. Algunas de estas nuevas funcionalidades han sido recientemente incorporadas, pero aún no han sido probadas con estudiantes, por lo que no hay información de uso disponible. 


\section{Bibliografía y referencias}

Allen, B., McAlpine, I., Hoffman, M. \& Munroe, P. (2009). A blended approach to collaborative learning: making large group teaching more student-centred. International Journal of Engineering Education, 25(3), 569-576.

Alonso, F., Viñes, J. M., López, G. \& Manrique, D. (Marzo 2005). Instructional model for e-learning with a blended learning process approach. British Journal of Educational Technology, 36(2), 217-235.

Anido-Rifon, L. (Abril 2008). Accessibility and supporting technologies in mlearning standardization. The 3rd International Conference on Systems, ICONS'08, Cancun, $162-167$.

Area, M. (2005). Internet y la calidad de la educación superior en la perspectiva de la convergencia europea, Revista española de Pedagogía, 63 (230), 85-100.

Ariño, A. (2009). La dimensión social y la innovación en el Espacio Europeo de Educación Superior, @ tic. Revista de innovación educativa, 2, 2-9.

Bates, T. (2002). Aspectos culturales y éticos en la educación internacional a distancia, Programa de doctorado interdisciplinar e internacional sobre la Sociedad de la Información y el Conocimiento. Universitat Oberta de Catalunya.

Beatty, I. D., Gerace, W. J., Leonard, W. J. \& Dufresne, R. J. (2006). Designing effective questions for classroom response system teaching, American Association of Physics Teachers, 74(1), 31-39.

Beekes, W. (2006). The "Millionaire" method for encouraging participation, Active Learning in Higher Education, 7, 25-36.

Berry, J. (2009). Technology Support in Nursing Education: Clickers in the Classroom, Nursing Education Perspectives, ProQuest Health and Medical Complete, 30(5), 295298.

Bode, M., Drane, D., Kolikant, B-D.Y. \& Schuller, M. (Febrero 2009). A Clicker Approach to Teaching Calculus, Notices of the AMS, 56(2), 253-256.

Boekaerts, P., Pintrich, P. R. \& Zeidner, M. (2000). Handbook of self-regulation, Elsevier Academic Press, EE. UU. 
Bousbia, N., Labat, J. -M., Rebai, I. \& Balla, A. (Julio 2009). Indicators for deducting the learners' learning styles: case of the navigation typology indicator. Proceedings of 9th International Conference on Advanced Learning Technology, ICALT'09, Riga (Latvia), 385-389.

Brown, E. J., Brailsford, T. J., Fisher, T. \& Moore, A. (Enero-Marzo 2009). Evaluating learning style personalization in adaptive systems: quantitative methods and approaches. IEEE Transactions on Learning Technologies, 2(1), 10-22.

Cabero, J. (2001). Tecnología educativa. Diseño y utilización de medios en la enseñanza, Barcelona, ediciones Paidós Ibérica.

Cabero, J. (2005). Las TIC y las Universidades: retos, posibilidades y preocupaciones, Revista de la Educación Superior XXXIV, 3, 77-100.

Cabero, J. (2006). Formación del profesorado universitario en estrategias metodológicas para la incorporación del aprendizaje en red en el Espacio Europeo de Educación Superior, Pixel-bit. Revista de medios y educación, 72, 11-29.

Cabrera Lozoya, A., Cerdán, F., Cano, M.-D., García Sánchez, D. \& Luján, S. (2012a). Estudio del estado del arte en el campo de la innovación educativa, Revista de las V Jornadas de la Asociación de Jóvenes Investigadores de Cartagena, AJICT-UPCT 2012.

Cabrera-Lozoya, A., Cerdan, F., Cano, M.-D., Garcia-Sanchez, D. \& Lujan, S. (2012b). Unifying heterogeneous e-learning modalities in a single platform: CADI, a case study, Computers \& Education, 58(1), 617-630. Índice de impacto JCR 2011: 2,617 .

Cabrera-Lozoya, A., Cerdan, F., Lujan, S. \& Garcia-Sanchez, D. (Agosto 2011). Design and Implementation of a Cooperative Protocol for Extending Coverage in Wireless Mesh Networks. The Fourth International Conference on Advances in Mesh Networks, MESH 2011, 26-32, awarded as one of the Conference's "Best Papers" based on the reviews of the original submission, the camera-ready version, and the presentation during the conference. [Diploma].

Cabrera-Lozoya, A., Cerdan, F., Lujan, S. \& Garcia-Sanchez, D. (2012). Extending Coverage in Wireless Mesh Networks: the xTender Cooperative Protocol. IARIA 
International Journal on Advances in Networks and Services, 5, ISSN: 1942-2644. En revisión.

Cabrera-Lozoya, A., Lujan, S. \& Cerdan, F. (2008). Desarrollo de un sistema interactivo de enseñanza basado en el uso de PDAs. VI Telecofórum, Universidad Politécnica de Cartagena. Edición 2008. ISSN 1968-2924.

Cano, M.-D., Martínez-Rojo, A., Sánchez-Iborra, R., Cabrera-Lozoya, A. \& Cerdán, F. (Enero-Febrero 2012). PLAIME: Multimedia Platform for the Integration of Handicapped Children in Music Education, The Fourth International Conference on Mobile, Hybrid, and On-line Learning, eL\&mL 2012, Valencia, Spain, 90-93.

Castro-Schez, J. J., Del Castillo, E., Hortolano, J. \& Rodriguez, A. (Febrero 2009). Designing and using software tools for educational purposes: FLAT, a case study. IEEE Transactions on Education, 52(1), 66-74.

Chafer, E. (2009). Una introducción a los sistemas de respuesta interactiva, Electrónica y Comunicaciones. Monográfico TICs en las aulas. Elementos Didácticos para la enseñanza, 242, 56-57.

Clearly, A.M. (2008). Using Wireless Response Systems to Replicate Behavioral Research Findings in the Classroom, Teaching of Psychology, 35(1), 42-44.

Comisión Europea. (2000). Designing tomorrow's education: Promoting innovation with new technologies, Bruselas, Report from the Commission to the Council and the European Parliament EU, 38 páginas.

Costa, R. J., Honkala, M. \& Lehtovuori, A. (Febrero 2007). Applying the problembased learning approach to teach elementary circuit analysis. IEEE Transactions on Education, 50(1), 41-48.

Dan, Y. \& XinMeng, C. (Febrero 2007). Supporting collaborative learning activities with IMS LD. Proceedings of the 9th International Conference on Advanced Communication Technology, ICACT'07, Phoenix Park (Korea), 316-320.

Daradoumis, T., Martínez-Mones, A. \& Xhafa, F. (Julio 2006). A layered framework for evaluating on-line collaborative learning interactions. International Journal of Human-Computer Studies, 64(7), 622-635.

De Benito, B. \& Salinas, J. (Marzo 2008). Los entornos tecnológicos en la universidad, Pixel-bit. Revista de medios y educación, 32, 83-101. 
DeBord, K. A., Aruguete, M. S. \& Muhlig, J. (2004). Are computer-assisted teaching methods effective?, Teaching of Psychology, 31, 65-68.

De Oliveira, R. \& Da Rocha, H. V. (Julio 2007). Conceptual multi-device design on the transition between e-learning and m-learning. Proceedings of 7th International Conference on Advanced Learning Technology, ICALT'07, Niigata (Japan), 332-334.

Delgado, A. M. \& Oliver, R. (2006). La evaluación continua en un nuevo escenario docente. Revista de Universidad y Sociedad del Conocimiento, Universitat Oberta de Catalunya, 3(1), 1-13.

Dewey, J. (2004). Comment nous pensons, Paris, Ed. Empecheurs de penser en rond, Sciences humaines edition, 293 páginas.

Draper, S. W., Cargill, J. \& Cutts, W. (2002). Electronically enhanced classroom interaction, Australian Journal of Educational Technology, 18(1),13-23.

Economides, A. A. (2008). Evaluation of handheld devices for mobile learning. International Journal of Engineering Education, 24(1), 3-13.

Ellis, R. A. \& Calvo, R. A. (2007). Minimum indicators to assure quality of LMSsupported blended learning. Journal of Educational Technology \& Society, 10(2), 6070.

Estrems-Amestoy, M., Sanchez-Reinoso, T., Franco-Chumillas, P., Cerdan, F., GarciaSánchez, D. \& Cabrera-Lozoya, A. (2008). Aplicación de instrumentos móviles con tecnología WiFi para la mejora del aprendizaje en clase. I Jornadas de Nuevas Tendencias en la Enseñanza de las Ciencias y las Ingenierías. Comunicaciones Murciencia. Edición 2008.

Evans, C. (Febrero 2008). The effectiveness of m-learning in the form of podcast revision lectures in higher education. Computers \& Education, 50(2), 491-498.

Felder, R.-M. \& Silverman, L.-K. (1988). Learning and Teaching Styles In Engineering Education. Engineering \& Education, 78(7), 674-681.

Fitzpatrick, C. (Mayo 2008). A problem based learning (PBL) module on electronics \& the environment. The 16th IEEE International Symposium for Engineering Education, ISEE'08, San Francisco, 1-6. 
Freeman, S., O’Connor, E., Parks, J.W., Cunningham, M., Hurley, D., Haak, D., Dirks, C. \& Wenderoth, M.P. (2007). Prescribed Active Learning Increases Performance in Introductory Biology, CBE-Life Science Education, 6, 132-139.

Frohberg, D., Gothe, C. \& Schwabe, G. (Abril 2009). Mobile learning projects - a critical analysis of the state of the art. Journal of Computer Assisted Learning, 25(4), $307-331$.

Gálvez, J., Guzmán, E. \& Conejo, R. (Mayo 2009). A blended E-learning experience in a course of object oriented programming fundamentals. Knowledge-Based Systems, 22(4), 279-286.

García Aretio, L. (2002). Lo que cambia y lo que no cambia en la educación a distancia de hoy. Revista Red Digital, 1, 17 páginas.

García Aretio, L. (2006). La educación a distancia, de la teoría a la práctica. Barcelona, Editorial Ariel, 328 páginas.

Garcia-Robles, R., Diaz-del-Rio, F., Vicente-Diaz, S. \& Linares-Barranco, A. (Agosto 2009). An eLearning standard approach for supporting PBL in computer engineering. IEEE Transactions on Education, 52(3), 328-339.

García-Sánchez, D., Cerdán, F., Cano, M.-D., Cabrera-Lozoya, A., Luján-Fernández, S. \& Almagro-Carrión, S. (2010). Evaluación Experimental de Tráfico IP Multimedia sobre una Red Wimax. Espacio-Teleco. Revista de la ETSIT - UPCT, Universidad Politécnica de Cartagena, 1, 11-18. ISSN 2171-2042.

Gardner, H. (2001). La inteligencia reformulada: Las inteligencias múltiples en el siglo XXI. Edición 2010. Editorial Paidós Ibérica. ISBN - 9788449310294. 270 páginas.

Gauci, S.A., Dantas, A.M., Williams, D.A. \& Kemm, R.E. (2009). Promoted Studentcentered Active Learning in Lectures with a Personal Response System, $A d v$. Physiology Education, 33, 60-71.

Georgouli, K., Skalkidis, I. \& Guerreiro, P. (2008). A framework for adopting LMS to introduce e-learning in a traditional course. Journal of Educational Technology \& Society, 11(2), 227-240.

Gomez-Sanchez, E., Bote-Lorenzo, M. L., Jorrin-Abellan, I. M., Vega-Gorgojo, G., Asensio-Perez, J. I. \& Dimitriadis, Y. A. (2009). Conceptual framework for design, 
technological support and evaluation of collaborative learning. International Journal of Engineering Education, 25(3), 557-568.

González-Rosende, M. E., Vega, S., Girbés, M.S., Ortega, J., Segura, E. \& Hernández, J.M. (2008). La Evaluación Continua en el Espacio Europeo de Educación Superior, VI Jornadas de Redes de Investigación en Docencia Universitaria. Universidad de Alicante.

Greer, L. \& Heaney, P. J. (2004). Real-time analysis of student comprehension: An assessment of electronic student response technology in an introductory earth science course, Journal of Geoscience Education, 52(4), 345-351.

Hamada, M. (Abril-Junio 2008). An integrated virtual environment for active and collaborative e-Learning in theory of computation. IEEE Transactions on Learning Technologies, 1(2), 117-130.

Hanson, C. M., Graham, C. R. \& Seawright, L. (2008). An evaluation of the effectiveness of the instructional methods used with a Student Response System at a large university, Interactive Educational Multimedia, 17, 29-47.

Hill, W. (1976). Teorías contemporáneas del aprendizaje, Editorial Paidós. Buenos Aires.

Hoic-Bozic, N., Mornar, V. \& Boticki, I. (Febrero 2009). A blended learning approach to course design and implementation. IEEE Transactions on Education, 52(1), 19-30.

Holbert, K. E. \& Karady, G. G. (Febrero 2009). Strategies, challenges and prospects for active learning in the computer-based classroom. IEEE Transactions on Education, 52(1), 31-38.

Hongru, Q., Wang, M., Tong, R., Shen, R., Wang, J. \& Gao, Y. (Julio 2006). The design and implementation of an interactive mobile learning system. Proceedings of 6th International Conference on Advanced Learning Technology, ICALT'06, Kerkrade (Netherlands), 947-951.

Huang, Y. M., Kuo, Y. H., Lin, Y. T. \& Cheng, S. C. (Noviembre 2008). Toward interactive mobile synchronous learning environment with contextawareness service. Computers \& Education, 51(3), 1205-1226. 
Huh, S., Lee, K. \& Jin, J.J. (2008). Does an Audience Response System Called Clicker Help Student Learning in Accounting, Proceedings of the Academy of Accounting and Financial Studies, 13(2), 4-7.

Hung, S. Y., Chen, C. C. \& Lee, W. J. (2009). Moving hospitals toward elearning adoption: an empirical investigation. Journal of Organizational Change Management, 22(3), 239-256.

Hurtado, C. \& Guerrero, L. A. (Abril 2009). A PDA-based collaborative tool for learning chemistry skills. Proceedings of the 13th International Conference on Computer Supported Cooperative Work in Design, CSCWD'09, Santiago de Chile, $378-383$.

Inglis, A et al. (Enero 2002). Delivering digitally, managing the transition to the knowledge media. London. Editorial Kogan Page. 272 páginas.

Jay, E. S. \& Perkins, D. N. (1997). Problem finding: The search for mechanism. The creativity research handbook, Cresskill, New Jersey: Hampton Press, 257-293.

Johnson, M. \& Robson, D. (2008). Clickers, Student Engagement and Performance in an Introductory Economics Course: a Cautionary Tale", Cheer, 20, 4-12.

Judson, E. \& Sawada, D. (2002). Learning from past and present: Electronic response systems in college lecture Shalls, Journal of Computers in Mathematics and Science Teaching, 21(2), 167-181.

Kao, G. Y. -M., Lin, S. S. J. \& Sun, C. -T. (2008). Beyond sharing: engaging students in cooperative and competitive active. Journal of Educational Technology \& Society, 11(3), 82-96.

Kazi, S. A. (2007). MILE: mobile intelligent learning environment - a conceptual framework for mLearning. International Journal of Engineering Education, 23(3), 468473.

Kennedy, G. E. \& Cutts, Q. I. (2005). The association between students' use of an electronic voting system and their learning outcomes, Journal of Computer Assisted Learning, 21, 260-268.

King, S. O. \& Robinson, C. L. (Agosto 2009). 'Pretty Lights' and Maths! Increasing student engagement and enhancing learning through the use of electronic voting systems. Computers \& Education, 53(1), 189-199. 
Konstantinidis, A., Tsiatsos, T. \& Pomportsis, A. (Septiembre 2009). Collaborative virtual learning environments: design and evaluation. Multimedia Tools \& Applications, 44(2), 279-304.

Koretsky, M. D., Amatore, D., Barnes, C. \& Kimura, S. (Febrero 2008). Enhancement of student learning in experimental design using a virtual laboratory. IEEE Transactions on Education, 51(1), 76-85.

Kuo, Y. H. \& Huang, Y. M. (2009). MEAT: an authoring tool for generating adaptable learning resources. Journal of Educational Technology \& Society, 12(2), 51-68.

Laine, T. H., Sedano, C. I., Vinni, M. \& Sutinen, E. (Julio 2009). Uncovering the richness of an authentic living museum through pervasive learning environment. Proceedings of 9th International Conference on Advanced Learning Technology, ICALT'09, Riga (Latvia), 655-657.

Leacock, T. L. \& Nesbit, J.C. (2007). A framework for evaluating the quality of multimedia learning resources. Journal of Educational Technology \& Society, 10(2), $44-59$.

Legrand, L. (1992). CRESAS, Naissance d'une pédagogie interactive. Revue française de pédagogie, 99(1), 124-125.

Len, P.M. (Septiembre 2006). Different Reward Structures to Motivate Student Interaction with Electronic Response Systems in Astronomy, Astronomy Education Review, 5(2), 5-15.

Linge, N. \& Parsons, D. (Febrero 2006). Problem-based learning as an effective tool for teaching computer network design. IEEE Transactions on Education, 49(1), 5-10.

Liu, T. -C., Lin, Y. -C. \& Bhattacharya, M. (Julio 2008). Introducing learning technologies into classroom in accordance with teacher's instructional approach. Proceedings of 8th International Conference on Advanced Learning Technology, ICALT'08, Santander (Spain), 1007-1008.

Liu, Y., Liu J. \& Yu S. (Diciembre 2008). A Case Study on Mobile Learning Implementation in Basic Education. Proceedings of International Conference on Computer Science and Software Engineering, CSSE'08, Wuhan (China), 5, 593-597. 
Macias-Guarasa, J., Montero, J. M., San-Segundo, R., Araujo, Á. \& Nieto-Taladriz, O. (Agosto 2006). A project-based learning approach to design electronic systems curricula. IEEE Transactions on Education, 49(3), 389-397.

Mallinson B. \& Nyawo, N. (2008). A proposed theoretical model for evaluating elearning. Multi-Conference in Computer Science and Information Systems; Proceedings on e-Learning, MCCSIS'08 - IADIS, Amsterdam, 411-418.

Martin, E. \& Carro, R. M. (Enero-Marzo 2009). Supporting the development of mobile adaptive learning environments: a case study. IEEE Transactions on Learning Technologies, 2(1), 23-36.

Martín-Laborda, R. (2005). Las nuevas tecnologías en la educación, Cuadernos/Sociedad de la Información. Fundación Auna.

Martinez-Torres, M. R., Toral, S. L. \& Barrero, F. (Mayo 2011). Identification of the design variables of eLearning tools. Interacting with Computers, 23(3), 279-288.

Martinez-Torres, M. R., Toral, S. L., Barrero, F., Gallardo, S., Oliva, M. \& Torres, T. (Noviembre 2008). A technological acceptance of e-learning tools used in practical and laboratory teaching, according to the European higher education area. Behaviour and Information Technology, 27(6), 495-505.

Matesic, M.A. \& Adams, J.M. (2008). Provocation to Learn - A Study in the Use of Personal Response Systems in Information Literacy Instruction, Partnership: the Canadian Journal of Library and Information Practice and Research, 3(1), 1-14.

Mazur, E. (1997). Peer Instruction: A User's Manual, Series in Educational Innovation, Prentice Hall, Upper Saddle River, NJ, 253 pages.

Mazur, E. (Noviembre 2006). Interactive Teaching DVD: Promoting Better Learning Using Peer Instruction and Just-In-Time Teaching.

Medina, M.S., Medina, P.J., Wanzer, D.S., Wilson, J.E., Er, N. \& Britton, M.L. (2008). Innovations in Teaching: Use of an Audience Response System (ARS) in a DualCampus Classroom Environment, American Journal of Pharmaceutical Education, $72(2), 1-7$.

Mikic, F., Anido, L., Valero, E. \& Picos, J. (Abril 2007). Accessibility and mobile learning standardization. The 2th International Conference on Systems, ICONS'07, Martinique, 32-37. 
Mondi, M., Woods, P. \& Rafi, A. (2008). A 'uses and gratification expectancy model' to predict students' perceived e-Learning experience. Journal of Educational Technology \& Society, 11(2), 241-261.

Morling, B., McAuliffe, M., Cohen, L. \& DiLorenzo, T.M. (2008). Efficacy of Personal Response Systems (“Clickers”) in Large, Introductory Psychology Classes, Teaching of Psychology, 35(1), 45-50.

Motiwalla, L. F. (Noviembre 2007). Mobile learning: a framework and evaluation. Computers \& Education, 49(3), 581-596.

Nelson, M.L. \& Hauk, R.V. (2008). Clicking to Learn: A Case Study of Embedding Radio-Frequency based Clickers in a Introductory Management Information SystemsCourse, Journal of Information Systems Education, 19(1)55-64.

Ozpolat, E. \& Akar, G. B. (Septiembre 2009). Automatic detection of learning styles for an e-learning system. Computers \& Education, 53(2), 355-367.

Parsons, D., Hokyoung, R. \& Cranshaw, M. (Julio 2006). A study of design requirements for mobile learning environments. Proceedings of 6th International Conference on Advanced Learning Technology, ICALT'06, Kerkrade (Netherlands), 96-100.

Pemberton, J. R., Borrego, J., \& Cohen, L. M. (2006). Using interactive computer technology to enhance learning, Teaching of Psychology, 33, 145-147.

Piaget, J. (1975). Seis estudios de psicología (Six études de psychologie). Editorial Barral, Barcelona, 199 páginas.

Pintrich, Paul R. (1995). Understanding Self-Regulated Learning. New Directions for Teaching and Learning, Jossey-Bass Publishers, EE. UU, 63, Fall 1995.

Regueras, L. M., Verdu, E., Munoz, M. F., Perez, M. A., de Castro, J. P. \& Verdu, M. J. (2009). Effects of competitive e-learning tools on higher education students: a case study. IEEE Transactions on Education, 52(2), 279-285.

Richardson, I. \& Delaney, Y. (Febrero 2009). Problem based learning in the software engineering classroom. Proceedings of the 22nd Conference on Software Engineering Education and Training, CSEET'09, Hyderabad (India), 174-181. 
Roca, J. C., Chiu, C. M. \& Martinez, F. J. (Agosto 2006). Understanding e-learning continuance intention: An extension of the Technology Acceptance Model. International Journal of Human-Computer Studies, 64(8), 683-696.

Ruiz Jiménez, A., Ceballos Hernández, C., González Guzmán, N., Ortega Fraile, F.J., Ríos Fornos, M. \& Delgado Lissen, J. (2010). Enseñanza interactiva en la docencia universitaria. Actas de las XX Jornadas Hispano Lusas de Gestión Científica. Setúbal (Portugal), 4-5.

de febrero de 2010.

Sacristán, M., Garrido, P., Alfalla, R., González, M.M., Moreno, A.M., Ríos, M. \& Ruiz, V.E. (2009). Evaluación a través de plataformas virtuales. Una herramienta para la mejora de la estrategia de enseñanza-aprendizaje, Nuevas enseñanzas de Grado en la Escuela Universitaria de Estudios Empresariales de la Universidad de Sevilla. Servicio de Publicaciones de la Universidad de Granada.

Salinas, J. \& Cabero, J. (2000). Y continuamos avanzando. Las nuevas tecnologías para la mejora educativa. Sevilla, Editorial Kronos, 451-465.

Sancho, P., Corral, R., Rivas, T., Gonzalez, M.J., Chordi, A. \& Tejedor, C. (2006). A blended learning experience for teaching microbiology. American Journal of Pharmaceutical Education, 70(5), art. no. 120.

Schunk H. D. (Diciembre 2001). Self-Regulation through goal setting, ERIC/CASS Digest ED462671.

Shaffer, D. M. \& Collura, M. (2009). Technology and Teaching: Evaluating the Effectiveness of a Personal Response System in the Classroom, Teaching of Psychology, 36, 273-277.

Shen, L., Callaghan, V. \& Shen, R. (Septiembre 2008). Affective e-Learning in residential and pervasive computing environments. Information Systems Frontiers. $10(4), 461-472$.

Shen, L., Wang, M. J. \& Shen, R. (2009). Affective e-Learning: using 'emotional' data to improve learning in pervasive learning environment. Journal of Educational Technology \& Society, 12(2), 176-189. 
Shen, R., Wang, M., Gao, W., Novak, D. \& Tang, L. (2009). Mobile learning in a large blended computer science classroom: system function, pedagogies, and their impact on learning. IEEE Transactions on Education, pendiente de publicación.

Silliman, S. E. \& McWilliams, L. (2004). Observations on benefits/limitations of an audience response system, Proceedings of the 2004American Society for Engineering Education Annual Conference \& Exposition, USA, 1511.

Stowel, J.R. \& Nelson, J.M. (2009). Benefits of Electronic Audience Response Systems on Student Participation, Learning, and Emotion, Teaching of Psychology, 34(4), 253258.

Tello, J. \& Aguaded (Marzo 2010). Desarrollo profesional docente ante los nuevos retos de las tecnologías TIC, Pixel-Bit. Revista de Medios y Educación, 38, 35-48.

Toral, S. L., Barrero, F. \& Martinez-Torres, M. R. (2007). Analysis of utility and use of a web-based tool for digital signal processing teaching by means of a technological acceptance model. Computers \& Education, 49(4), 957-975.

Valdivia, R. \& Nussbaum, M. (2007). Face-to-face collaborative learning in computer science classes. International Journal of Engineering Education, 23(3), 434-440.

Vygostki, L. S. (Marzo 2000). El desarrollo de los procesos psicológicos superiores, Editorial Crítica, Barcelona, España, 224 páginas.

Wang, M. J., Novak, D. \& Shen, R. M. (Agosto 2008). Assessing the effectiveness of mobile learning in large hybrid/blended classrooms. Proceedings of 1st International Conference on Hybrid Learning and Education, ICHL'08, Hong Kong (China), 304315.

Wattinger, C., Guggisberg, M., Burkhart, H., Nguyen, D. P., Gyalog, T. \& Fornaro, P. (Julio 2006). Problem-based learning using mobile devices. Proceedings of 6th International Conference on Advanced Learning Technology, ICALT'06, Kerkrade (Netherlands), 835-839.

Weerts, S. E., Miller, D. \& Altice, A. (2009). Clicker Technology Promotes Interactivity in an Undergraduate Nutrition Course, Journal of Nutrition Education and Behavior, 41(3), 227-228. 
Yang, S. J. H. \& Chen, I. Y. L. (Julio 2006). Providing context aware learning services to learners with portable devices. Proceedings of 6th International Conference on Advanced Learning Technology, ICALT'06, Kerkrade (Netherlands), 840-842.

Yang, S. J. H. \& Chen, I. Y. L. (Julio 2006). Universal access and content adaptation in mobile learning. Proceedings of 6th International Conference on Advanced Learning Technology, ICALT'06, Kerkrade (Netherlands), 1172-1173.

Zabala Vidiella, A. (1998). Las relaciones interactivas en clase. El papel del profesorado y del alumno, Barcelona Gaó, Serie pedagógica 120, 91-113.

Zimmerman, B. J. (1989). Models of Self-Regulated and Academic Achievement. Ed. Self Regulated Learning and Academic Achievement. Springer-Verlag, Michigan, EE. $U U$.

Zimmerman, B. J., Kitsantas, A., y Campillo, M. (Julio 2005). Evaluación de la autoeficacia regulatoria. Revista Evaluar, 5.

Zurita, G. \& Nussbaum, M. (Marzo 2007). A conceptual framework based on activity theory for mobile CSCL. British Journal of Education and Technology, 38(2), 211-235. 
Anexos 


\section{Anexo I}

Encuesta final sobre la utilización del sistema CADI 


\section{CUESTIONARIO DE EVALUACIÓN CADI}

Por favor, rellena este cuestionario. La información que nos proporciones será utilizada para conocer el grado de aceptación y beneficio en la docencia de este nuevo servicio. La encuesta dura aproximadamente 5 minutos. Muchas gracias por tu colaboración.

(Marca con una X la puntuación que consideres más acorde con tu opinión sobre el sistema)

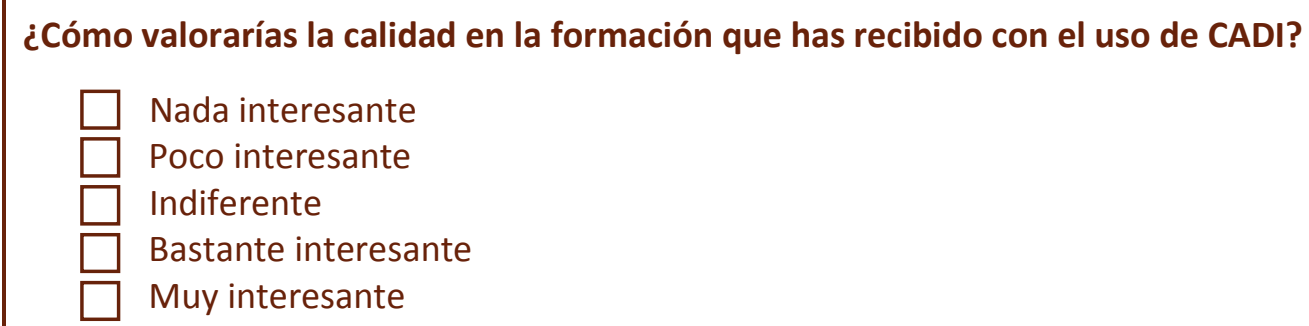

¿Qué opinas de este nuevo servicio en el sistema educativo?

No lo necesito. No ayuda

Es aburrido y complicado. No aporta ningún beneficio

Me es indiferente

Es interesante y útil

Es muy útil y necesario. Me gusta mucho. Ayuda

\begin{tabular}{|c|c|c|c|c|c|}
\hline \multirow{2}{*}{\multicolumn{6}{|c|}{ Simplicidad }} \\
\hline & & & & & \\
\hline \multicolumn{6}{|l|}{ Facilidad de uso } \\
\hline \multicolumn{6}{|l|}{ Accesibilidad } \\
\hline \multicolumn{6}{|l|}{ Diseño } \\
\hline \multicolumn{6}{|l|}{ Utilidad } \\
\hline \multicolumn{6}{|l|}{ Funcionalidad } \\
\hline \multicolumn{6}{|l|}{ Comodidad } \\
\hline \multicolumn{6}{|l|}{ Calidad } \\
\hline Valoración global & & & & & \\
\hline
\end{tabular}

(1 = Muy poco, 2 = Poco, 3 = Regular, 4 = Bastante, 5 = Mucho)

Indica tu grado de satisfacción con los siguientes aspectos de CADI...

Facilidad en la implantación del sistema Ayuda en la aclaración de las explicaciones

Transparencia en su funcionamiento Promoción de la comunicación con el profesor

Operatividad, facilidad y agilidad de uso Valoración global

(1 = Nada satisfactorio, 2 = Poco satisfact., 3 = Indiferente, 4 = Satisfact., 5 = Muy satisfact.) 
¿Has tenido oportunidad de participar activamente en la exposición?

$\square$ Sí

No

¿Es la primera vez que participas en clases con CADI o un sistema similar?

Sí

No

En cuanto a las metas pedagógicas que se persiguen con un sistema de enseñanza interactivo como CADI... ¿Se han satisfecho tus expectativas?

Sí, el sistema ayuda a resaltar los aspectos que quedan dudosos en la explicación Sólo en parte. El sistema no aporta ningún beneficio adicional

No, han quedado asuntos pendientes con las explicaciones...

En cuanto al ritmo de la clase... ¿Cómo ha afectado la presencia y uso del sistema CADI?

La clase se ha desarrollado de manera eficiente

La clase se ha desarrollado razonablemente bien

El ritmo de la clase no ha sido eficiente

La clase ha sido una pérdida de tiempo

¿Recomendarías trabajar con este sistema a otros compañeros o profesores?

$\square$ Sí

No

¿Cómo valoras las ventajas que te ofrece CADI?

Excelente. Resolvió todas mis dudas

Aceptable. Es lo que esperaba de un sistema como éste

Deficiente. Debe mejorar muchos aspectos

No lo he utilizado

¿Tienes algún comentario o sugerencia para futuras clases con CADI? Escríbelo a continuación.

¿En qué aspectos crees que podría mejorar el sistema CADI? Escríbelos a continuación.

Por último, valora de 1 a 10 el nivel de satisfacción de tu experiencia con CADI.

$\begin{array}{llllllllll}\square & \square & \square & \square & \square & \square_{6} & \square & \square & \square & \square \\ 1 & 2 & 3 & 4 & 5 & 6 & 7 & 8 & 9\end{array}$

Muchas gracias por tu colaboración y tu tiempo. 


\section{Anexo II}

Breve manual de usuario del sistema CADI 


\section{CADI - Breve manual de usuario}

\section{Introducción}

Este anexo explica de forma muy breve la interacción de los usuarios con el sistema, a modo de manual. Se aborda así la descripción de dicha interacción asumiendo los dos roles posibles: como profesor o ponente y como alumno o asistente.

Asimismo, se asume a partir de este punto que existe una instancia del sistema CADI operativa en el escenario de prueba que, recordemos, consta únicamente del servidor de contenidos dedicado de CADI y de un punto de acceso WiFi que, a su vez, despliega la red inalámbrica a la que se conectarán todos los actores de la comunicación.

Nótese asimismo que todos estos actores involucrados (tanto el profesor como los alumnos) accederán a la plataforma mediante sus respectivos navegadores web de uso común, por lo que no tendrán que instalar ningún software adicional en sus dispositivos. Los siguientes párrafos detallan estas interacciones.

\section{Acceso como alumno}

Para acceder a los contenidos de CADI, los alumnos no tendrán más que conectarse a la red WiFi desplegada. Una vez conectados, podrán acceder a los contenidos de CADI sin más que abrir el navegador web de sus correspondientes dispositivos móviles. El sistema CADI integra un portal captivo que redirige cualquier intento de acceso a URL externa hacia el propio sistema. La Figura II.1 muestra la interfaz principal de CADI para los clientes del sistema o frontend del sistema (nótese el soporte multi-idioma de la plataforma).

Una vez ahí, los clientes pueden interactuar con la intuitiva interfaz para lanzar preguntas, valorar las publicadas en cierto momento o votar en encuestas, entre otras muchas cosas. 


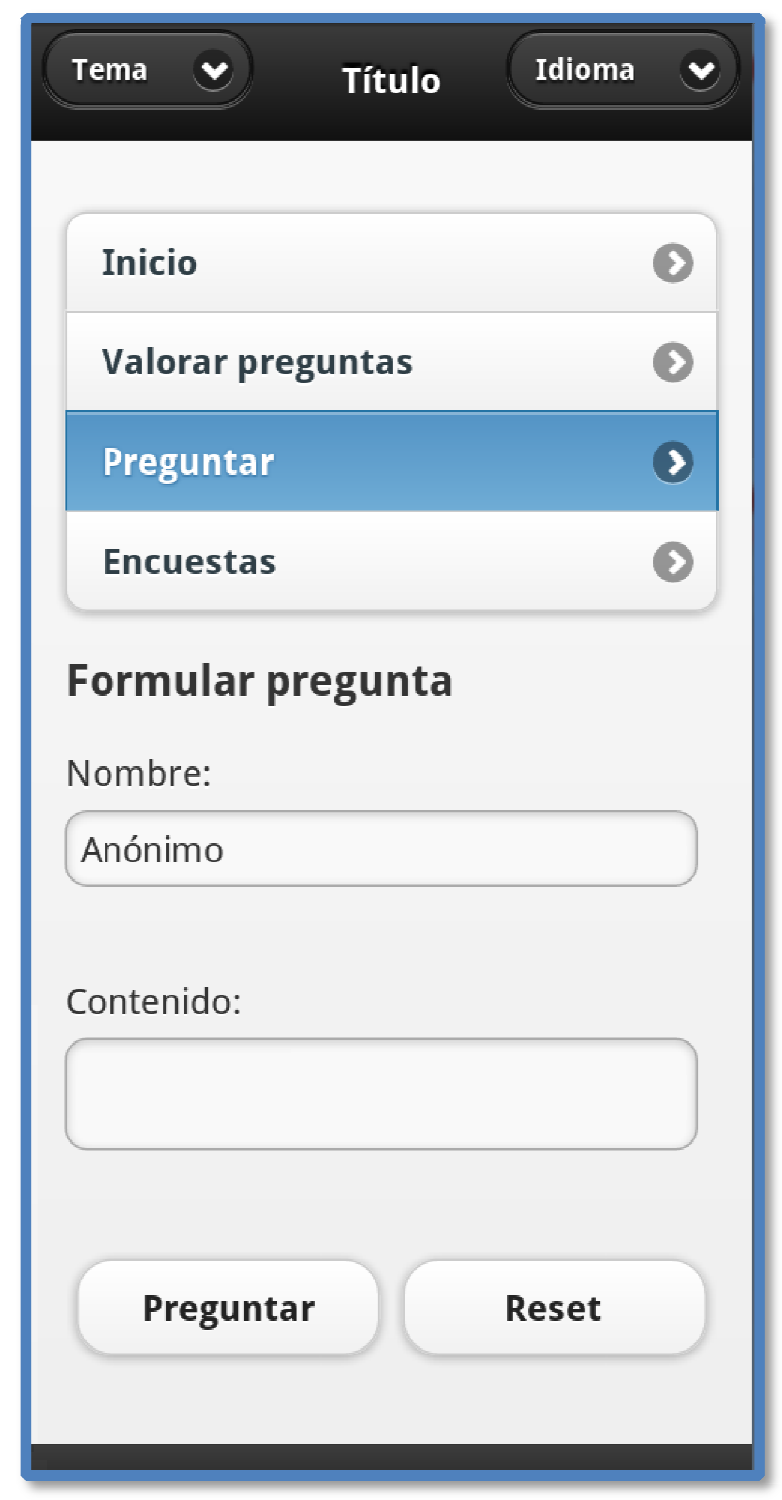

Figura II.1. Interfaz principal de CADI para los clientes del sistema con los módulos de preguntas y encuestas cargados

\section{Acceso como profesor}

En este escenario tipo propuesto, el profesor o ponente también es considerado como un cliente del sistema, por lo que debe conectarse a la red WiFi de CADI de forma totalmente análoga a la de los alumnos con su dispositivo.

La única diferencia con ellos es que se trata de un usuario privilegiado. Por ello, además de al frontend, tendrá acceso a una interfaz de administración o backend que se encuentra colgando del directorio admin de la plataforma. 
Así, para acceder a esta interfaz, el profesor escribirá en la barra de direcciones de su navegador web cualquier URL concatenándole "/admin". Figura II.2 muestra la pantalla de login para el profesor.

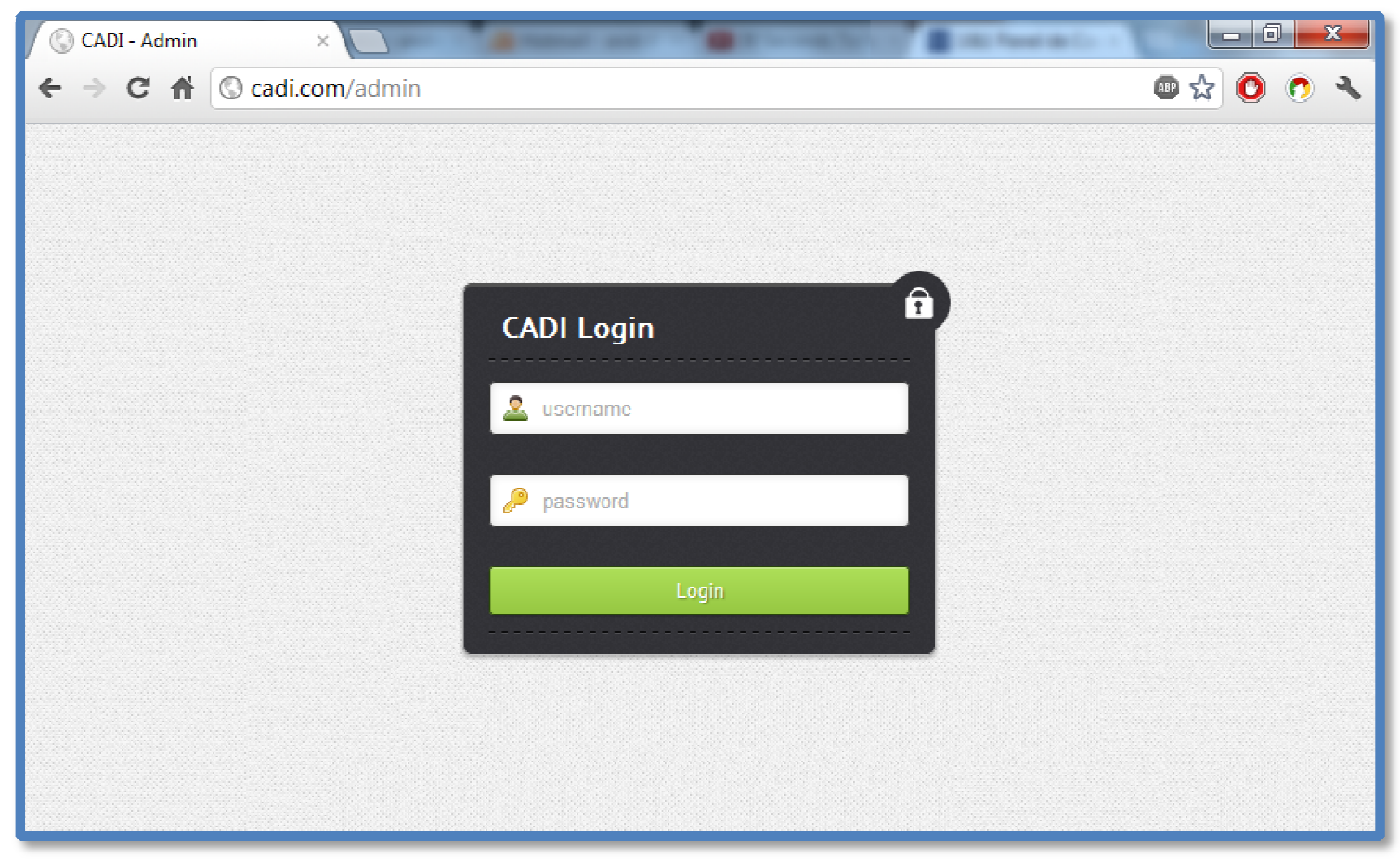

Figura II.2. Pantalla de acceso a la interfaz de administración del profesor

Y una vez introducidas las credenciales, el profesor tendrá a su disposición una gran cantidad de opciones para cada módulo ofrecido a los estudiantes (preguntas, encuestas, exámenes, recursos, cuestionarios, etc.). Por ejemplo, para el módulo de preguntas, será a través de esta interfaz desde donde el profesor pueda moderar las enviadas para filtrarlas. Podrá asimismo editarlas en tiempo real y borrar las inadecuadas. La siguiente Figura II.3 muestra finalmente el marco de trabajo de dicha interfaz. 


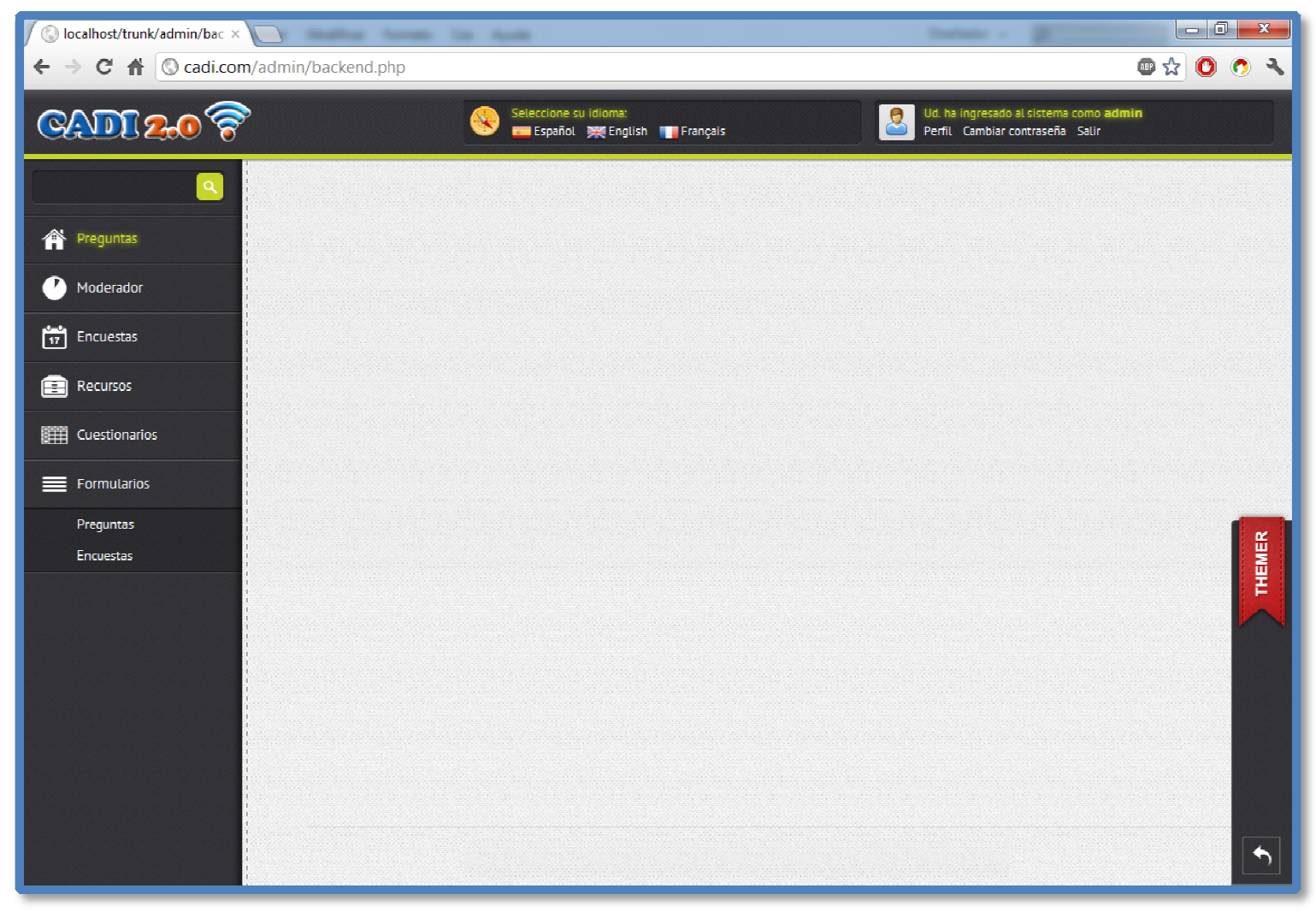

Figura II.3. Interfaz de administración del profesor. Marco de trabajo de CADI 